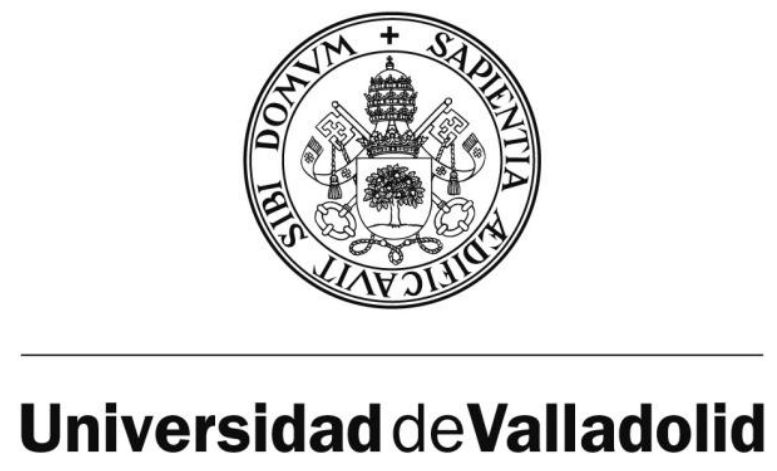

FACULTAD / ESCUELA

DEPARTAMENTO

Anatomía y Radiología

TESIS DOCTORAL

\title{
ESTUDIO DE LA SUPERVIVENCIA EN PACIENTES CON MELANOMA UVEAL DE UNA UNIDAD REFERENCIAL DE TUMORES INTRAOCULARES
}

Presentada por Pilar Alonso Martínez para optar al grado de

Doctora por la Universidad de Valladolid

Directores:

Dr. Francisco López-Lara Martín

Dra. $M^{a}$ Antonia Saornil Álvarez 
A mis padres. 


\section{AGRADECIMIENTOS}

Al Dr. López- Lara, no solo por ser una pieza clave en mi desarrollo como profesional, sino por haberme facilitado los medios suficientes para llevar a cabo las actividades necesarias para el desarrollo de este proyecto. Por sus consejos, su paciencia y sus palabras de ánimo.

A la Dra. Saornil, por su dedicación, el valor de sus enseñanzas como investigador, por todo el tiempo invertido en este trabajo de manera desinteresada y por sus buenos deseos de futuro.

Al Dr. García Álvarez, por estar siempre disponible para ayudarme con su reciente experiencia como doctorando.

A Mํ Fe Muñoz, porque sin ella este proyecto no se podría haber realizado. Por su amabilidad y su disponibilidad incondicional.

A Jesús de Frutos, por todos sus buenos consejos y palabras de ánimo.

A la Dra. Diezhandino, por colaborar en mi formación y regalarme el privilegio de su amistad.

A todo el servicio de Oncología/Radioterapia del Hospital Clínico de Valladolid, adjuntos, residentes, enfermeros, auxiliares y técnicos de radioterapia, porque de una manera u otra, todos han colaborado en la realización de este proyecto.

A Brotis, Rocío, Sara, María, Engri, Mํㅡ Carmen, Juanra, Gema, Mónica, Carmen, Rebeca e Iván, por su amistad y su apoyo en los momentos difíciles.

A Mario, Milagros, Elisa y Jaime, por su apoyo incondicional a lo largo de este proyecto. A Milagros por su optimismo en las tardes de domingo. A Elisa, que durante un tiempo renunció a parte de sus sueños para que yo hoy logre realizar los míos.

A Santi, por creer en mi más que yo misma y hacerme sentir que podía conseguirlo.

A mis tíos y primos, por estar siempre a mi lado apoyándome y recordándome que soy una persona afortunada.

A todos los pacientes que forman parte de este estudio, sin ellos este trabajo carecería de sentido.

A todos, mi eterno agradecimiento.

- 3 - $\quad$ Estudio de la supervivencia en pacientes con Melanoma Uveal de una Unidad Referencial de Tumores Intraoculares. 2013 


\section{SIGLAS Y UNIDADES}

AV: Agudeza visual

BMU: Biomicroscopía ultrasónica

BQ: Braquiterapia

CC: Cuerpo Ciliar

COMS: Collaborative Ocular Melanoma Study

DS: Desviación estándar

FA: Fosfatasa Alcalina

GOT: Glutámico Oxalacético Transaminasa

GPT: Glutámico Pirúvico Transaminasa

Gy: Gray (unidad de medida de radiación absorbida)

HR: Hazard Ratio

IC: Intervalo de Confianza

Ki-67: Marcador inmunohistoquímico de proliferación celular

LDH: Lactato Deshidrogenasa

Max: Máximo

Min: Mínimo

mm: Milímetros (unidad de medida de longitud)

M1: presencia de metástasis

NO: Nervio óptico

N.C.: No conocido

OCT: Tomografía de coherencia óptica

OD: Ojo derecho

OI: Ojo izquierdo

PET: Tomografía por emisión de positrones

PIO: Presión intraocular

ps: probabilidad de sobrevivir

QT: Quimioterapia

RNM: Resonancia magnética nuclear

RTE: Radioterapia externa

TAC: Tomografía axial computerizada

TTT: Termoterapia transpupilar 
JUSTIFICACIÓN Y PROPÓSITO DEL ESTUDIO........................................10

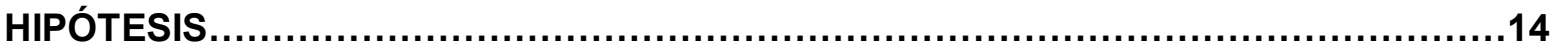

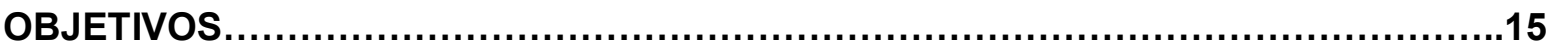

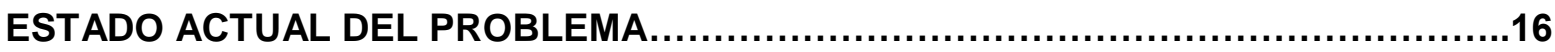

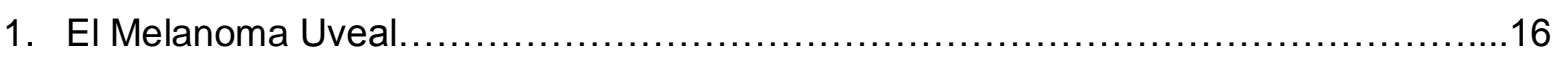

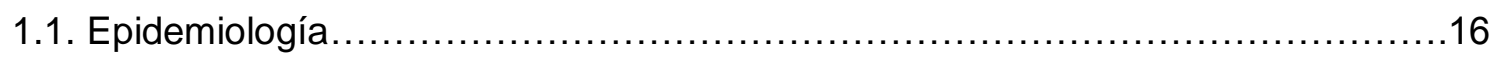

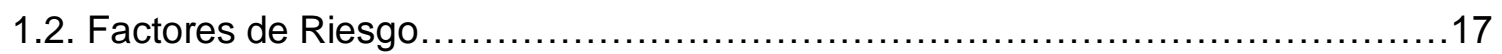

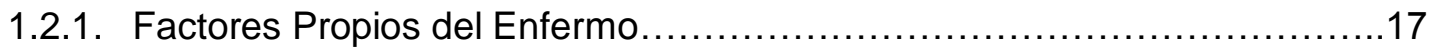

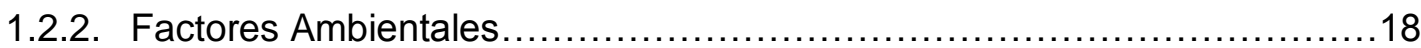

1.2.3. Enfermedades Predisponentes........................................ 18

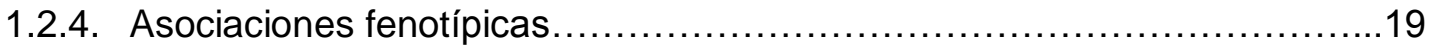

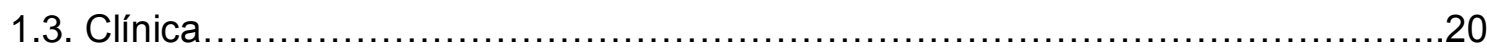

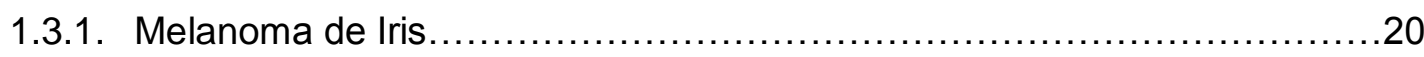

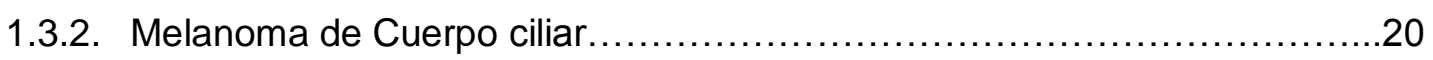

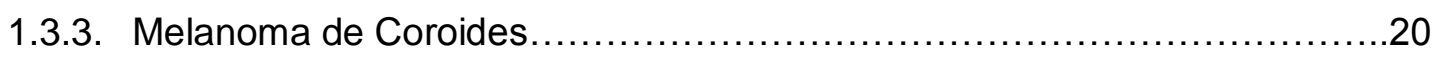

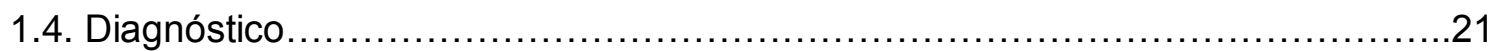

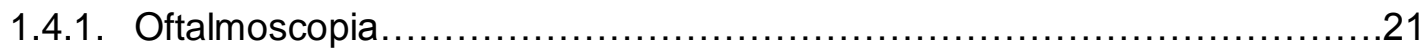

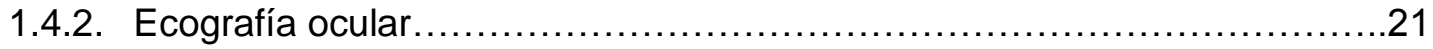

1.4.3. Diagnóstico de Extensión Extraocular...................................21

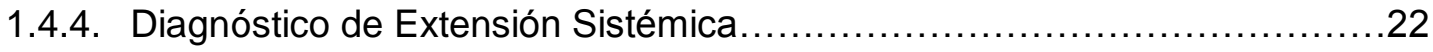

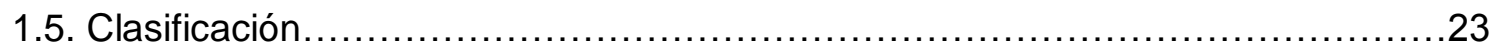

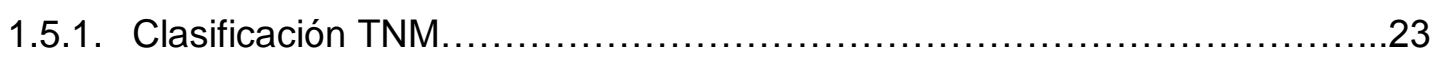

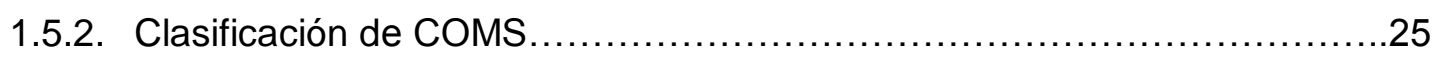

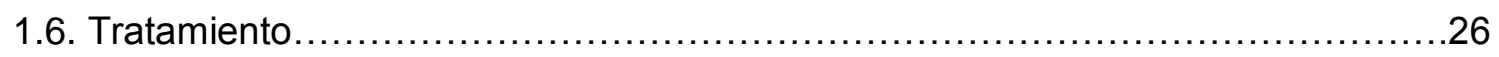

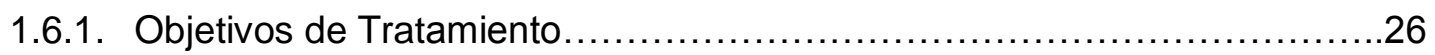

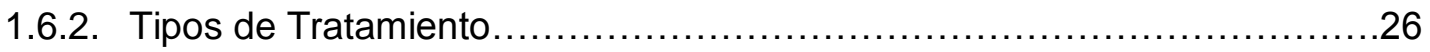

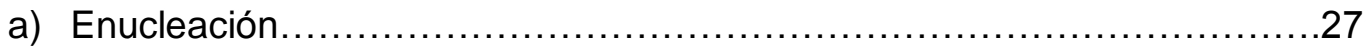

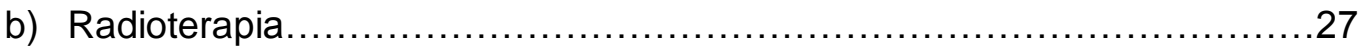

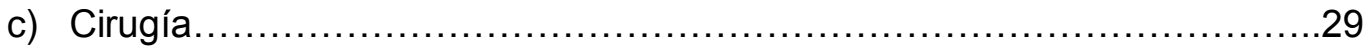

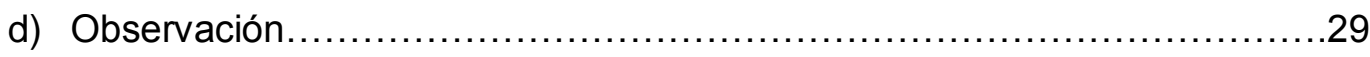


2. Supervivencia, Enfermedad Metastásica y Factores Pronósticos......................30

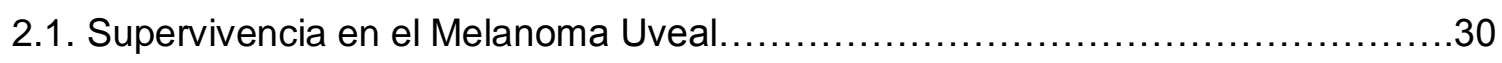

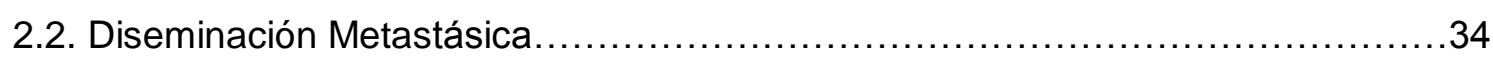

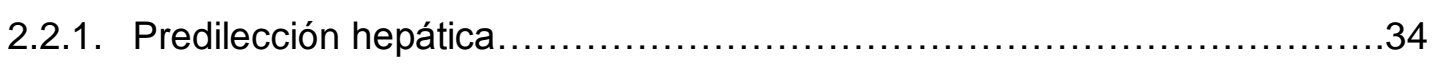

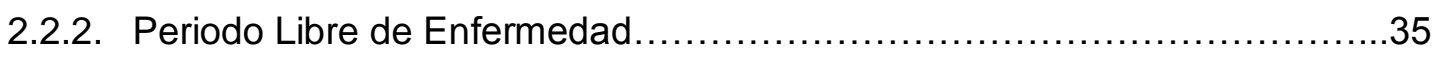

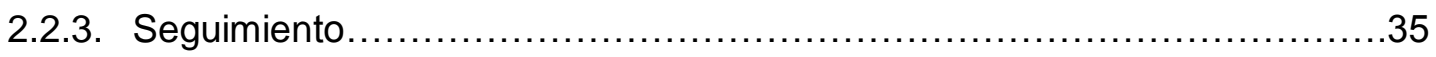

2.2.4. Tratamiento de la Enfermedad Metastásica...............................36

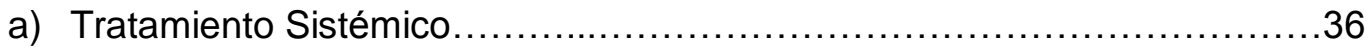

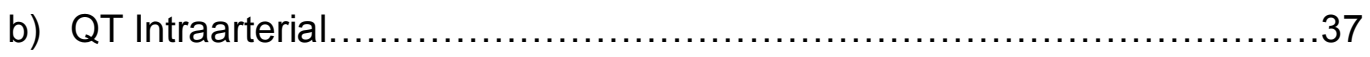

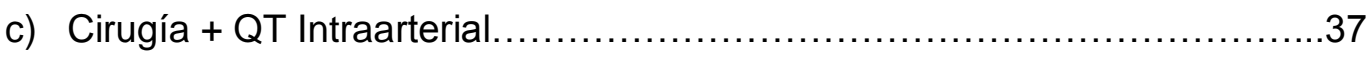

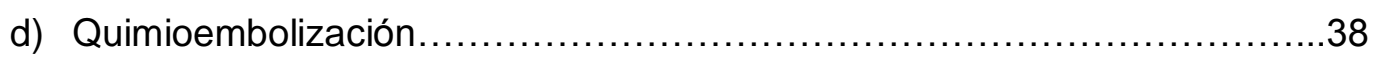

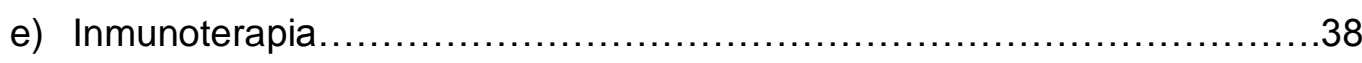

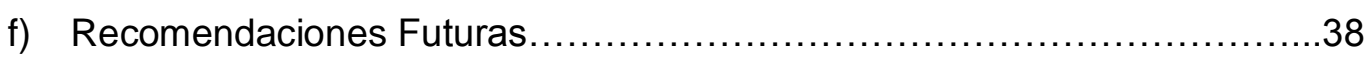

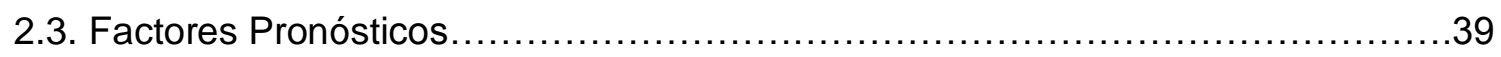

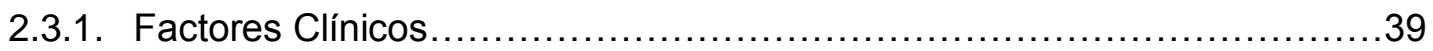

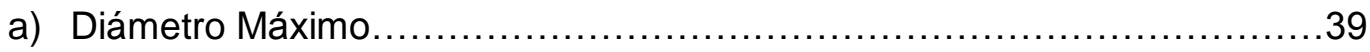

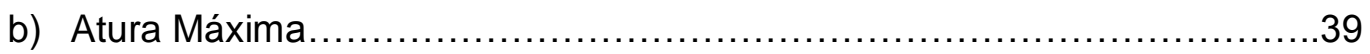

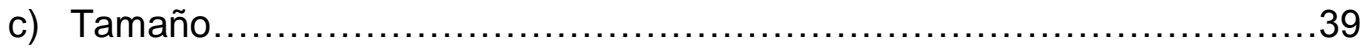

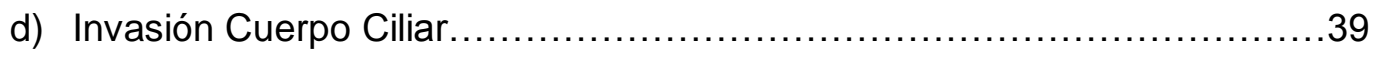

e) Extensión Extraescleral.............................................40

f) Regresión Rápida Masa Tumoral......................................40

g) Localización Yuxtapapilar...........................................40

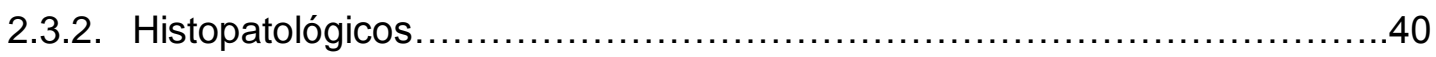

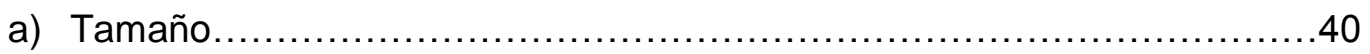

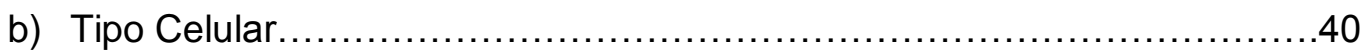

c) Aparición de Patrones Vasculares en Redes..............................41

d) Índice de Proliferación................................................ 41

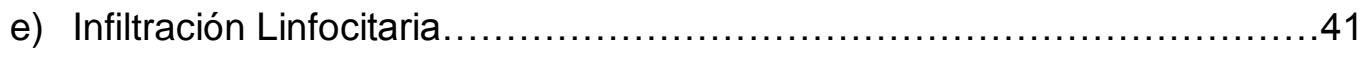

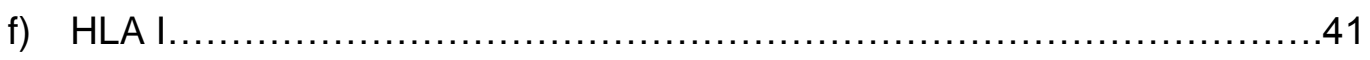

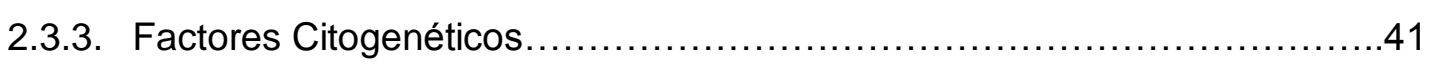

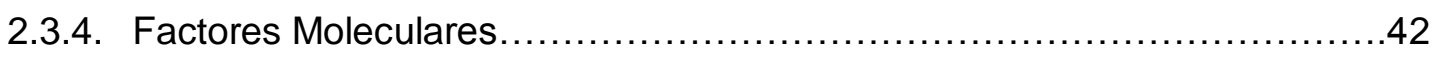

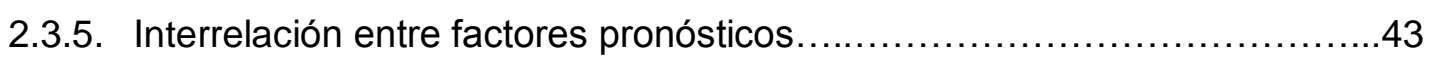




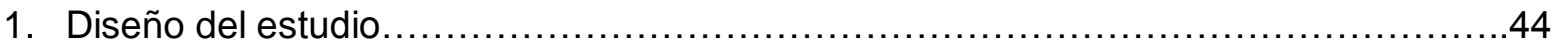

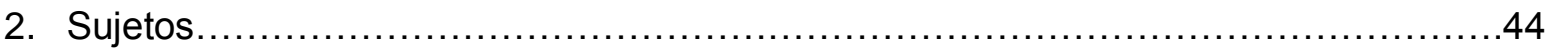

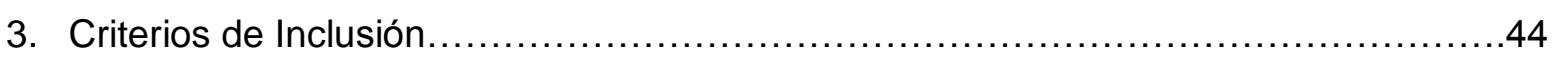

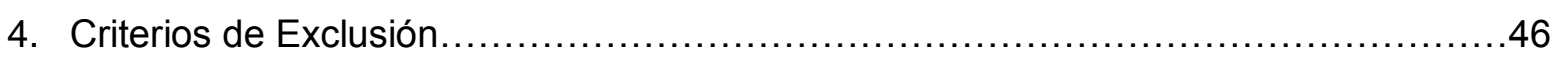

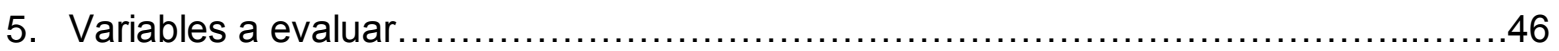

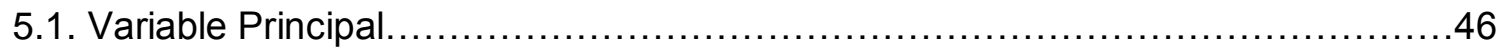

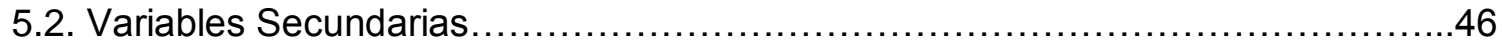

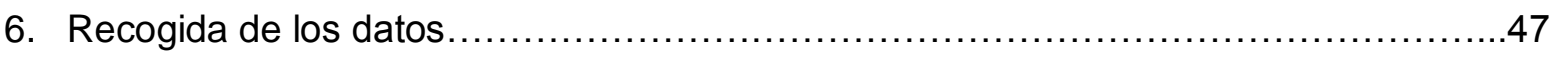

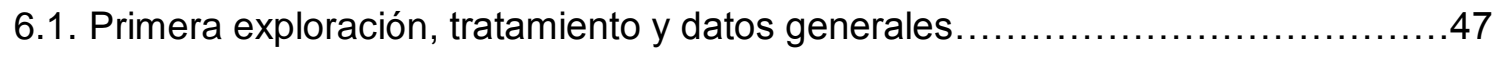

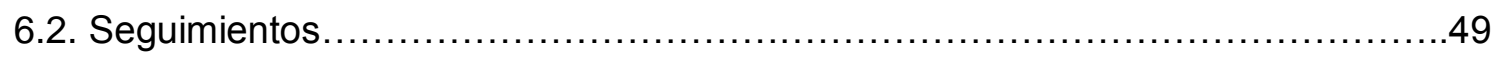

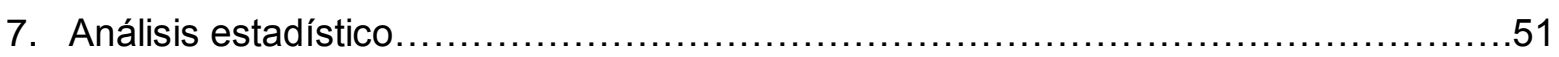

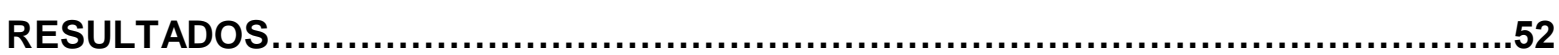

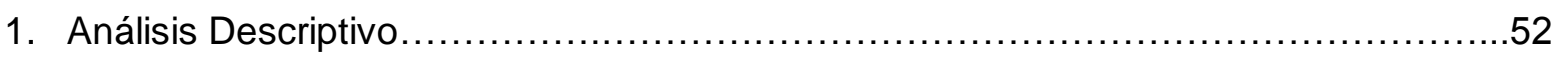

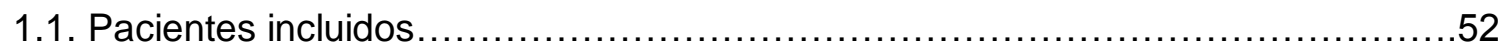

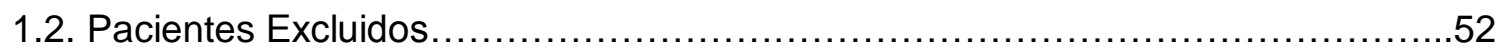

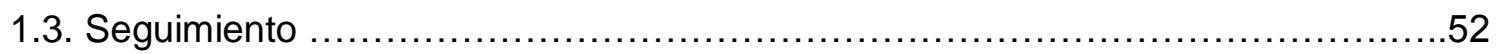

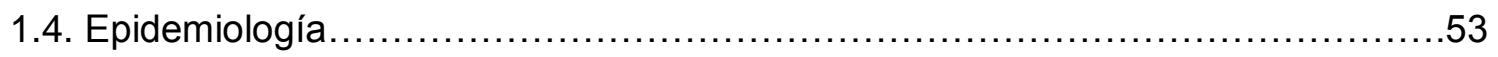

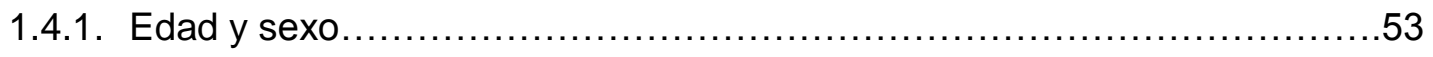

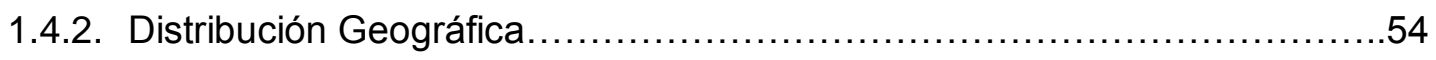

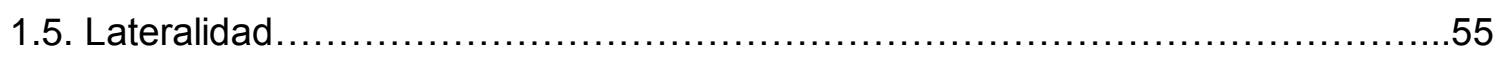

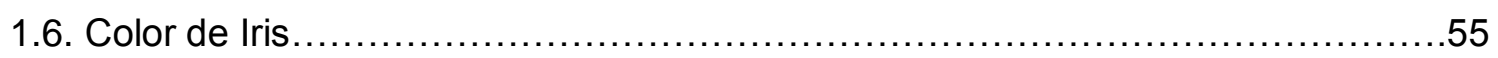

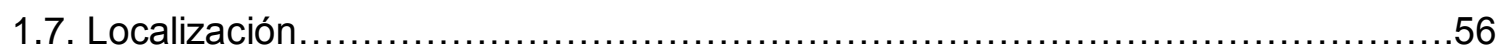

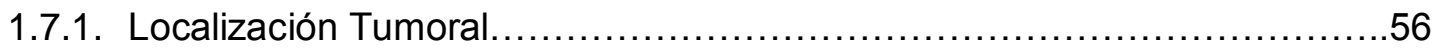

1.7.2. Localización de Borde Anterior.......................................56

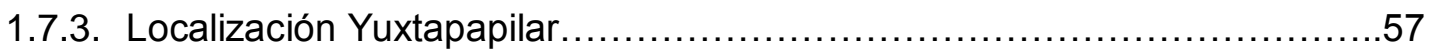

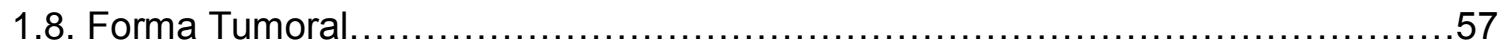

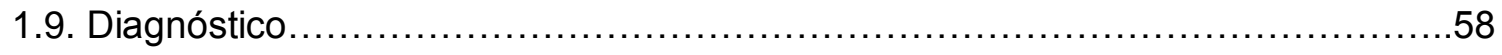

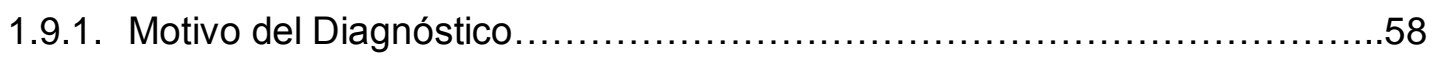

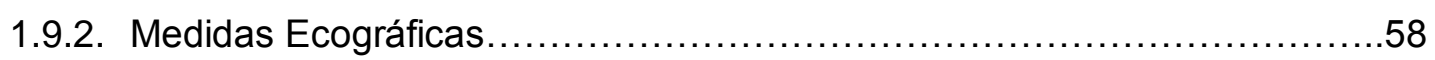

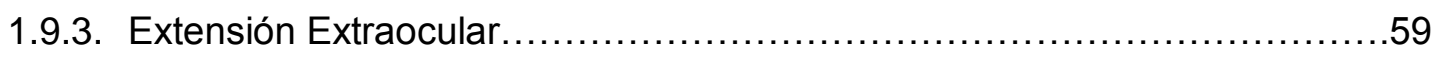

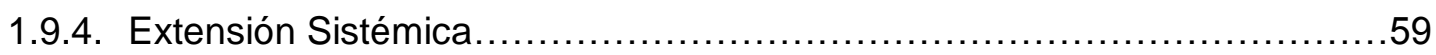




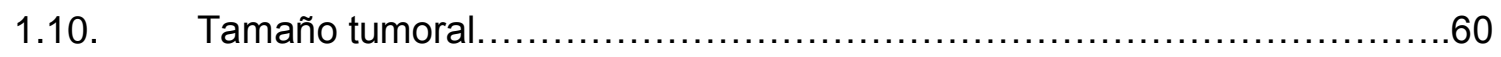

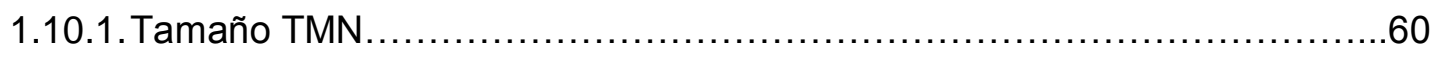

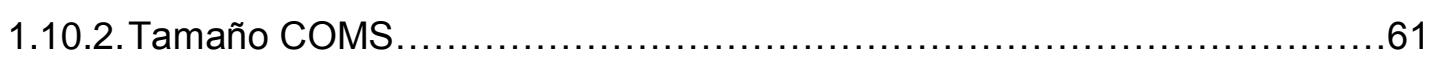

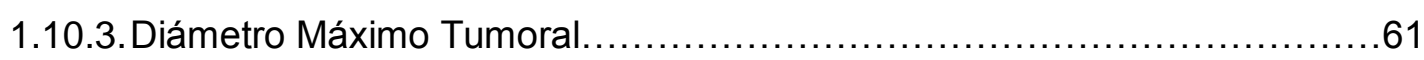

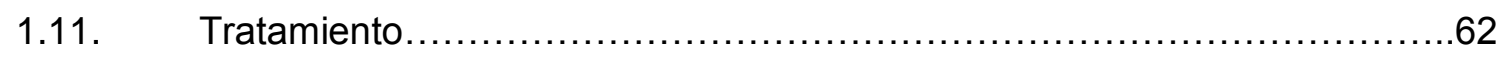

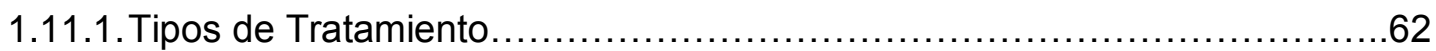

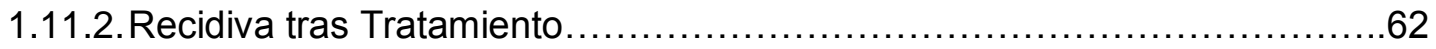

1.11.3. Motivos de Enucleación Secundaria.......................................63

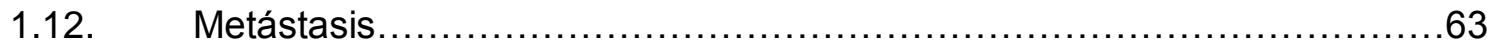

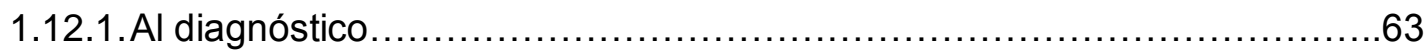

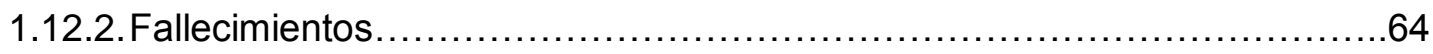

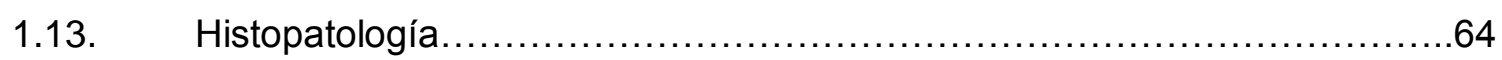

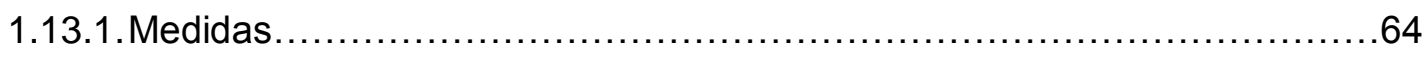

1.13.2. Localización borde anterior tumoral........................................65

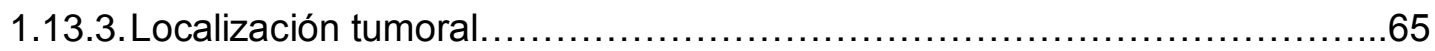

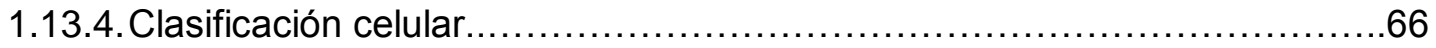

1.13.5. Características Anatomopatológicas ......................................66

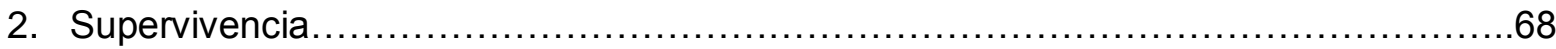

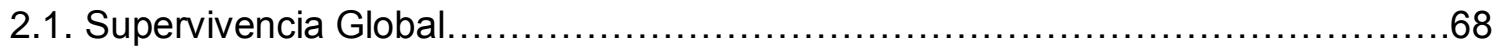

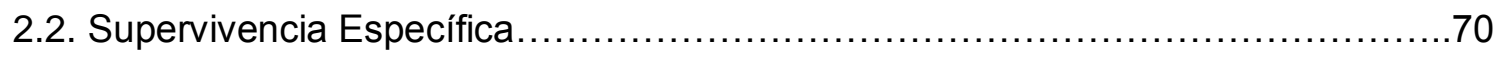

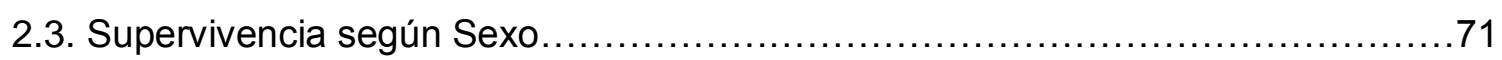

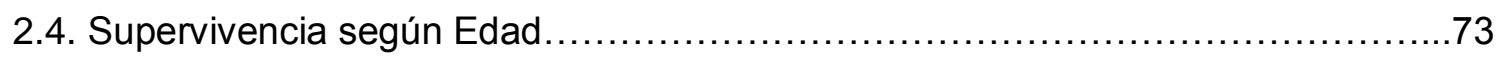

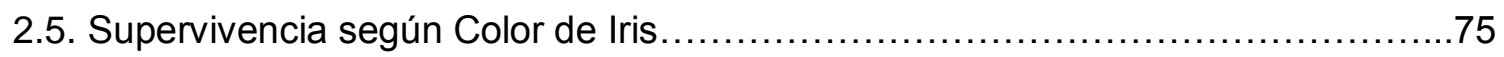

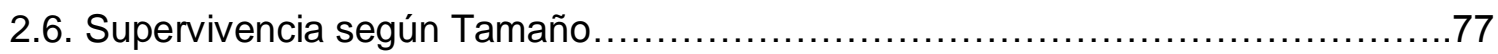

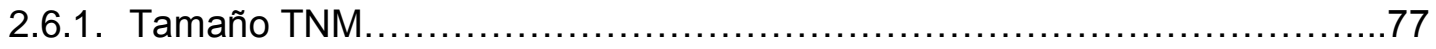

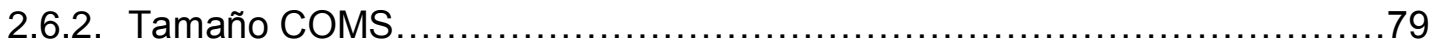

2.6.3. Diámetro Máximo Tumoral............................................. 81

2.7. Supervivencia según Invasión Cuerpo Ciliar.................................. 83

2.8. Supervivencia Según Localización Yuxtapapilar................................ 85

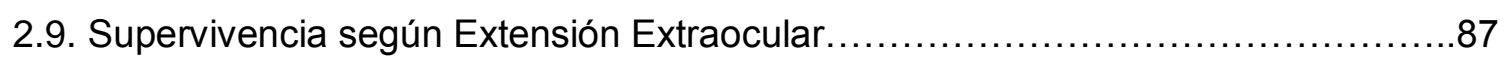

2.10. Supervivencia según Tamaño Histológico.............................. 89

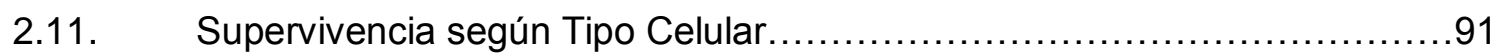

2.12. Supervivencia según Localización Histopatológica........................93

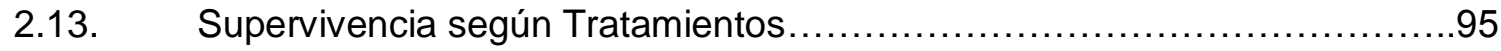

2.14. Modelo de Regresión Multivariante.........................................97 


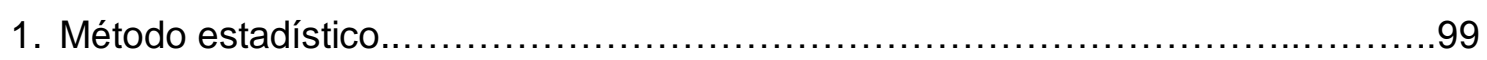

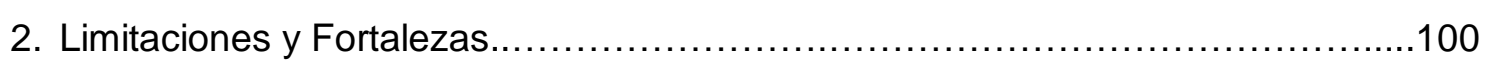

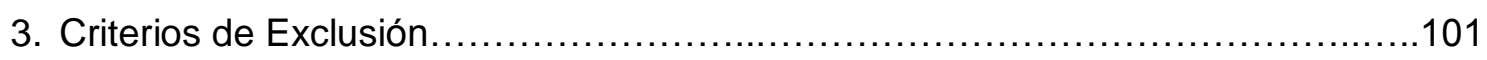

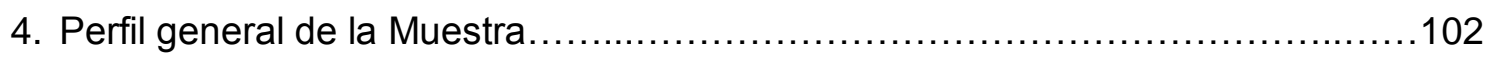

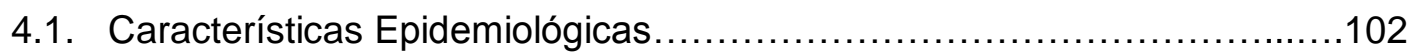

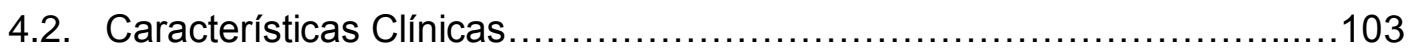

4.3. Distribución de Tratamientos....................................... 104

4.4. Características Hispopatológicas.....................................106

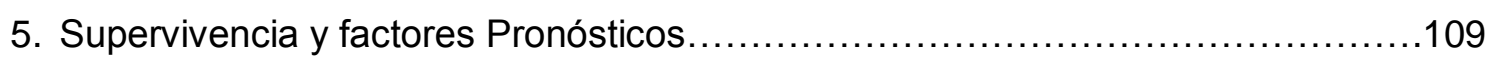

5.1. Supervivencia Global y Específica.................................109

5.2. Supervivencia Específica según Sexo, Edad y color de Iris................111

5.3. Supervivencia Específica según Tamaño Tumoral.......................114

5.4. Supervivencia Específica según otras características Clínicas: Invasión de Cuerpo Ciliar, Localización Yuxtapapilar y Extensión Extraocular.................116

5.5. Supervivencia Específica según características Histopatológicas: tamaño, tipo celular y Localización en Cuerpo Ciliar...................................117

5.6. Supervivencia Específica según Tratamientos............................118

5.7. Modelo de Regresión de Cox Multivariante............................120

CONCLUSIONES......................................................................121

BIBLIOGRAFÍA ....................................................................... 122

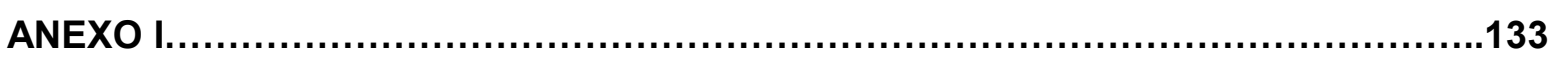

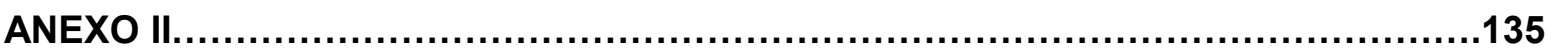




\section{JUSTIFICACIÓN Y PROPÓSITO DEL ESTUDIO}

El melanoma ocular se origina en los melanocitos de la úvea y supone el 5\% del total de los melanomas, siendo el tumor intraocular primario maligno más frecuente del adulto. ${ }^{1}$ Es una neoplasia agresiva con una mortalidad global a los 15 años aproximadamente del $50 \%$ cualquiera que sea el tratamiento que se aplique.$^{23}$

La incidencia del melanoma uveal varía entre los 4,3 y los 10,9 casos por millón de habitantes y año en función de las poblaciones estudiadas. ${ }^{4}$ Estos datos proceden de estudios en población norteamericana y de países de Europa del norte, no encontrándose datos de incidencia publicados de nuestro país ni de forma global ni por comunidades autónomas. La comparación de estudios, no obstante, indica que la incidencia es muy similar en Estados Unidos, el centro y norte de Europa y Australia. En España se encuentra catalogado dentro del sistema de enfermedades raras (SIERE) aunque no hay datos epidemiológicos. La incidencia aumenta con la edad, estando el pico en la década de los 70 para los hombres y en la de los 60 para las mujeres. ${ }^{15}$

Clínicamente el tumor puede descubrirse en una exploración rutinaria o presentarse de forma sintomática como una pérdida de agudeza o de campo visual, descubriéndose en la exploración una masa de pigmentación variable en el fondo de ojo. La precisión diagnóstica en manos de expertos (consultas de referencia de tumores intraoculares) ha demostrado ser mayor del 99,5\% mediante la oftalmoscopia y la ecografía ocular, reservando otras técnicas de imagen (TAC, RM) para casos en los que no se puede explorar el interior del globo ocular (cataratas, hemorragia vítrea) y para la valoración de la extensión del tumor fuera del globo ocular. ${ }^{6} 7$

Hasta los años setenta el único tratamiento disponible para controlar esta enfermedad era la enucleación, pero actualmente existen tratamientos más conservadores que consiguen el control tumoral utilizando técnicas terapéuticas menos mutilantes para el paciente y que permiten conservar el globo ocular con efectos secundarios mínimos y manteniendo la función visual, sin reducir la supervivencia del paciente. ${ }^{8} 9$

La enucleación actualmente es la terapia de elección en tumores grandes, ojos ciegos sin expectativa visual o dolorosos por hipertensión ocular causada por el tumor. ${ }^{10} 11$ 
La radioterapia es a día de hoy el tratamiento empleado en la mayoría del resto de los casos. Existen varias formas específicas que pueden emplearse de manera aislada o combinada. La braquiterapia, la radioterapia con partículas aceleradas como los protones o la radiocirugía permiten un control tumoral con conservación de globo ocular en el $90 \%$ de los casos manteniendo función útil en el $50 \%$ de los mismos ${ }^{12}{ }^{13}$. La escisión en este tipo de tumores es poco empleada debido a su complicación y la necesidad de ser asociada con braquiterapia para evitar recurrencia en los bordes ${ }^{14}$. La observación periódica está reservada para tumores pequeños y sin signos de actividad..$^{15} 16$

A pesar del éxito de los tratamientos con respecto al tumor primario, ninguno de ellos ha demostrado mejorar la supervivencia de los pacientes. El tumor se disemina por vía hematógena con elevada predilección por el hígado, siendo en el 85\% de los casos la primera localización y en el $55 \%$ de los casos la única. Una vez diagnosticada la diseminación, la supervivencia media es inferior a 12 meses, no existiendo un tratamiento eficaz. ${ }^{17} 18$

Aunque solo el 1-2\% de los casos presentan extensión sistémica en el momento del diagnóstico y el tratamiento, el $50 \%$ de los pacientes presentan metástasis en los siguientes 15 años. Los periodos libres de enfermedad pueden llegar hasta los 40 años desde el tratamiento del tumor primario, por lo que Zimmerman acuñó el término de "metástasis subclínicas", que se mantienen quiescentes por mecanismos aun desconocidos. ${ }^{19} 20$

Los factores de riesgo que han demostrado relacionan con la aparición de metástasis y pueden indicar el pronóstico del paciente son ${ }^{21}$ :

- Propios del enfermo: Se ha descrito una mayor incidencia de melanoma de úvea en pacientes con piel clara, ojos claros, raza blanca. ${ }^{22}$

- Factores ambientales: No se ha encontrado una relación claramente significativa con la exposición a la luz solar, ciertas profesiones (agricultura y electricidad) o exposición a luz ultravioleta. ${ }^{23}$

- Clínicos: Diámetro máximo, invasión cuerpo ciliar, extensión extraescleral, regresión rápida de la masa tumoral. ${ }^{21} 24$

- Histopatológicos: Tamaño, tipo celular, índice mitótico, índice de proliferación, aparición de patrones vasculares en redes, infiltración linfocitaria; todas ellas están relacionadas con un peor pronóstico. ${ }^{25}$

- 11 - Estudio de la supervivencia en pacientes con Melanoma Uveal de una Unidad Referencial de Tumores Intraoculares. 2013 
- Citogenéticos: Se han descrito anormalidades en cromosomas 3 y 8 con factores de riesgo para el desarrollo de metástasis. ${ }^{26}$

- Factores moleculares: Tras el análisis de más de 1000 genes se han establecido dos subtipos genéticos, clase I y clase II, que clasifican los melanomas en dos grupos, uno de mal pronóstico por alto poder metastático de otro de buen pronóstico. ${ }^{27}$

- Factores epidemiológicos: Se han publicado varios trabajos que muestran un peor pronóstico de la mujer frente al hombre ${ }^{28}$ y la ausencia de relevancia de la edad en el momento del diagnóstico del melanoma uveal. ${ }^{29}$

Los estudios de la supervivencia en el melanoma uveal comienzan de la mano de Zimmerman en EEUU ${ }^{20}$ y Jensen ${ }^{30}$ en Dinamarca a finales de los años 70 . Zimmerman publica una revisión de 1146 pacientes, mostrando una mortalidad del $46 \%$ a los 15 años con un pico de la mortalidad entre los dos y los tres años, atribuyendo este pico a la diseminación de la enfermedad durante el acto quirúrgico. Jensen et al, revisaron 302 pacientes obteniendo unas cifras de mortalidad específica del 50\% a los 25 años, pero obtuvieron un pico de mortalidad del $10 \%$ en el primer año de seguimiento. Estos trabajos son los impulsores principales del desarrollo de los tratamientos conservadores, ya que hasta los años 80 , la enucleación era el tratamiento estándar del melanoma uveal pero los resultados de estos estudios sugieren que puede existir una relación entre la enucleación y los picos de mortalidad encontrados.

En 1992, Diener-West ${ }^{3}$ publico un metaanálisis resumiendo todos los trabajos publicados en materia de supervivencia entre 1966-1988. Observó que la mortalidad a los 5 años post-enucleación para tumores pequeños, medianos y grandes era del $16 \%, 32 \%$ y $52 \%$ respectivamente. Este trabajo confirmó que el tamaño tumoral es un importante factor pronóstico y sirvió como dato de partida para futuros estudios que tratan de comparar la supervivencia de tratamientos conservadores frente a la enucleación, el principal de los cuales es el "Collaborative Ocular Melanoma Study" en norteamerica. Este estudio comienza en los años 90 incluyendo pacientes diagnosticados de melanoma uveal de 43 centros diferentes, aportando una clasificación por tamaños estandarizada y que realiza y publica diferentes estudios prospectivos randomizados por tamaños y comparando la supervivencia según tratamientos conservadores frente a enucleación. ${ }^{31}$

$\operatorname{Singh}^{32}$ publicó un estudio en el cual estudió supervivencia de 4070 pacientes incluidos desde 1973 a 2008 observando que los datos de supervivencia en melanoma 
uveal se han mantenido estables con respecto a los publicados a lo largo de los últimos treinta años confirmando que la supervivencia es independiente del tratamiento realizado.

En España son muy escasos los estudios publicados hasta el momento en materia de supervivencia. Caminal et $\mathrm{al}^{33}$ recientemente han publicado un trabajo consistente en el seguimiento de 155 pacientes mostrando datos de supervivencia específica superiores a los publicados hasta el momento. Acorde con esta publicación, en la unidad de tumores intraoculares en la que se realiza el presente estudio, se ha realizado una revisión ${ }^{34}$ de más de 500 pacientes en la cual se ha concluido que, igual que la muestra estudiada por Caminal, en un análisis global, nuestra población tiene una supervivencia superior a las poblaciones previamente publicadas.

La Unidad de Tumores Intraoculares del Adulto del Hospital Clínico Universitario (HCU) de Valladolid lleva recibiendo y tratando pacientes con melanoma uveal desde 1992 y ha sido reconocida como una de las 3 unidades de referencia nacionales para el tratamiento de este tipo de tumores por el Ministerio de Sanidad en 2008. Desde su comienzo se han diagnosticado y tratado más de 500 pacientes con este tipo de tumor, observando que la población es diferente en cuanto a características raciales, geográficas y ambientales que la de las poblaciones previamente publicadas, que pertenecen a Norteamerica o Europa del Norte. Esta observación hace pensar que tanto el desarrollo del tumor, como su comportamiento y pronóstico puedan ser diferentes a las series previamente publicadas.

El propósito del presente trabajo es estudiar la supervivencia en una muestra de más de 500 pacientes diagnosticados de melanoma de úvea y tratado en la Unidad de Tumores Intraoculares del HCU de Valladolid, dado que las características clínicas y epidemiológicas de estos pacientes, así como el tratamiento empleado pueden ser diferentes de las poblaciones previamente estudiadas y publicadas.

- 13 - $\quad$ Estudio de la supervivencia en pacientes con Melanoma Uveal de una Unidad Referencial de Tumores Intraoculares. 2013 


\section{HIPÓTESIS}

Debido a las diferencias raciales y epidemiológicas de la población española con respecto a países Nórdicos y a Norteamérica, puede que la supervivencia y los factores pronósticos de los pacientes españoles diagnosticados de melanoma de úvea, sean diferentes a las series previamente publicadas en otros países. 


\section{OBJETIVOS}

1. Estudiar las características clínicas y epidemiológicas de la población de pacientes con diagnóstico de melanoma de úvea en la Unidad de Tumores Intraoculares del Hospital Clínico Universitario de Valladolid.

2. Estudiar la supervivencia global y específica de los pacientes incluidos con respecto a:

2.1. Factores Epidemiológicos: Edad, sexo y raza.

2.2. Factores Clínicos: Color de iris, tamaño tumoral, invasión del cuerpo ciliar, invasión yuxtapapilar, extensión extraocular.

2.3. Factores Histopatológicos: Tipo celular, tamaño tumoral, localización tumoral.

2.4. Tratamiento empleado: Enucleación, Braquiterapia, TTT, Observación, radioterapia externa con protones.

3. Comparar los datos obtenidos con los previamente publicados en otros países. 


\section{ESTADO ACTUAL DEL PROBLEMA}

\section{EL MELANOMA UVEAL}

\subsection{EPIDEMIOLOGÍA}

Los melanomas oculares suponen el $5 \%$ del total de los melanomas, originándose el $85 \%$ en los melanocitos de la úvea y siendo el tumor intraocular primario maligno más frecuente del adulto. ${ }^{1}$

Su incidencia aumenta con la edad, estando el pico en la séptima década en los hombres y en la sexta en las mujeres ${ }^{521}$ Estos datos han permanecido estables a lo largo del tiempo, a diferencia del incremento demostrado con el melanoma cutáneo ${ }^{35}$ y de conjuntiva. ${ }^{36}$

La incidencia del melanoma uveal varía entre los 4,3 y los 10,9 casos por millón de habitantes y año en función de las poblaciones estudiadas. ${ }^{21}$ Estos datos proceden de estudios en población norteamericana y de países de Europa del norte, no encontrándose datos de incidencia publicados de nuestro país de forma global ni por comunidades autónomas. En España se encuentra catalogado dentro del sistema de enfermedades raras (SIERE) aunque no hay descritos datos epidemiológicos.

EI Programa SEER (Surveillance and Epidemiology and End Result) del Instituto Nacional de Salud de los Estados Unidos es hoy por hoy la fuente más fiable respecto a la incidencia de esta enfermedad, ${ }^{37}$ que es estimada en 4,9 casos por millón de habitantes y año en Estados Unidos para los hombres y de 3,7 en el caso de las mujeres. La comparación de estudios, no obstante, indica que la incidencia es muy similar en Estados Unidos, Europa y Australia. ${ }^{21}$ 


\subsection{FACTORES DE RIESGO}

Se han descrito varios factores de riesgo propios para el desarrollo del melanoma, entre ellos:

\subsubsection{Propios del enfermo:}

a) Raza: Se ha observado que el diagnóstico de melanoma uveal es 150 veces más frecuente en raza blanca ${ }^{38}$ que en la raza negra. A su vez, se ha descrito una menor incidencia entre los hispanos ${ }^{39}$ y los asiáticos ${ }^{40}$ que en la raza blanca.

b) Latitud geográfica: Se ha publicado una mayor incidencia de melanoma de úvea en pacientes cuyo país está más distante del ecuador. Se encontraron datos similares en población estrictamente europea, asumiendo la exposición solar y la raza como un factor de riesgo establecido y que la latitud geográfica es un factor íntimamente relacionado. ${ }^{38}$ Es decir, se observa mayor o menor incidencia de melanoma uveal dependiendo de la situación geográfica de los pacientes sometidos a estudio.

c) Pigmentación: Se ha objetivado predilección por individuos rubios y con los ojos claros para el desarrollo de la enfermedad. La mayoría de los pacientes diagnosticados de melanoma de úvea ${ }^{21}$ tienen un color claro de iris, preferentemente gris-azul. ${ }^{22}$ Sin embargo, en un estudio realizado en una cohorte de 221 pacientes afectos por melanoma de úvea, diagnosticados y tratados en la unidad de referencia de este mismo estudio (UTI HCU Valladolid) se concluyó que, tras estandarizar y validar una clasificación simple de color de iris y comparar con los datos publicados hasta el momento, la población española presenta una distribución de color de iris diferente a las poblaciones previamente estudiadas. ${ }^{41}$

d) Nevus de coroides preexistente:

Existe evidencia clínica e histopatológica de que los melanomas uveales pueden desarrollarse a partir de nevus coroideos preexistentes ${ }^{42} \mathrm{o}$ de novo, siendo por ello un factor de riesgo importante. Se ha estimado que la tasa de transformación de nevus a melanomas en la uvea es de aproximadamente 1 de cada $8500 .{ }^{32}$ 


\subsubsection{Factores ambientales}

a) Exposición a luz solar: Se han realizado diversos estudios que han resultado contradictorios. En líneas generales se ha observado una correlación positiva entre la exposición a la luz solar y el desarrollo de melanoma uveal, pero que no alcanza la significación estadística a diferencia de lo que ocurre con el melanoma cutáneo. ${ }^{21}$

b) Luz Ultravioleta: al igual que ocurre con la exposición a la luz solar, aunque hay escasos estudios a este respecto, se intenta relacionar el desarrollo de melanoma uveal y la exposición a la luz ultravioleta, no encontrándose en ninguno de los trabajos significación estadística. ${ }^{21}$

c) Profesión: En relación a la exposición a luz solar o ultravioleta, varios estudios fueron encaminados a la predisposición o no de ciertas profesiones (agricultores, secretarias, maestros, químicos) con el mayor desarrollo del melanoma de úvea. Al igual que lo ocurrido al intentar establecer ambas exposiciones como factores de riesgo, se comprobó que no existe una significancia entre la profesión del paciente y una mayor incidencia de este tipo de enfermedad. ${ }^{21} 23$

\subsubsection{Enfermedades predisponentes}

Pese a la no evidencia de factores genéticos claros relacionados con el melanoma uveal, existen ciertas enfermedades que suponen una mayor predisposición a su desarrollo:

\section{a) Melanoma Uveal familiar:}

Este tipo de tumor se encuentra establecido como un factor de riesgo debido a que el $0,6 \%$ de todos los melanomas uveales se debe a un desarrollo a partir de este tipo de melanoma. ${ }^{43}$

b) Melanoma uveal bilateral:

Es muy poco frecuente ${ }^{44}$ ( 1 caso cada 18 años en EEUU) y por ello no se ha podido relacionar con predisposición genética a padecer otros tumores. ${ }^{45}$ 


\subsubsection{Asociaciones fenotípicas:}

a) Melanocitosis oculodérmica (Nevus de Ota):

Es una hiperpigmentación congénita, con aumento del número de melanocitos, de la piel periocular, la epiesclera, la úvea, la órbita y las meninges. Aumenta el riesgo de padecer melanoma uveal, enmarcándose por ello dentro de los factores de riesgo. Se han descrito cifras que indican que 1 de cada 400 pacientes con Nevus de Ota desarrollan melanoma de úvea y que aproximadamente un $3 \%$ de los pacientes con melanoma uveal sufren esta enfermedad predisponerte. ${ }^{46} 47$

\section{b) Síndrome del nevus displásico familiar y melanoma:}

Se define como la concurrencia de más de 50 nevus cutáneos y presencia de melanomas cutáneos en familiares de $1^{\circ} \circ 2^{\circ}$ orden. En las series de pacientes con melanoma uveal, se ha observado que la incidencia de este síndrome es mucho mayor que en la población general. ${ }^{48}$ Sin embargo no se ha encontrado una mayor incidencia de melanomas uveales en las series de pacientes afectos de esta entidad. ${ }^{49}$ Por otro lado, la mutación CDKN2A que aparece en el 50\% de los pacientes afectos del Síndrome del nevus displásico familiar, no se ha encontrado en los pacientes afectos de melanoma uveal. ${ }^{50}$ 


\subsection{CLÍNICA}

La clínica es muy diferente dependiendo del origen (iris, cuerpo ciliar o coroides), el tamaño, la pigmentación y la localización dentro del globo ocular.$^{51}$

1.3.1. El melanoma de iris, que representa el $3 \%$ de todos los melanomas de la úvea, puede presentarse como una tumoración de pigmentacion variable, de forma circunscrita o difusa en la superficie del iris. El diagnóstico se realiza con lámpara de hendidura, gonioscopia y ultrasonido (Biomicroscopia Ultrasónica-BMU) y se basa en el crecimiento de la lesión que puede invadir el ángulo de la cámara anterior, provocando hipertensión ocular, o producir hemorragias. Una vez establecido el diagnóstico el tratamiento más habitual es resección quirúrgica con un margen de seguridad, y posteriormente se recomienda aplicar braquiterapia epiescleral para evitar recurrencias en los bordes quirúrgicos. ${ }^{52}$

1.3.2. El melanoma de cuerpo ciliar puede ser circunscrito o anular (raro). Suele manifestarse clínicamente como una masa de pigmentación variable, retrocristaliniana que suele diagnosticarse cuando se acerca al eje visual e interfiere con la visión del paciente, o cuando invade el iris, el ángulo o produce una extensión extraocular.

El melanoma del cuerpo ciliar, puede complicarse con una compresión y desplazamiento del cristalino ocasionando opacidades con la consiguiente pérdida de la agudeza visual llegando a una subluxación del cristalino en etapas avanzadas. El diagnóstico se basa en examen con lámpara de hendidura, gonioscopia, transiluminación y la ecografía y el tratamiento depende del tamaño, pudiéndose tratar de forma conservadora (radioterapia externa, protones, braquiterapia o resección quirúrgica) en los casos en que su tamaño lo permita.

1.3.3. El melanoma de coroides (úvea posterior) según diferentes series estadísticas, supone el $80-90 \%$ de los melanomas de úvea. Pueden descubrirse en una exploración rutinaria (asintomáticos), representando el 10\% de los casos aproximadamente, o presentar síntomas como disminución de la agudeza o campo visual. Con frecuencia (10$30 \%$ de los casos) aparecen fotopsias, escotomas o metamorfopsias. El tumor con extensión extraocular puede ocasionar proptosis, la aparición de una masa subconjuntival visible o sintomatología inflamatoria orbitaria, y tiene peor pronóstico que aquel que se mantiene confinado al interior del globo ocular. ${ }^{53}$.

- 20 - Estudio de la supervivencia en pacientes con Melanoma Uveal de una Unidad Referencial de Tumores Intraoculares. 2013 


\subsection{DIAGNÓSTICO}

El diagnostico del melanoma uveal posterior se realiza principalmente mediante la exploración del fondo del ojo y la ecografía, habiéndose demostrado que en manos de personal experto, la precisión diagnóstica es mayor del $99,5 \%{ }^{7}$ y la asociación americana de braquiterapia reconoce este hecho permitiendo la realización de tratamientos conservadores sin necesidad de realizar una biopsia diagnóstica previa. ${ }^{54}$.

\subsubsection{Oftalmoscopia:}

Es el primer paso en el diagnóstico del melanoma uveal. Se trata de una exploración rutinaria y de fácil acceso para cualquier oftalmólogo. Los melanomas suelen aparecer como lesiones pigmentadas, de coloración marrón-grisácea que pueden tener una forma nodular, o muy característica en champiñón en estadios avanzados y que en ocasiones pueden ocupar más de la mitad del globo ocular. Pueden asociar desprendimiento de retina y hemorragias e incluso cataratas, en cuyo caso las técnicas de imagen cobran gran importancia en su evaluación. Además de ser muy importante en el diagnóstico su aspecto, los registros fotográficos y de autofluorescencia pueden aportar medidas que nos ayudan a clasificarlo, y a registrar signos de actividad (crecimiento, pigmento naranja, presencia de fluido subretiniano) esenciales para la decisión terapéutica. ${ }^{55}$

\subsubsection{Ecografía ocular:}

Es la prueba más útil para llegar al diagnóstico de melanoma uveal ${ }^{56}$ observándose el tumor como una masa hiperecogénica, con vacio ecogénico central, excavación coroidea, y sombra ecogénica posterior que en ocasiones adopta forma de champiñón, al romper la membrana de Bruch, siendo esta imagen prácticamente patognomónica ${ }^{57} 58$.

Es muy característico que en el vector $A$ el tumor presente un pico en la superficie anterior que decrece gradualmente hasta la esclera denominándose "ángulo kappa" y es altamente representativo de los melanomas.

La ecografía ocular además puede ser útil para el diagnóstico de enfermedad extraocular y en la evaluación del crecimiento, estabilidad o regresión del tumor.

- 21 - Estudio de la supervivencia en pacientes con Melanoma Uveal de una Unidad Referencial de Tumores Intraoculares. 2013 


\subsubsection{Extensión Extraocular:}

Otras técnicas de imagen de la órbita como la Tomografia axial computerizada (TAC) y la Resonancia Magnética (RM) se reservan para casos en los que no se puede explorar el interior del globo ocular (cataratas, hemorragia vítrea) y son esenciales para la valoración de la extensión del tumor fuera del globo ocular. ${ }^{7}$

\subsubsection{Extensión Sistémica:}

Una vez establecido el diagnóstico de melanoma de úvea, se debe llevar a cabo un estudio de extensión para descartar enfermedad a distancia o sistémica.

Las pruebas deben de estar encaminadas a la detección de lesiones hepáticas primordialmente, ya que, debido a la ausencia de linfáticos en el globo ocular, la diseminación es hematológica mostrando gran predilección por el hígado.

El hígado es el primer órgano afectado de enfermedad metastásica en el $85 \%$ de los casos y en el $55 \%$ es el único órgano afecto. ${ }^{59}$

Lo más extendido entre los diversos centros, es la realización de un TAC toracoabdominal, aunque una ecografía hepática para descartar afectación hepática puede resultar suficiente.

EI PET actualmente es de dudosa utilidad en el diagnóstico de extensión. Se han realizado estudios de comparación entre el PET y la RMN, sobre todo a nivel hepático, que concluyen que la resonancia magnética es superior al PET para el diagnóstico de metástasis hepáticas de novo o para aclarar el origen de lesiones hepáticas sospechosas $^{60}$. Este estudio fue llevado a cabo en Paris por Servois et al, quienes estudiaron las lesiones hepáticas de 12 pacientes afectos de melanoma uveal metastásico. La sensibilidad y el valor predictivo positivo fueron del $67 \%$ y $95 \%$ para la RMN y del $41 \%$ y 100\% para el PET. La limitación del uso del PET en esta enfermedad puede ser explicada por la escasa resolución espacial que le impide diagnosticar metástasis subcentimétricas y por el metabolismo de la glucosa en el hígado que disminuye la sensibilidad de la técnica. 


\subsection{CLASIFICACIÓN}

La estadificación/clasificación del tumor es fundamental para el cuidado del paciente oncológico y el melanoma de úvea no es una excepción. Desafortunadamente, a diferencia de otros tipos de cáncer, el Sistema de estadificación TNM no ha sido generalizado en este tipo tumoral debido sobre todo a su complejidad en la utilización en la clínica diaria.

Por ello, una variedad de sistemas alternativos basados en el diámetro mayor del tumor, el grosor tumoral, la extensión extraocular, y la afectación del cuerpo ciliar, entre otras características tumorales, son los parámetros utilizados para establecer una clasificación que permita establecer el grado de afectación, seleccionar el tratamiento más adecuado y realizar una valoración del pronóstico.

La clasificación difundida por el Collaborative ocular melanoma Study (COMS) norteamericano está muy implantada en las clínicas de oncología ocular y tiene tanto un valor pronostico para el paciente como de selección de tratamiento.

\subsubsection{Clasificación TNM}

Se basa en la afectación anatómica $(\mathrm{T})$, la presencia de extensión linfática $(\mathrm{N})$ y en la presencia de metástasis. Se encuentra reflejada en la tabla 1.

Tabla 1 Estadificación del melanoma de úvea

(Tomado de AJCC Cancer Staging Manual. 7º Edición. Ed. Springer. Nueva York)

\section{IRIS}

\begin{tabular}{|l|l|}
\hline T1 & Tumor limitado al iris \\
T1a & Tumor limitado al iris que no afecta más de 3 husos horarios \\
T1b & Tumor limitado al iris que afecta más de 3 husos horarios \\
T1c & Tumor limitado al iris con glaucoma $2^{\circ}$ \\
\hline T2 & Afectación de iris con invasión de cuerpo ciliar y/o coroides \\
T2a & Invasión de cuerpo ciliar (CC) y/o coroides con $2^{\circ}$ \\
\hline T3 & Invasión de cuerpo ciliar y/o coroides con extensión escleral \\
T3a & Invasión de cuerpo ciliar y/o coroides con extensión escleral y glaucoma $2^{\circ}$ \\
\hline T4 & Extensión extraescleral \\
T4a & Extensión extraescleral menor o igual de 5 mm de diámetro \\
T4b & Extensión extraescleral mayor de $5 \mathrm{~mm}$ de diámetro \\
\hline
\end{tabular}

23 - Estudio de la supervivencia en pacientes con Melanoma Uveal de una Unidad Referencial de Tumores Intraoculares. 2013 


\begin{tabular}{|c|c|}
\hline & $\begin{array}{c}\text { CUERPO CILIAR Y COROIDES } \\
\text { Según las medidas del tumor, este se organiza en } 4 \text { categorías } \\
\text { representadas en el siguiente diagrama: }\end{array}$ \\
\hline & 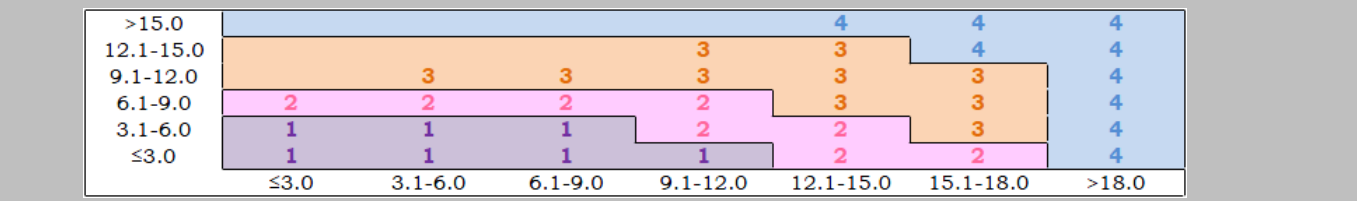 \\
\hline $\mathrm{T} 1$ & Tumor con tamaño categoría 1 \\
\hline T1a & Tumor con tamaño categoría 1 sin invasión del CC ni extensión extraocular \\
\hline T1b & Tumor con tamaño categoría 1 con invasión del CC \\
\hline T1c & $\begin{array}{l}\text { Tumor con tamaño categoría } 1 \text { sin invasión del CC y con extensión extraocular } \\
\leq 5 \mathrm{~mm}\end{array}$ \\
\hline T1d & $\begin{array}{l}\text { Tumor con tamaño categoría } 1 \text { con invasión del CC y con extensión extraocular } \\
\leq 5 \mathrm{~mm}\end{array}$ \\
\hline T2 & Tumor con tamaño categoría 2 \\
\hline T2a & Tumor con tamaño categoría 2 sin invasión del CC ni extensión extraocular \\
\hline T2b & Tumor con tamaño categoría 2 con invasión del CC \\
\hline T2c & $\begin{array}{l}\text { Tumor con tamaño categoría } 2 \text { sin invasión del CC y con extensión extraocular } \\
\leq 5 \mathrm{~mm}\end{array}$ \\
\hline T2d & $\begin{array}{l}\text { Tumor con tamaño categoría } 2 \text { con invasión del CC y con extensión extraocular } \\
\leq 5 \mathrm{~mm}\end{array}$ \\
\hline T3 & Tumor con tamaño categoría 3 \\
\hline ТЗа & Tumor con tamaño categoría 3 sin invasión del CC ni extensión extraocular \\
\hline T3b & Tumor con tamaño categoría 3 con invasión del CC \\
\hline T3c & $\begin{array}{l}\text { Tumor con tamaño categoría } 3 \text { sin invasión del CC y con extensión extraocular } \\
\leq 5 \mathrm{~mm}\end{array}$ \\
\hline T3d & $\begin{array}{l}\text { Tumor con tamaño categoría } 3 \text { con invasión del CC y con extensión extraocular } \\
\leq 5 \mathrm{~mm}\end{array}$ \\
\hline$\overline{\mathrm{T} 4}$ & Tumor con tamaño categoría 4 \\
\hline $\mathrm{T} 4 \mathrm{a}$ & Tumor con tamaño categoría 4 sin invasión del CC ni extensión extraocular \\
\hline $\mathrm{T} 4 \mathrm{~b}$ & Tumor con tamaño categoría 4 con invasión del CC \\
\hline $\mathrm{T} 4 \mathrm{c}$ & $\begin{array}{l}\text { Tumor con tamaño categoría } 4 \text { sin invasión del CC y con extensión extraocular } \\
\leq 5 \mathrm{~mm}\end{array}$ \\
\hline T4d & $\begin{array}{l}\text { Tumor con tamaño categoría } 4 \text { con invasión del CC y con extensión extraocular } \\
\leq 5 \mathrm{~mm}\end{array}$ \\
\hline $\mathrm{T} 4 \mathrm{e}$ & Cualquier tamaño con extensión extraocular $\geq 5 \mathrm{~mm}$ \\
\hline
\end{tabular}




\subsubsection{Clasificación de COMS:}

La clasificación más aceptada y usada es la acuñada por el COMS.

Se basa en la medidas ecográficas del tumor siendo de gran utilidad para la selección terapéutica como para el pronóstico de la enfermedad ${ }^{61}$ :

\begin{tabular}{|lcc|}
\hline \multicolumn{3}{c}{ Tabla 2. Tamaño COMS } \\
\hline Tamaño & Diámetro basal & Altura Tumoral \\
\hline Pequeño & $<5 \mathrm{~mm}$ & $1-<2,5 \mathrm{~mm}$ \\
Mediano & $<16 \mathrm{~mm}$ & $2,5-10 \mathrm{~mm}$ \\
Grande & $>16 \mathrm{~mm}$ & $>10 \mathrm{~mm}$ \\
\hline
\end{tabular}




\subsection{TRATAMIENTO}

\subsubsection{Objetivos del tratamiento:}

Una vez establecido el diagnóstico se debe llevar a cabo un correcto tratamiento cuyos objetivos son:

a) Control del tumor (Destruir/Inactivar):

El melanoma de coroides, como toda neoplasia, sin un tratamiento oncológico asociado, tiende a crecer y destruir e invadir toda estructura a su paso. Por ello, el primero de los objetivos debe de ser la destrucción o detención de progresión tumoral.

b) Conservar el globo ocular

En la medida de lo posible se debe tender a la conservación del órgano y la preservación de las estructuras oculares.

c) Disminuir el número de complicaciones/ efectos secundarios: Una vez conservado el globo ocular, los tratamientos conservadores deben intentar preservar al máximo las estructuras oculares para que el paciente mantenga el máximo de función visual posible.

d) Mejorar la supervivencia:

Hasta la actualidad ningún tratamiento ha mostrado superioridad sobre otros en cuanto a la mejora de los datos de supervivencia. La supervivencia está fuertemente influida por el tamaño tumoral y por ello un diagnóstico precoz es actualmente la forma más definitiva de influir en la supervivencia. ${ }^{2}$

\subsubsection{Tipos de Tratamiento:}

Hasta hace unos años, el único tratamiento disponible para erradicar esta enfermedad era la enucleación, actualmente disponemos de múltiples alternativas terapéuticas más conservadoras.

La enucleación actualmente queda relegada a tumores muy avanzados, permitiendo con las nuevas terapéuticas, en mayor o menor medida, conservar la función visual.

Para ello la elección de tratamiento debe de realizarse de manera individualizada, eligiendo entre todas las posibles terapéuticas de las que disponemos:

- 26 - Estudio de la supervivencia en pacientes con Melanoma Uveal de una Unidad Referencial de Tumores Intraoculares. 2013 
a) Enucleación:

Técnica empleada en la mayoría de los casos hasta 1970. Actualmente sigue siendo la terapia de elección de ojos ciegos o con dolor y en tumores grandes $(>16 \mathrm{~mm})$ que invaden nervio óptico o producen glaucomas graves no susceptibles de terapias conservadoras. ${ }^{62}$

Los ojos que desde el momento del diagnóstico cursan con extensión extraescleral se tratan de igual manera con enucleación ya que terapias más agresivas no han demostrado mejorar el pronóstico. En estos casos se puede valorar la asociación de terapia oncológica adyuvante como la radioterapia externa previa o posterior a la cirugía. ${ }^{63}$

\section{b) Radioterapia:}

En más de dos tercios de los casos, el tratamiento empleado en este tipo de tumores. Se basa en formas muy específicas de radioterapia (braquiterapia epiescleral, radioterapia con protones o radiocirugía). Estos tratamientos pueden emplearse de manera aislada o asociados a otros tipos de terapéuticas como las resecciones quirúrgicas y diferentes tipos de tratamientos con láser.

Estas modalidades terapéuticas nos permiten el control del tumor y conservar el globo ocular en aproximadamente el $90 \%$ de los casos, conservando función visual útil en más del $50 \%$ de los pacientes. ${ }^{64}$

\section{a. Braquiterapia Epiescleral:}

La braquiterapia epiescleral con isotopos radiactivos es uno de los métodos más empleados en la actualidad para el tratamiento de los melanomas uveales. Desde que esta técnica comenzó en los años 30 con el uso del radón por Moore ${ }^{65}$, diversos isótopos como el cobalto $\left({ }^{60} \mathrm{Co}\right)$, el rutenio $\left({ }^{106} \mathrm{Ru}\right)$, el iridio $\left({ }^{192} \mathrm{Ir}\right)$, el estroncio $\left({ }^{90} \mathrm{Sr}\right)$, el paladio $\left({ }^{103} \mathrm{Pd}\right)$ y el yodo $\left({ }^{125} \mathrm{I}\right)$ se han empleado, siendo en la actualidad el yodo y el rutenio los más utilizados. La técnica se basa en la colocación de una placa cargada con alguno de estos isótopos sobre la proyección escleral externa del tumor. Dicha placa se sutura para inmovilizarla y que el tumor sea expuesto a la dosis programada de radiación. Esta técnica garantiza una adecuada irradiación del tumor puesto que la 
placa se desplaza junto con el ojo. Actualmente se considera que la dosis terapéutica en el ápex tumoral debe ser de 85 Gy. ${ }^{66} 54$

Debido a la radiación asociada de tejidos circundantes sanos, esta terapéutica trae consigo el desarrollo de efectos secundarios tales como las cataratas, la retinopatía y la neuropatía por radiación que comprometen de manera reversible o irreversible la función visual del paciente. ${ }^{67}$

\section{b. Radioterapia con Protones:}

Otra alternativa conservadora para el tratamiento de los melanomas de la úvea es el uso de radiación externa con protones. Se basa en el bombardeo del tumor con protones o núcleos de helio que son acelerados mediante un ciclotrón. Es un tratamiento menos empleado debido a la escasez de equipos. Los aceleradores tienen un elevadísimo coste de construcción y mantenimiento, causa por la cual actualmente su uso está bastante restringido. ${ }^{68}$ Sus indicaciones son similares a las de la braquiterapia, pudiendo ser usada en tumores de mayor tamaño.

\section{c. Radiocirugía:}

La radiocirugía es otra modalidad de tratamiento con radiación. Hoy en día existen distintos sistemas como son el gammaknife (consiste en un dispositivo con múltiples fuente de cobalto $\left({ }^{60} \mathrm{Co}\right)$ colocadas en una estructura hemisférica que hace que la emisión de rayos y converja en el tumor), el ciberknife (es un acelerador lineal de electrones colocado en un brazo robótico con múltiples grados de movimiento que permite irradiar el tumor en múltiples planos espaciales que convergen en éste), la tomoterapia (consiste en un acelerador lineal de electrones montado junto con un sistema de tomografía axial computerizada que permite recalcular la dosis suministrada en función de la información que en tiempo real se recoge mediante el sistema de tomografía) o la radioterapia estereoatáxica (consiste en un acelerador de electrones que varia la dosis de radiación suministrada según realiza un movimiento circular con centro en el tumor). No existe experiencia en el tratamiento del melanoma uveal con dispositivos de tomoterapia, y con el cyberknife es escasa ${ }^{69}$. Si bien el gammaknife ${ }^{70}$ y la radioterapia estereoatáxica ${ }^{71}$ 
han demostrado una eficacia comparable a la de la braquiterapia epiescleral, presentan el inconveniente de la necesidad de una fijación temporal del globo ocular mientras se aplica el tratamiento ${ }^{72}$.

c) Cirugía:

Se pueden realizar resecciones transesclerales (resección del tumor desde su proyección epiescleral) o externas, o endoresecciones mediante vitrectomia (eliminación del tumor a a través de la retina mediante vitrectomía). Son técnicas complejas a las que debe asociarse posteriormente braquiterapia para evitar las recurrencias en los bordes quirúrgicos. ${ }^{52}$

\section{d) Observación periódica:}

Se opta sobre todo cuando el diagnóstico diferencial entre nevus y melanoma resulta difícil. La vigilancia periódica se recomienda cuando los melanomas son pequeños y no se documentan signos de actividad. ${ }^{15}{ }^{16}$ Los signos de actividad son de vital importancia en el seguimiento de los melanomas uveales en observación, puesto que su detección determina la aplicación de tratamiento. Estos signos son la presencia de fluido subretiniano, la presencia de pigmento naranja en la superficie tumoral, la disminución de la agudeza visual, la forma en "champiñón" y la objetivación de crecimiento. ${ }^{73}$ En este sentido, el estudio de las lesiones sospechosas con tomografía de coherencia óptica (OCT) puede ser de gran utilidad, puesto que esta tecnología tiene capacidad de poner de manifiesto el fluido subretininano antes de que éste sea clínicamente detectable.

Ninguna de las modalidades de tratamiento ha demostrado mejorar la supervivencia de los pacientes, considerándose que la enfermedad sistémica es independiente de la forma de tratamiento del tumor primario. ${ }^{874}$ 


\section{SUPERVIVENCIA, ENFERMEDAD METASTÁSICA Y FACTORES PRONÓSTICOS}

La extensión sistémica y la supervivencia de los pacientes con melanoma uveal, tienen una serie de características peculiares como la predilección por su desarrollo en el hígado, y periodos libres de enfermedad que oscilan entre los pocos meses posteriores al diagnóstico y más de 40 años, sin presentar signos de extensión ni recidiva local.

\subsection{SUPERVIVENCIA EN EL MELANOMA UVEAL}

Los estudios más relevantes que llaman la atención acerca de la supervivencia en el melanoma de la úvea comienzan con los trabajos de Zimmerman en Estados Unidos ${ }^{20}$ y Jensen en Dinamarca ${ }^{30}$ a finales de los años 70.

Hasta entonces, el tratamiento que se realizaba en los pacientes diagnosticados de melanoma uveal era la enucleación, como método de eliminar el tumor local sin signos de extensión sistémica con la idea de que la extirpación quirúrgica y completa del tumor podría prevenir la aparición de la enfermedad sistémica. Zimmerman et al en 1978, publican una revisión de 1146 casos de ojos enucleados del Registro de Patologia Ocular del "Armed Forces Institute of Pathology" de Washington entre 1950 y 1960, aportando unos datos de mortalidad del $45 \%$ a los 15 años, con una proporción del 1\% anual, excepto alrededor del segundo y tercer año en que se incrementa al $8 \%$, atribuyendo este pico de mortalidad a la diseminación del melanoma durante el acto quirúrgico de la enucleación.

Por otra parte, Jensen ${ }^{30}$ en 1981 publica la revisión de 302 casos de melanoma uveal diagnosticados en Dinamarca entre 1943 y1952 con un seguimiento de 25 años posterior a la enucleación mostrando una mortalidad global a los 25 años del $82 \%$ y específica a causa del melanoma del $50 \%$ confirmando la existencia de un pico de mortalidad del $10 \%$ en el primer año de seguimiento.

Estos trabajos hacen que a partir de la década de los 80 se desarrollen y apliquen mas tratamientos conservadores (Radioterapia con partículas aceleradas y braquiterapia con placas epiesclerales) que permitan destruir el tumor disminuyendo el riesgo de diseminación de la enfermedad. Pero ya estos autores sugieren la necesidad de realizar estudios prospectivos randomizados (enucleación vs tratamientos conservadores) para valorar el impacto real de los tratamientos en la supervivencia de los pacientes. 
En 1992, Diener-West et al ${ }^{3}$ publican un estudio meta-analitico que trata de sistematizar toda la información publicada acerca de la mortalidad a los 5 años, causada por el melanoma uveal post-enucleacion, como paso previo del diseño de un estudio multicéntrico randomizado de enucleación vs braquiterapia. Los autores revisan los trabajos publicados entre 1966 y 1988 encontrando que la mortalidad a los 5 años según tamaños era del $16 \%$ para tumores pequeños, $32 \%$ para medianos y $53 \%$ para tumores grandes, confirmando que el tamaño es un importante factor pronóstico.

Hasta los años 90, la mayoría de los estudios publicados eran retrospectivos, y de series cortas de pacientes tratadas en un solo centro. Por esta razón, y con el objetivo de averiguar la influencia del tratamiento conservador con radioterapia frente a la enucleación en la supervivencia de los pacientes, se diseña el "Collaborative Ocular Melanoma Study" (COMS) en Norteamérica. Este estudio multicéntrico, prospectivo, que involucra 43 centros, aporta una clasificación por tamaños estandarizada, y randomiza los pacientes con tumores de tamaño mediano a braquiterapia o enucleación, para evaluar la influencia sobre la supervivencia. También como otros brazos del estudio, evalúa la mortalidad de tumores pequeños y grandes.

En el grupo de tumores pequeños (204 pacientes), la mayoría sometidos a observación a los 5 años encuentran una mortalidad global del $6 \%$ y específica del $1 \%$, mostrando una baja mortalidad por melanoma. ${ }^{75}$

En el grupo más importante del estudio, el de los melanomas medianos, randomizados a enucleación o braquiterapia con 1125 compuesto por 1317 pacientes, aportan una mortalidad global a los 5 años del 19\% y $18 \%$, y específica\% del 11 y $9 \%$ respectivamente no encontrando diferencias significativas entre ambos brazos del estudio. $^{76}$

En el grupo de tumores grandes randomizan los pacientes a enucleación o enucleación previa radioterapia externa (20 Gy), con el fin de comprobar si la esterilización de las células neoplásicas previa a la cirugía ejercía alguna influencia en la mortalidad causada por la enfermedad. De los 1003 pacientes enrolados, 435 fallecieron durante el estudio, con cifras de mortalidad a los 5 años global similares en ambos brazos del estudio: $57 \%$ para enucleación y $62 \%$ para enucleación previa radiación. ${ }^{77}$

- 31 - Estudio de la supervivencia en pacientes con Melanoma Uveal de una Unidad Referencial de Tumores Intraoculares. 2013 
Posteriormente, y con la mayor expansión de los tratamientos conservadores, Singh et $\mathrm{al}^{1}{ }^{21} \mathrm{a}$ través del "Surveillance, Epidemiology and End results (SEER)", del Instituto Nacional de Cáncer de Estados Unidos, estudian la evolución de la supervivencia de 4070 pacientes desde 1973 a 2008. Estos autores observan que en el periodo de tiempo estudiado, los tratamientos conservadores basados en radiación pasan del 1,8\% al $62 \%$, esperando que este hecho influya en la supervivencia. Sin embargo concluyen que no se observan diferencias en la supervivencia de los pacientes a los 5 años manteniéndose estable alrededor del $80 \%$ durante los más de 30 años de observación.

Los resultados del COMS study y estos trabajos posteriores, concluyen que los avances en el tratamiento local del tumor primario no han conducido a una mejoría en la supervivencia por lo que se debe abordar el tratamiento del melanoma uveal desde una perspectiva sistémica.

Al mismo tiempo que se publican estos resultados de estudios norteamericanos, en Europa los grupos de oncología ocular publican estudios de cada centro con diferentes métodos y grupos de pacientes, difícilmente comparables, pero principalmente procedentes del Reino Unido, y países nórdicos donde la incidencia de esta neoplasia es mucho mayor. Los resultados de estos trabajos apoyan la falta de influencia del tratamiento en la enfermedad metastásica y ratifican una mortalidad a los 10 años de alrededor del $50 \%$. Virgili et al en $2008,{ }^{78}$ publican una revisión de la supervivencia de los pacientes de melanoma uveal en Europa, revisando los resultados de 32 registros de cáncer de 16 países europeos entre 1983 y 1994, con seguimiento hasta 1999. Encuentran un total de 5788 pacientes, de los cuales tan solo 31 proceden de España (9 de Mallorca, 15 de Navarra y 7 de Tarragona). Encuentran una supervivencia relativa a los 5 años del 68,9\% que permanece estable durante el periodo de estudio. También encuentran una supervivencia similar en países nórdicos y en el Reino Unido y menor en el resto de los países.

En España, son muy escasos los trabajos dedicados al estudio de la supervivencia. Recientemente ha sido publicado un estudio realizado Caminal et $\mathrm{al}^{33}$ en el cual han sido enrolados 155 pacientes diagnosticados y tratados entre 1995-2004 para el estudio de la supervivencia global y relativa. Se entiende como supervivencia relativa el riesgo aumentado de mortalidad que confiere determinada enfermedad a un sujeto de determinado sexo y edad teniendo en cuenta el porcentaje de mortalidad basal que posee. Es el gold Standard para el análisis de mortalidad causa-específica, pero hace que sea

- 32 - Estudio de la supervivencia en pacientes con Melanoma Uveal de una Unidad Referencial de Tumores Intraoculares. 2013 
muy complicada la comparación con lo hasta ahora publicado. Caminal completó su trabajo con un análisis multivariante de Cox. Se encontró una supervivencia relativa del $90 \%$ con especial significancia en el peor pronóstico de mujeres, mayores de 60 años, con tumores grandes y sobre todo al tercer o cuarto año de seguimiento.

En la Unidad de tumores Intraoculares de Valladolid, unidad desde la que se realiza el presente trabajo, ha realizado una revisión ${ }^{34}$ de más de 500 pacientes en la cual, al igual que lo observado en el estudio de Caminal, se obtienen cifras de supervivencia global y específica por encima de las publicadas hasta el momento actual en otras poblaciones estudiadas. 


\subsection{DISEMINACIÓN METASTÁSICA}

El melanoma uveal se disemina por vía hematógena principalmente debido a la ausencia de linfáticos en el globo ocular, presentando una elevada predilección por el hígado, siendo en el $85 \%$ de los casos la primera localización y en el 55\% la única. ${ }^{79}$

Una vez diagnosticada la diseminación de la enfermedad, la supervivencia media es inferior a 12 meses, con una media aproximada de 7 meses. ${ }^{80}$ Aunque la localización más frecuente de afectación de las metástasis es el hígado (56-90\%), también se han descrito otras localizaciones como pulmón (31\%), hueso (7-23\%) y piel $(17-36,5 \%){ }^{81}{ }^{82}$ En el momento actual no existe un tratamiento eficaz de la enfermedad diseminada. ${ }^{17}$

A pesar de que únicamente el $1-2 \%$ de los pacientes diagnosticados de melanoma uveal presentan extensión sistémica en el momento del diagnóstico, el $50 \%$ de los pacientes presentan metástasis en los siguientes 15 años, con periodos libres de enfermedad que llegan hasta los 40 años desde el tratamiento del tumor primario por lo que se cree que, ya en el momento del diagnóstico, existen metástasis subclínicas, indetectables con los medios de que disponemos, que se mantienen quiescentes por mecanismos aun desconocidos. ${ }^{8320}$

La mortalidad debida al melanoma uveal aumenta proporcionalmente con el tamaño y el tiempo transcurrido desde el diagnóstico en todas las series publicadas, aunque las cifras difieren según el tamaño de la muestra, y el tiempo de seguimiento de los pacientes. Según Kujala (2003) en un estudio a largo plazo de 239 pacientes finlandeses el riesgo de desarrollar metástasis es del $31 \%$ a los 5 años, $45 \%$ a los 15 años, $49 \%$ a los 25 años y $52 \%$ a los 35 años. ${ }^{84}$

\subsubsection{Predilección hepática:}

Una de las características principales en el proceso metastático de esta enfermedad es la especificidad hepática de las lesiones. Se ha demostrado que la mayoría de las células con potencial metastásico se comportan de una manera no randomizada a la hora de establecerse en algún órgano.

Como se ha descrito con anterioridad, en el caso del melanoma de úvea, la predilección hepática es llamativa y parece estar en relación con la sobreexpresión de quimiocinas quimioatrayentes por parte del hígado. Estas quimiocinas favorecen migración 
específica de las células metastásicas que expresan sus receptores hacia aquellos órganos que las producen y las secretan favoreciendo también su proliferación una vez se han establecido en el órgano diana. ${ }^{85}$

\subsubsection{Periodo Libre de Enfermedad:}

Siguiendo con la idea de Zimmerman y la presencia de enfermedad metastásica décadas después del tratamiento local de la enfermedad cobra especial importancia el término periodo libre de enfermedad y su relación con la supervivencia.

Entendemos como periodo libre de enfermedad el tiempo transcurrido desde la desaparición de la evidencia clínica, analítica y radiológica de la enfermedad hasta la recurrencia de la misma.

En la actualidad, el periodo libre de enfermedad, está determinado por las características clínicas, histopatológicas, citogenéticas y moleculares que influyen en la frecuencia y el intervalo entre el diagnóstico del tumor primario y la aparición de la enfermedad metastásica. Este hecho es muy importante y será determinante en un futuro para la identificación y tratamiento profiláctico de pacientes con un alto poder metastásico ${ }^{21}$.

Hay pocos estudios hasta el momento analizando este tema, quizás el más relevante es un estudio realizado en Tejas sobre 463 pacientes diagnosticados de melanoma. Una vez tratado el tumor primario se observó recurrencia sistémica a los 5 años en 305 pacientes, entre 5 y 10 años en 97 pacientes y finalmente posteriores a 10 años del diagnóstico únicamente el 61 pacientes. Este estudio concluyó que un aumento del periodo libre de enfermedad llevaba consigo un aumento significativamente mayor en la media de la supervivencia posterior al diagnóstico de las metástasis. ${ }^{86}$

\subsubsection{Seguimiento:}

Actualmente el seguimiento que se realiza en la unidad en la que se ha llevado a cabo este estudio, consiste en la realización anual de un estudio de imagen (ecografia hepática o TAC toracoabdominal) y una analítica con perfil hepático (LDH, FA, GOT, GPT).

Pero lo cierto es, que a día de hoy, el seguimiento de esta enfermedad es un tema controvertido al no existir aun un tratamiento eficaz de la enfermedad diseminada.

El protocolo del COMS, únicamente incluye una exploración física exhaustiva, un perfil hepático y una radiografía de tórax. ${ }^{87}$ Sin embargo, el paciente metastásico suele 
permanecer asintomático en el $60 \%$ de los casos y con pruebas hepáticas normales en el $30 \%$. Por lo que resulta necesario añadir al protocolo una prueba de imagen cada 6-12 meses para descartar enfermedad a distancia. ${ }^{88}$

Kolandjian, en un estudio realizado en Tejas en 2011, con pacientes en seguimiento por melanoma de coroides, ha obtenido datos que reflejan que el estado físico del paciente en el momento del diagnóstico de las metástasis, así como su edad o niveles de albumina, fosfatasa alcalina (FA) o lactato deshidrogenada (LDH) son factores pronósticos independientes de la supervivencia del paciente. Aun así, son datos básicos que se manejan hoy en día en las analíticas de seguimiento de este tipo de pacientes ${ }^{86}$.

Siguiendo con la validez de este tipo de métodos diagnósticos empleados en el seguimiento, el COMS en 2004 publico un estudio sobre 2320 pacientes, estudiando la seguridad del seguimiento de los pacientes tratados del tumor primario con un perfil hepático. Se concluyó que este tipo de prueba complementaria posee una alta especificidad pero baja sensibilidad, por lo que no resulta un test de screening útil para el diagnóstico temprano de metástasis hepáticas ${ }^{89}$.

Ambos estudios corroboran la necesidad y la superioridad de las técnicas de imagen en la capacidad de detección de metástasis en el paciente con melanoma uveal metastásico.

\subsubsection{Tratamiento de la enfermedad metastásica:}

La enfermedad metastásica hoy por hoy no tiene tratamiento eficaz y la supervivencia es muy pobre. Pero en la actualidad se están ensayando diversos tipos de tratamiento.

a) Tratamiento Sistémico:

El melanoma de coroides tiene un comportamiento muy diferente al melanoma cutáneo en cuanto a su comportamiento clínico-patológico. Por ello no responde al tratamiento con quimioterapia (QT) sistémica con interferón alfa.

Se han probado nuevos esquemas terapéuticos, entre los más ensayados se encuentra la combinación de Dacarbazina, Lomustina, Vincristina, Bleomicina (Esquema BOLD) con o sin interferón alfa. 
Esta terapia fue estudiada por Kivela en 2003 sobre 20 pacientes metastáticos, y a parte de estar poco extendida y por ello ser poco utilizada, el porcentaje de respuesta fue menor del $20 \%$ de los pacientes. ${ }^{90}$

Otro esquema probado en este tipo de pacientes es el esquema Dartmouth (Dacarbazina, Carmustina, Cispatino y Tamoxifeno), al igual que lo ocurrido con el esquema anterior su eficacia fue muy escasa. Fue ensayado en 1994, administrándoselo a 16 pacientes metastásicos encontrando respuestas del $6 \%{ }^{91}$

Entre las nuevas terapias experimentales se encuentra la monoterapia con temozolamida no disponiendo de datos alentadores en el momento actual. ${ }^{92}$

b) QT Intraarterial:

Consiste en la infusión a través de un catéter por la Arteria Hepática de diversos citotóxicos. Se han investigado diversos esquemas de quimioterapia, pero el número más alto de respuestas completas se ha encontrado con el empleo de fotemustina con o sin interferón alfa añadiendo IL-2 o con el esquema de interferón alfa y Mefalan.

En un estudio ${ }^{93}$ realizado en Suecia sobre 31 pacientes metastásicos tratados con Fotemustina $100 \mathrm{mg} / \mathrm{m} 2$ una vez por semana y posterioremente cada tres semanas hasta la recurrencia o la aparición de toxicidad, se encontraron datos de respuesta de hasta el 40\% (12 pacientes, 4 de ellos respuesta completa). La media de supervivencia fue de 14 meses, levemente superior a lo establecido en el paciente metastásico, no encontrándose mayor toxicidad.

c) Cirugía + QT Intraarterial:

Estudios basados en la combinación del tratamiento local seguidos el tratamiento sistémico han sido los únicos trabajos alentadores en cuanto a los resultados de supervivencia media se refiere. El trabajo más relevante sobre este aspecto se realizó sobre una muestra de 75 pacientes sometidos a: resección completa de la metástasis en el $28 \%$ de los casos, resección parcial en el $34 \%$ y únicamente biopsia en el 23\% restante. Posterior a la cirugía recibieron QT intraarterial con fotemustina o Dacarbazina+Cisplatino. La media de supervivencia fue de 9 meses, no siendo diferente a publicaciones previas, pero la media de supervivencia para los pacientes con resección completa fue de 22 meses, no habiendo diferencias entre los dos esquemas de QT utilizados. 
d) Quimioembolización:

El método consiste en alcanzar una concentración alta y prolongada de agentes citotóxicos en la metástasis del melanoma uveal. Los estudios realizados hasta el momento, siendo el más relevante el realizado en M.D. Anderson Center ${ }^{94}$ llevado a cabo con Cisplatino y una esponja de polivinilo y se han encontrado respuestas en más de un tercio de los casos. Otros centros que han intentado llevar a cabo este tratamiento no han logrado objetivar respuesta en un solo caso.

e) Inmunoterapia:

Dado el éxito del Ipilimumab en el melanoma cutáneo se están comenzando a plantear estudios en este sentido para el melanoma uveal metastásico. Hasta la fecha no disponemos de publicaciones alentadoras en este campo.

f) Recomendaciones Futuras:

Con la identificación actual de los factores pronósticos, es posible reconocer a los pacientes con un alto riesgo metastásico. Estudios multicéntricos prospectivos, van encaminados al papel de terapias profilácticas en pacientes identificados como alto poder metastásico por sus factores clínicos, histopatológicos, citogenéticos o moleculares. 


\subsection{FACTORES PRONÓSTICOS}

Existen una serie de factores con valor pronóstico demostrado para la predicción de aparición de enfermedad sistémica. ${ }^{21}$

\subsubsection{Clínicos:}

\section{a) Diámetro Máximo:}

Uno de los factores pronósticos más importantes es el tamaño tumoral ${ }^{25} 95$, de forma que tumores pequeños (diámetro menor o igual a $10 \mathrm{~mm}$ o altura menor 0 igual a $3 \mathrm{~mm}$ ) presentan una supervivencia a los 20 años del $78 \%$, mientras que en tumores medianos (diámetro entre 11 y $15 \mathrm{~mm}$ y altura entre 3 y $10 \mathrm{~mm}$ ) es del $55 \%$ y en tumores grandes (diámetro mayor o igual a $15 \mathrm{~mm}$ o altura mayor o igual a $10 \mathrm{~mm}$ ) es del $30 \% .^{96}$

\section{b) Altura máxima:}

Se considera también una característica relacionada con el pronóstico, aunque en mucha menor medida que el diámetro ${ }^{97}$, pero nos ayuda a establecer una clasificación tumoral adecuada lo cual es fundamental para establecer un correcto plan terapéutico y un adecuado pronóstico.

\section{c) Tamaño:}

Se ha demostrado una correlación entre el tamaño del tumor y una peor supervivencia independientemente de la forma de clasificación que se elija .² Este factor pronóstico se encuentra en íntima relación con el diámetro tumoral, que se obtendrá ecográficamente y que nos permitirá clasificar al tumor. Todos los trabajos publicados hasta el momento relacionan un mayor tamaño tumoral con un peor pronóstico. ${ }^{98}$

\section{d) Invasión cuerpo ciliar:}

La invasión de cuerpo ciliar se considera un factor de riesgo fundamental para la aparición de enfermedad a distancia. ${ }^{25}$

En una revisión realizada sobre 510 pacientes tratados con protones se observó un aumento de la mortalidad en los casos que presentaban invasión del cuerpo ciliar. Se observó un aumento de la mortalidad específica a los 5 años que aumentaba en estos pacientes de un $10 \%$ a un $16 \%{ }^{99}$ 


\section{e) Extensión Extraescleral:}

Aunque en muchas ocasiones no se manifieste clínicamente, la extensión de la enfermedad fuera del globo ocular es un indicador de progresión y agresividad tumoral que empeora notablemente el pronóstico.$^{100}$

\section{f) Regresión Rápida de la Masa Tumoral:}

Al contrario de lo que se podía esperar, una pérdida superior al $10 \%$ de la altura total del tumor cada mes tras el tratamiento supone un empeoramiento significativo de la supervivencia. ${ }^{101}$

\section{g) Localización Yuxtapapilar:}

La localización yuxtapapilar del tumor esta unida en un alto porcentaje de casos de invasión del nervio óptico con lo que conlleva un pérdida de visión y disminución de las cifras de supervivencia ${ }^{102}$. En los estudios realizados hasta el momento no se ha encontrado repercusión en cuanto a la supervivencia en los análisis multivariantes ${ }^{103}$, aun así, la presencia de esta característica clínica en la mayoría de los casos lleva consigo la realización de una enucleación como terapéutica de elección.

\subsubsection{Histopatológicos:}

\section{a) Tamaño:}

Se ha demostrado que cuanto mayor es el tamaño peor es la supervivencia del paciente, sea cual fuere la forma de clasificarlo ${ }^{25}$.

\section{b) Tipo celular:}

Según la clasificación de Callender los tipos celulares de los melanomas de úvea se pueden clasificar en fusiformes $A$, fusiformes $B$ y epitelioides pudiendo aparecer en diferentes proporciones en un mismo tumor. La proporción de células epitelioides, confieren un peor pronóstico ${ }^{104}$.

Se ha observado un aumento de la mortalidad a los 15 años en pacientes en cuya histología predominan las células epitelioides respecto a los melanomas de úvea en la que la anatomía patológica describía únicamente o gran predominio de células fusiformes tanto del subtipo $A$ como el subtipo $B^{25}$. 


\section{c) Aparición de patrones vasculares en redes:}

Los tumores que presentan, la asociación de 3 o más "loops" vasculares se han asociado con peor pronóstico del paciente ${ }^{105}$.

d) Índice de proliferación:

Los marcadores de proliferación celular como el Ki-67 ${ }^{106}$ y un mayor índice mitótico reflejan mayor actividad tumoral y por ello un peor pronóstico de la enfermedad por aumento de la agresividad y crecimiento tumoral. ${ }^{107}$

e) Infiltración linfocitaria:

Al contrario de lo que ocurre en los melanomas cutáneos, la presencia de linfocitos infiltrando el tumor se ha relacionado con un peor pronóstico. ${ }^{108}$

\section{f) HLA I:}

Está relacionado con la vigilancia inmunológica tumoral. En el caso del melanoma, se ha demostrado que una baja expresión de este, al contrario que en otros tumores, esta unido a un mejor pronostico tumoral. Se plantea que la causa sea, que la vigilancia inmune del melanoma está más ligada a NK que a los linfocitos $\mathrm{T}^{109}$.

\subsubsection{Citogenéticos:}

Basado principalmente en dos detecciones de anormalidades en cromosoma 3 y $8{ }^{27}$.

Se ha observado que la asociación de monosomía en el cromosoma 3 y polisomía en el 8 es el factor con mayor poder de predicción en la supervivencia del paciente, presentando estos pacientes una mortalidad cercana al $80 \%$ en los dos primeros años.

Distintos estudios han relacionado un mayor riesgo de desarrollo de enfermedad diseminada en los pacientes que presentan tumores con una de las dos alteraciones cromosómicas, especialmente si portan la monosomía del cromosoma tres o ambas alteraciones combinadas ${ }^{26}$. 


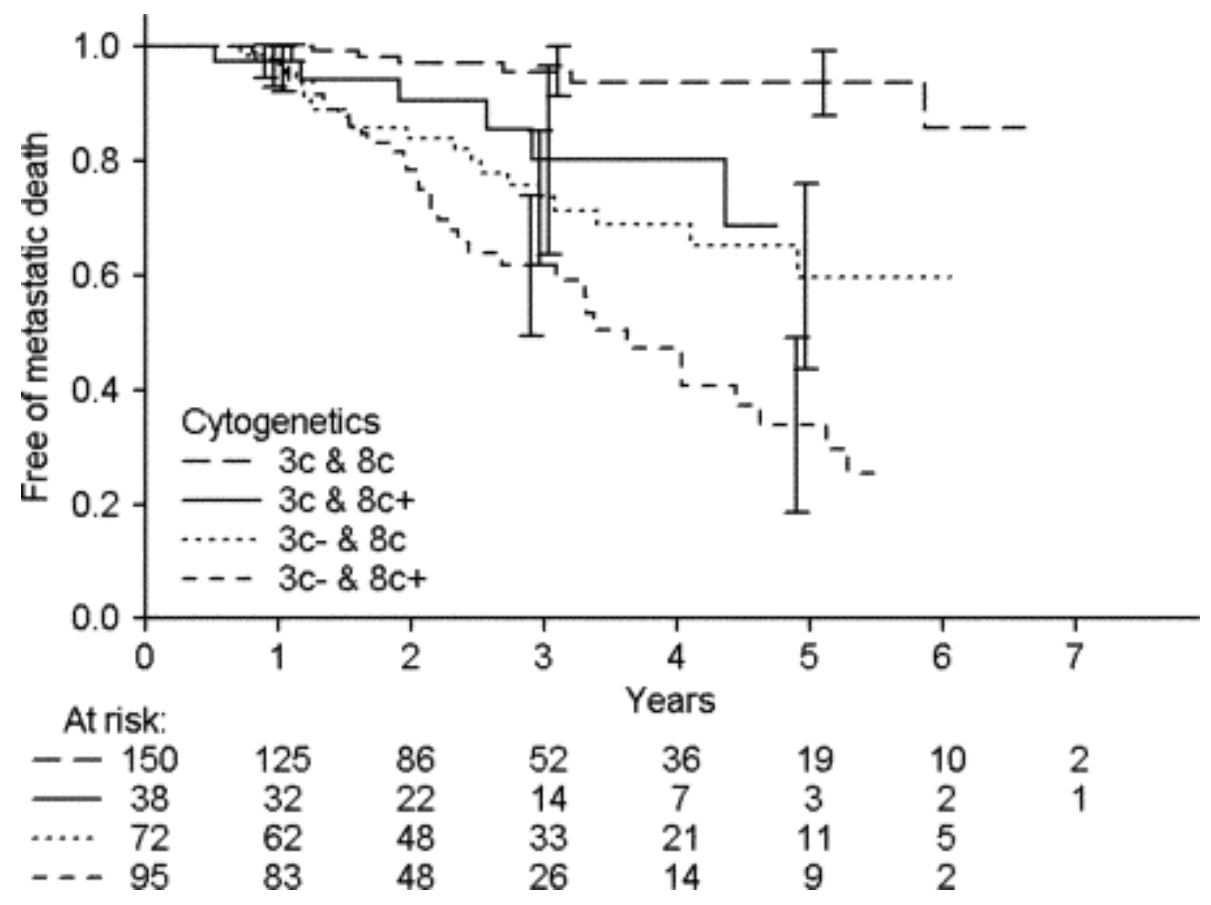

\subsubsection{Factores moleculares}

El estudio con microchips del perfil genético de más de 1000 genes, ha conseguido identificar 2 tipos de melanomas en relación con el pronóstico: Clase I, buen pronóstico, clase 2 mal pronóstico ${ }^{27}$.

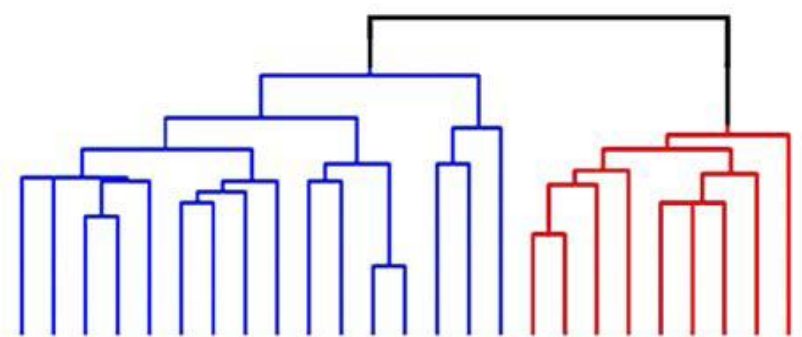

Class 1
Class 2
Molecular class

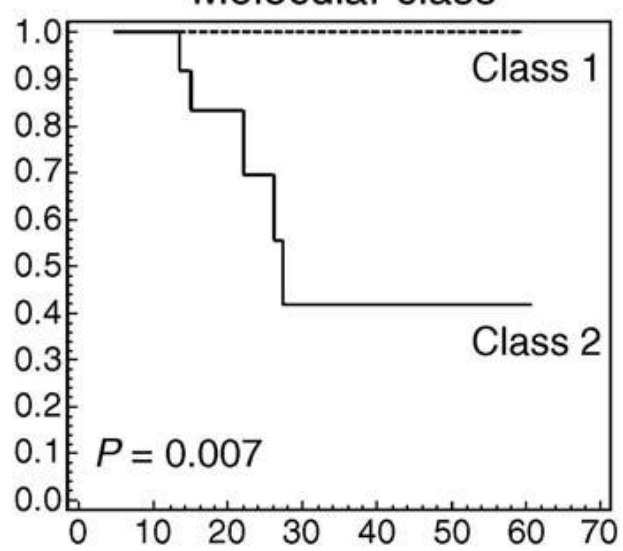

Damato et $\mathrm{al}^{27}$ han hecho hincapié en la importancia de combinar el tipo de tumor genómico con el estadio clínico del tumor y el grado histológico de malignidad. Esto indicaría aproximadamente el tiempo estimado de metastatización y la velocidad de crecimiento. 


\subsubsection{Interrelación entre factores pronósticos}

Cabe destacar que todos los factores pronósticos anteriormente descritos no son independientes entre sí ya que, por ejemplo, los tumores grandes, tienen más probabilidades de tener elevado porcentaje de células epiteliodes, y de presentar una monosomía en el cromosoma 3 y polisomía del $8 .{ }^{110}$ 


\section{MATERIAL Y MÉTODOS}

\section{DISEÑO DEL ESTUDIO}

El presente estudio se corresponde con un estudio histórico de cohorte única.

\section{SUJETOS}

Pacientes que fueron diagnosticados de melanoma de coroides en la unidad de oncología ocular del Hospital Clínico Universitario de Valladolid desde enero de 1992 hasta diciembre de 2012 . El diagnóstico de melanoma de coroides se realizó atendiendo a las características oftalmoscópicas (masa coroidea melanótica o amelanótica que puede asociar la presencia de pigmento naranja (lipofucsina) en su superficie, desprendimiento de retina exudativo o fluido subretiniano y drusas en su superficie) y características ecográficas cómo son el ángulo kappa (pico en el vector A seguido de una caida progresiva de la reflectividad), vacio ecogénico central, excavación coroidea y sombra posterior.

\section{CRITERIOS DE INCLUSIÓN}

1. Pacientes diagnósticados de melanoma de coroides y cuerpo ciliar que se clasificaron por su tamaño ecográfico según la clasificación COMS.

Según las medidas ecográficas, los melanomas de coroides se clasificaron como:

A.- Pequeños: aquellos tumores que tenían una altura máxima menor o igual a 2,5 $\mathrm{mm}$ y una base máxima menor o igual a $16 \mathrm{~mm}$.

B.- Medianos: aquellos que tenían una altura máxima mayor de 2,5 $\mathrm{mm}$ y menor o igual a $10 \mathrm{~mm}$ y una base máxima menor o igual a 16 $\mathrm{mm}$. 
C.- Grandes: aquellos que teían una altura máxima mayor de $10 \mathrm{~mm}$ o una base máxima mayor de $16 \mathrm{~mm}$

En un principio la diferencia entre pequeños y grandes se estableción en $3 \mathrm{~mm}$, pero en 1990 se modificó a 2,5 mm. Las lesiones menores de $5 \mathrm{~mm}$ de base y de 1 $\mathrm{mm}$ de altura se consideraron nevus (figura 21 ).

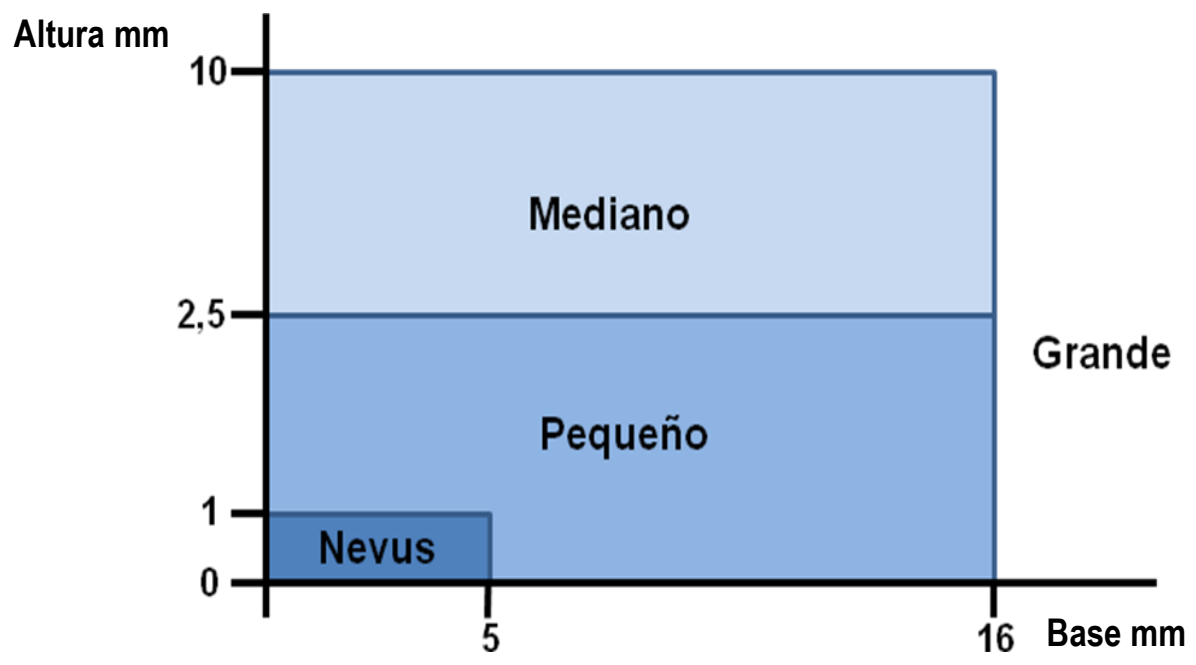

Figura 1: Clasificación de los melanomas de coroides según el COMS por tamaños en mm.

2. El paciente debía ser mayor de edad.

3. El paciente debía haber firmado el pertinente consentimiento informado. (De acuerdo a la Ley Orgánica 15/1999 de 13 de diciembre sobre protección de datos de carácter personal) (Anexo I).

4. El paciente debía ser absolutamente competente.

5. El paciente debía estar dispuesto y capacitado para el seguimiento. 


\section{CRITERIOS DE EXCLUSIÓN}

1. Pacientes que presentaron tumores originados en el iris.

2. Pacientes que se sometieron a enucleación en centro de origen o referencia.

3. Pacientes que solo acudieron a nuestro centro en busca de una segunda opinión.

4. Pacientes de reciente incorporación a la unidad de Tumores Intraoculares del Adulto pendientes de tratamiento y posterior seguimiento.

\section{VARIABLES A EVALUAR}

\subsection{PRINCIPALES}

- Supervivencia Global.

- Supervivencia Específica.

\subsection{SECUNDARIAS}

- Sexo.

- Edad.

- Tamaño:

- COMS

- TNM

- Diámetro Máximo Tumoral.

- Invasión Cuerpo ciliar.

- Tumor Yuxtapapilar.

- Extensión Extraescleral.

- Histopatología:

- Tipo celular

- Localización tumoral.

- Extensión extraescleral.

- Tratamientos

○ TTT

- Observación.

- Radioterapia con Protones.

- Braquiterapia.

- Enucleación. 


\section{RECOGIDA DE LOS DATOS}

\subsection{PRIMERA EXPLORACIÓN, TRATAMIENTO Y DATOS GENERALES}

En todos los pacientes se realizó una exploración ocular completa que se recogió en un formulario diseñado al efecto dividido en los siguientes apartados (El cuestionario completo se presenta en el anexo II):

Datos del paciente: número de protocolo, número de historia clínica, nombre y apellidos, fecha de nacimiento, sexo, dirección y teléfono.

Antecedentes generales: exposición solar (se clasificó a los pacientes según exposiciones mayores o menores del $50 \%$ de las horas de luz), presencia de cáncer cutáneo, otros cánceres, inmunosupresión, depresión, antecedentes familiares de melanoma y hábito tabáquico.

Antecedentes oftalmológicos que afectaban a la agudeza visual en el ojo afecto y en el contralateral: ambliopía, degeneración macular asociada a la edad, glaucoma, catarata, retinopatía diabética u otros.

Datos clínicos: fecha de inicio de los síntomas, fecha de diagnóstico, motivo del diagnóstico (revisión rutinaria o sintomatología visual), tumor recidivado y tratamiento previo.

Exploración ocular: lateralidad, agudeza visual de ambos ojos, presión intraocular de ambos ojos, biomicroscopia del polo posterior (color del iris, invasión del iris, rubeosis, afectación del cristalino, hemovitreo u otras), gonioscopia (invasión del ángulo), localización y tamaño (base máxima ecográfica y funduscópica, base a 90º ecográfica y funduscópica, altura máxima ecográfica y funduscópica, localizacion del borde anterior y del borde posterior, localización temporal o nasal, afectación macular y forma del tumor (nodular, champiñón o difuso)).

Signos de actividad: drusas, desprendimiento de retina, pigmento naranja, tumor yuxtapapilar, crecimiento demostrado, fluido subretiniano comprobado mediante tomografia de coherencia óptica o forma de champiñón.

- 47 - Estudio de la supervivencia en pacientes con Melanoma Uveal de una Unidad Referencial de Tumores Intraoculares. 2013 
Causas de disminución de la agudeza visual por melanoma: catarata, glaucoma, hemovitreo, desprendimiento de retina, hemorragia subretiniana, edema macular o tumor macular.

Tomografia de coherencia óptica (OCT): presencia de edema macular y fluido subretiniano.

Pruebas de extensión extraocular: tomografia axial computerizada y/o resonancia magnética nuclear.

Pruebas de extensión sistémica: ecografía hepática alterada, perfil bioquímico analítico hepático o presencia de metástasis.

Clasificación del melanoma: tamaño (pequeño, mediano o grande) localización (coroides, cuerpo ciliar o iris), actividad, extensión extraocular, extensión sistémica, aspecto melanótico y clasificación TNM.

Tratamientos: braquiterapia (fecha de implante y retirada, dosis en Gy en apex nervio óptico y fovea, isótopo empleado, tamaño de la placa y forma de la placa), radioterapia externa con protones (fecha), termoterapia transpupilar (número de sesiones, fecha, nº de spots, tamaño del espot y potencia), resección quirúrgica (fecha), enucleación (fecha, con o sin radioterapia o en centro de origen) y observación (fecha y motivo: pequeño inactivo, rechazo de tratamiento, edad avanzada, ojo unico o mal estado general).

Recidiva: fecha en la que se presentan signos evidenciables de actividad del tumor después de haber sido tratado.

Enucleación secundaria: fecha de la intervención y motivo (efectos secundarios del primer tratamientoconservador aplicado o bien recidiva despues de haber sido tratado).

Metástasis: fecha en la que se objetiva la diseminación sistémica de la enfermedad.

Defunción: fecha y motivo (melanoma u otros)

48 - $\quad$ Estudio de la supervivencia en pacientes con Melanoma Uveal de una Unidad Referencial de Tumores Intraoculares. 2013 


\subsection{SEGUIMIENTOS}

Una vez diagnosticado el paciente y tratado en función de los hallazgos obtenidos, se le revisó al mes, a los tres, seis, nueve y doce meses durante el primer año, de forma semestral los primeros cinco años y de forma anual a partir del quinto año. En las visitas de revisión los datos de la exploración se codificaron en un cuestionario diseñado al efecto (este cuestionario se presenta en el Anexo II) en el que se incluyeron los siguentes datos: número de revisión, tiempo de seguimiento, fecha de revisión, nombre y apellidos, número de registro, número de historia clínica, tratamiento realizado, agudeza visual del ojo afecto y el contralateral, presión intraocular del ojo afecto y el contralateral, tamaño ecográfico (base máxima, a 90 grados y altura máxima), pruebas de extensión sistémica (ecografia hepatica o TAC toracoabdominal y analítica sanguinea), complicaciones del tratamiento (ptosis, necrosis escleral, dolor, catarata, diplopia, desprendimiento de retina, retinopatía por radiación, neuropatía por radiación, hemorragia vítrea, glaucoma neovascular, membrana epirretiniana, exposición del implante en el caso de enucleados u otros), espesor macular medido mediante OCT, recidiva si la hay, metástasis si las hay y fecha de defunción.

Las pruebas de extensión se realizan de forma anual a lo largo del seguimiento.

El encargado de recoger los datos en los cuestionarios fue un oftalmólogo (adjunto, residente o alumno master) perteneciente a la unidad. Una vez completado el cuestionario, se codificó en una base de datos diseñada en Microsoft@ Acces $\AA^{\circledR}$ (figura 2) previo consentimiento informado del paciente.

Se consideró pérdida de seguimiento aquel sujeto del estudio que no acudió a revisión en los 365 días previos al 31 de diciembre de 2012.

- 49 - $\quad$ Estudio de la supervivencia en pacientes con Melanoma Uveal de una Unidad Referencial de Tumores Intraoculares. 2013 


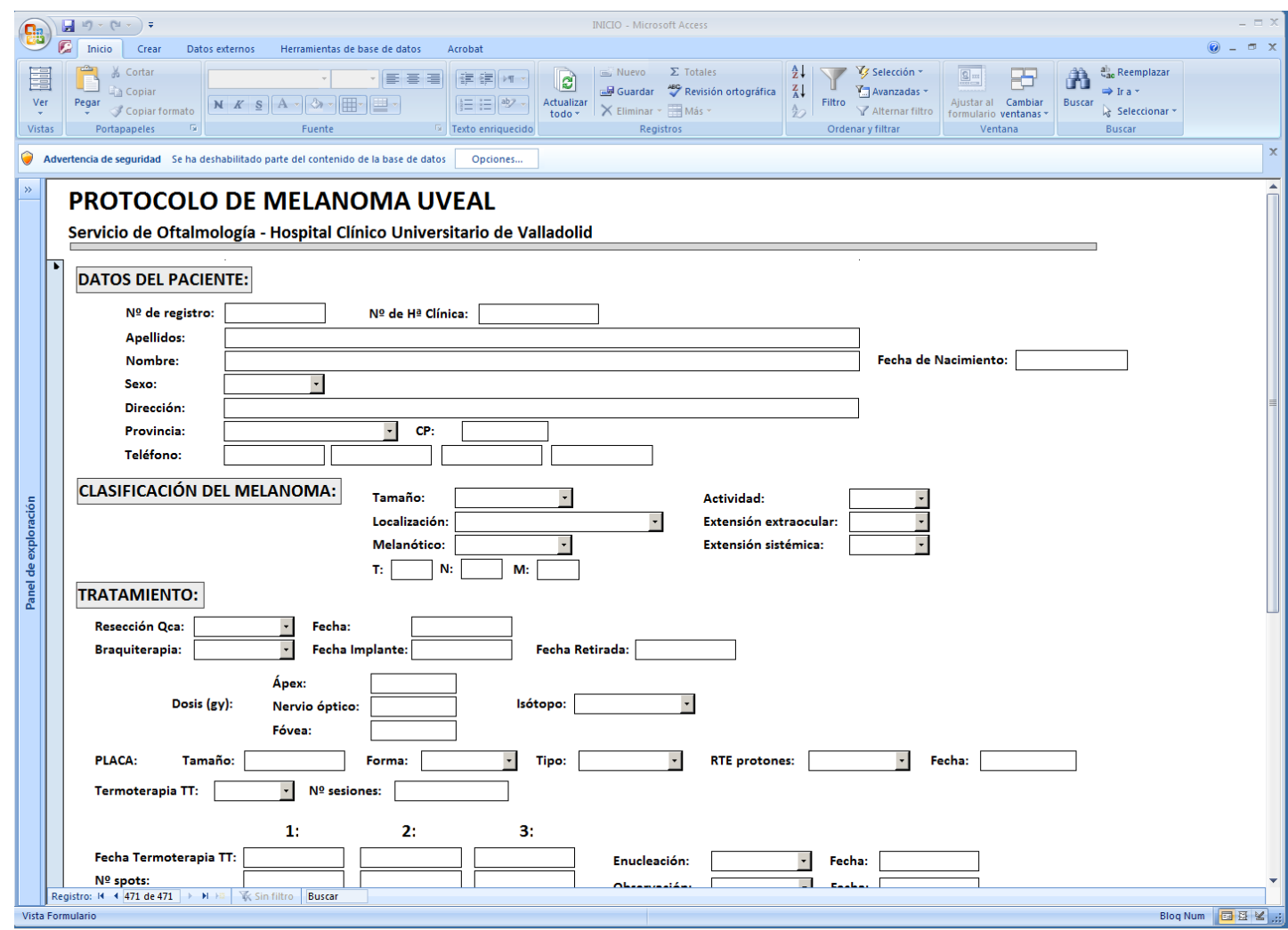

Figura 2 : Base de datos del protocolo de melanoma uveal del Hospital Clinico Universitario de Valladolid. 


\section{ANÁLISIS ESTADÍSTICO}

Las variables cuantitativas se presentan con la media y la desviación típica y las cualitativas según su distribución de frecuencias.

Mediante el test Chi-cuadrado de Pearson, se ha analizado la asociación de las variables cualitativas. En el caso de que el número de celdas con valores esperados menores de 5 sea mayor de un $20 \%$, se ha utilizado el test exacto de Fisher o el test Razón de verosimilitud para variables con más de dos categorías.

Las comparaciones de los valores cuantitativos se ha realizado mediante la prueba $T$ de Student para muestras independientes.

En el análisis de supervivencia se ha utilizado el método de Kaplan-Meier, las comparaciones entre las supervivencias medias han sido realizadas con el test de log-rank en aquellos casos en los cuales las curvas de supervivencias son proporcionales, en los que no, se ha utilizado el test de Tarone-Ware. La probabilidad de sobrevivir a un determinado periodo, se ha calculado a partir de las tablas de mortalidad considerando como intervalo un año.

Para cada uno de los factores de estudio, además de los análisis de supervivencia anteriores, se ha realizado un modelo de regresión univariante de Cox. Aquellas variables que han resultado ser estadísticamente significativas a nivel 0,1 han sido han sido incluidas en un modelo de regresión de Cox multivariante ajustando los resultados por edad y sexo. Los datos han sido analizados con el programa estadístico SPSS versión 20.0 para Windows. Aquellos valores de $p<0,05$ serán considerados estadísticamente significativos. 


\section{RESULTADOS}

\section{DESCRIPTIVA}

\subsection{PACIENTES}

Se incluyeron en el estudio 480 pacientes diagnosticados de melanoma de úvea de los 551 pacientes diagnosticados en la Unidad de Tumores Intraoculares del Adulto del Hospital Clínico Universitario de Valladolid entre enero de 1992 y diciembre de 2012.

Todos los pacientes incluidos en el presente estudio son españoles a excepción de un hispano de origen mejicano.

\subsection{EXCLUIDOS}

Las causas de la exclusión de los 71 pacientes restantes fueron, en 34 de los casos la realización del proceso de enucleación en el centro de referencia y por ello la no existencia de datos de seguimiento del paciente. En 22 de los casos, la consulta con nuestro centro fue solo como segunda opinión, por lo que carecemos de datos de seguimiento, al igual que ocurre en 7 casos más de reciente diagnóstico los cuales están a la espera de tratamiento y posterior seguimiento. Se han descartado también los tumores de iris (8) basándonos en su diferente evolución respecto a la supervivencia y pronóstico del paciente.

\subsection{SEGUIMIENTO}

El seguimiento medio de los pacientes fue de 58,59 meses (DS 48,9; Mínimo 1 meses; Máximo 235 meses) con una pérdida de seguimiento menor de $1 \%$.

Tabla 3. Seguimiento

\section{Seguimiento Medio(DS)}

$58,59(48,9)$

Mínimo.

Máximo
1

235 


\subsection{EPIDEMIOLOGÍA}

1.4.1. Edad y sexo:

Tabla 4. Género y Sexo

\begin{tabular}{|c|c|c|c|c|c|}
\hline Género & $\mathrm{N}$ & $\%$ & Media(DS) & \multicolumn{2}{|c|}{ Edad } \\
\hline \multirow{2}{*}{ Hombre } & \multirow{2}{*}{233} & \multirow{2}{*}{48,54} & \multirow{2}{*}{$61,73(14,29)$} & Máxima & 93 \\
\hline & & & & Mínima & 16 \\
\hline \multirow[t]{2}{*}{ Mujer } & \multirow[t]{2}{*}{247} & \multirow[t]{2}{*}{51,45} & \multirow{2}{*}{$62,61(14,34)$} & Máxima & 94 \\
\hline & & & & Mínima & 26 \\
\hline
\end{tabular}

Prueba T para la Igualdad de medias:0,477

La edad media de los pacientes en el momento del diagnóstico fue de 62,18 (DS 14,31), siendo de 61,61 (DS14,34) en el caso de las mujeres y de 62, 73 (DS14,29) en el caso de los hombres. La edad máxima en el caso de los hombres fue de 93 y la mínima 16, en el caso de la mujer la máxima fue de 94 y la mínima de 26.

Respecto a la prueba $T$ el p-valor fue igual a 0,477 por lo que se deduce que no hay diferencias estadísticamente significativas en las edades medias según sexo.

\section{Tabla 5. Edad}

\begin{tabular}{|ccc|}
\hline Edad & N & $\%$ \\
\hline$<50$ años & 116 & 24,2 \\
\hline$>=50$ años & 364 & 75,8 \\
\hline Total & 480 & 100 \\
\hline
\end{tabular}

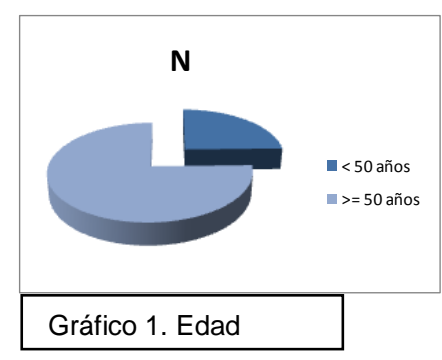

Se estratificó a los pacientes en dos grupos según su edad, menores de 50 años (116) y mayores o iguales a 50 años (364); mostrando el segundo grupo una mayoría del $75,8 \%$ respecto al $24,2 \%$ al primero como muestra el gráfico1. 
1.4.2. Distribución geográfica.

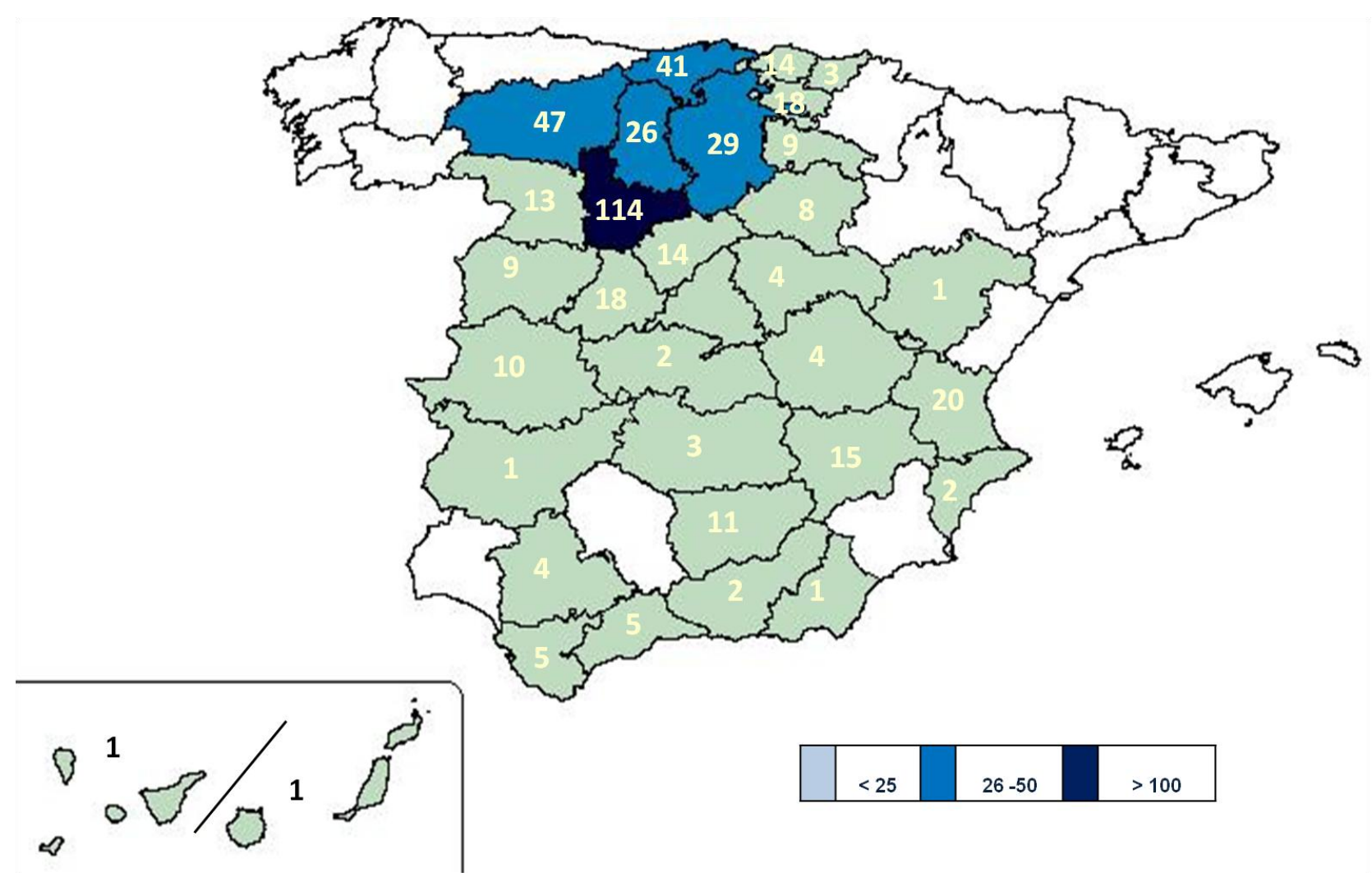

Valladolid fue la provincia con más número de casos de melanoma uveal tratados en la unidad (114), seguida de León (47), Cantabria (41), Burgos (30) y Palencia (26). 


\subsection{LATERALIDAD}

Tabla 6. Lateralidad

\begin{tabular}{|ccc|}
\hline Ojo & N & $\%$ \\
\hline OD & 220 & 45,8 \\
\hline Ol & 260 & 54,2 \\
\hline Total & 480 & 100,0 \\
\hline
\end{tabular}

En cuanto a la lateralidad de los tumores, la muestra no arroja muchas diferencias, siendo el $45,8 \%$ de los casos el ojo derecho el afecto y el $54,2 \%$ restante el ojo izquierdo.

\subsection{COLOR DE IRIS}

\begin{tabular}{|ccc|}
\hline \multicolumn{2}{|c|}{ Tabla 7. Color de Iris } \\
\hline Color Iris & N & $\%$ \\
\hline Verde-avellana & 196 & 43,8 \\
\hline Marrón & 167 & 37,3 \\
\hline Azul-gris & 85 & 19,0 \\
\hline Total & 448 & 100,0 \\
\hline
\end{tabular}

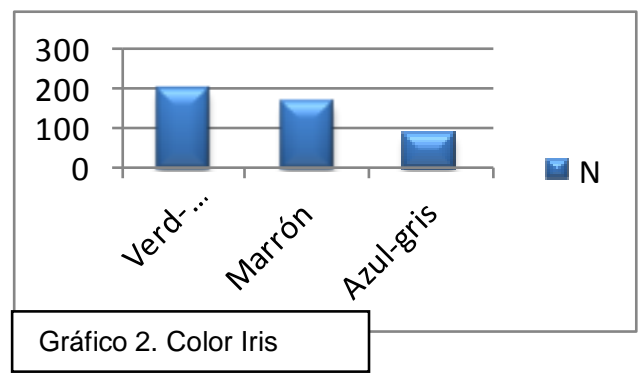

Se dividió la muestra en según su color de iris, verde-avellana, el más prevalente, que representó el 43,8\% de la muestra; marrón, el segundo en prevalencia con el 37,3\% de la muestra y por último el azul-gris que únicamente representó el 19\% de la muestra. 


\subsection{LOCALIZACIÓN}

1.7.1. Localización del tumor.

Tabla 8. Localización Tumoral

\begin{tabular}{|ccc|}
\hline Localización & N & $\%$ \\
\hline Coroides & 459 & 95,62 \\
\hline Cuerpo Ciliar & 21 & 4,38 \\
\hline Total & 480 & 100,0 \\
\hline
\end{tabular}

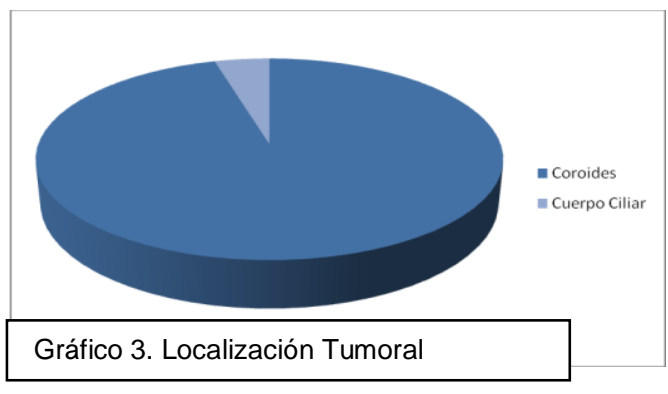

La amplia mayoría de los tumores uveales (95,62 \%) se localizaron en la coroides, solo un $4,38 \%$ se localizaron en cuerpo ciliar.

1.7.2. Localización del borde anterior.

Tabla 9. Localización Borde Anterior

\begin{tabular}{|ccc|}
\hline Localización & N & $\%$ \\
\hline Camara Ant. & 13 & 2,7 \\
\hline Cuerpo Ciliar & 33 & 6,9 \\
\hline Ecuad-ora & 143 & 30,0 \\
\hline Post-ecua & 287 & 60,3 \\
\hline Total & 476 & 100,0 \\
\hline
\end{tabular}

En cuanto a la localización del borde anterior tumoral, la gran mayoría, un $60 \%$ se situaron post-ecuador, siendo menos frecuentes las localizaciones entre ecuador y ora serrata $(30 \%)$, cuerpo ciliar $(6,9 \%)$ y cámara anterior $(2,7 \%)$. 
1.7.3. Localización Yuxtapapilar.

Tabla 10. Localización Yuxtapapilar

\begin{tabular}{|ccc|}
\hline Yuxtapapilar & N & $\%$ \\
\hline No & 413 & 87,1 \\
\hline Si & 61 & 12,9 \\
\hline Total & 474 & 100,0 \\
\hline
\end{tabular}

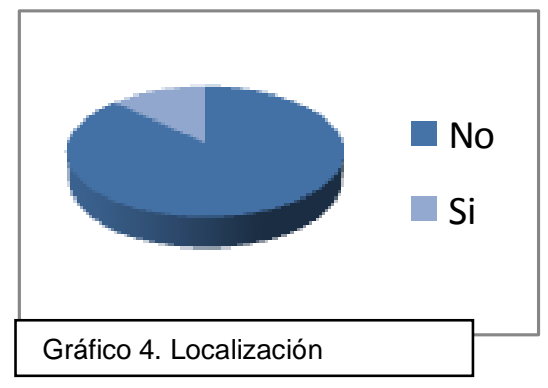

La localización yuxtapapilar tumoral no fue muy frecuente, representando únicamente el $12,9 \%$ de la muestra.

\subsection{FORMA TUMORAL}

Tabla 10. Forma Tumoral

\begin{tabular}{|ccc|}
\hline Forma & N & $\%$ \\
\hline Nodular & 372 & 77,7 \\
\hline Champi. & 101 & 21,1 \\
\hline Difuso & 6 & 1,3 \\
\hline Total & 479 & 100,0 \\
\hline
\end{tabular}

La forma de presentación tumoral se muestra de manera resumida en la tabla 10 siendo la forma más frecuente de presentación la nodular $(77,7 \%$ de los casos), seguida de la forma en champiñón $(21,1 \%)$. 


\subsection{DIAGNÓSTICO}

1.9.1. Motivo del diagnóstico.

\begin{tabular}{|ccc|}
\hline \multicolumn{3}{|c|}{ Tabla 11. Motivo del Diagnóstico } \\
\hline Motivo del Diagnóstico & N & $\%$ \\
\hline Revisión Rutinaria & 188 & 39,5 \\
\hline Síntomas Visual & 289 & 60,6 \\
\hline Total & 477 & 100,0 \\
\hline
\end{tabular}

Los motivos que llevaron al paciente a su especialista para posteriormente poder ser diagnosticados de melanoma uveal son diversos, un 60,6\% de los pacientes refirieron síntomas visuales y un 39,5\% fueron diagnosticados durante una revisión rutinaria.

1.9.2. Medidas Ecográficas.

Tabla 12. Medidas Ecográficas

\begin{tabular}{|cccccc|}
\hline Medidas & N & Media(DS) & Mediana & Mínimo & Máximo \\
\hline Altura Máx & 479 & $5,38(3,64)$ & 4,1 & 1 & 18,15 \\
\hline Base Máx & 479 & $10,75(3,90)$ & 10 & 4 & 24,61 \\
\hline
\end{tabular}

Las medidas tumorales ecográficas muestran una altura media de 5,38 (DS 3,64) y una base máxima de 10,77(DS 3,93). 
1.9.3. Diagnóstico de Extensión Extraocular.

Tabla 13. Extensión Extraocular.

\begin{tabular}{|c|ccc|}
\hline Prueba & Extensión & N & $\%$ \\
\hline TAC & Si & 16 & 3,4 \\
\hline & Total & 467 & 100,0 \\
\hline \multirow{2}{*}{ RMN } & Si & 17 & 3,6 \\
\hline & Total & 468 & 100,0 \\
\hline
\end{tabular}

La extensión extraocular resultó positiva en 16 (3,4\%) pacientes sometidos a TAC y el 17 pacientes $(3,6 \%)$ pacientes sometidos a $\mathrm{RMN}$.

1.9.4. Diagnóstico de Extensión Sistémico.

Tabla 14. Extensión Sistémica.

\begin{tabular}{|c|c|c|c|}
\hline Prueba & Extensión & N & $\%$ \\
\hline TAC/Eco Hepática & $\mathrm{Si}$ & 6 & 1,3 \\
\hline & Total & 470 & 100,0 \\
\hline P. Hepático patológico & $\mathrm{Si}$ & 8 & 1,7 \\
\hline & Total & 470 & 100,0 \\
\hline
\end{tabular}

Se diagnosticaros metástasis a distancia desde el momento del diagnóstico a 6 pacientes, lo que supone el $1,3 \%$ total de la muestra. A su vez, un $1,7 \%$ reflejaron alteraciones analíticas en el perfil hepático. 


\subsection{TAMAÑO TUMORAL}

\subsubsection{Tamaño TNM.}

Tabla 15. Clasificación TNM

\begin{tabular}{|c|c|c|}
\hline T & N & $\%$ \\
\hline T1 & 201 & 42 \\
\hline T2 & 135 & 28,2 \\
\hline T3 & 118 & 24,6 \\
\hline T4 & 25 & 5,2 \\
\hline Total & 479 & 100,0 \\
\hline N & $\mathrm{N}$ & $\%$ \\
\hline N0 & 479 & 100,0 \\
\hline Total & 479 & 100,0 \\
\hline M & $\mathrm{N}$ & $\%$ \\
\hline M0 & 473 & 98,70 \\
\hline M1 & 6 & 1,30 \\
\hline Total & 479 & 100,00 \\
\hline
\end{tabular}

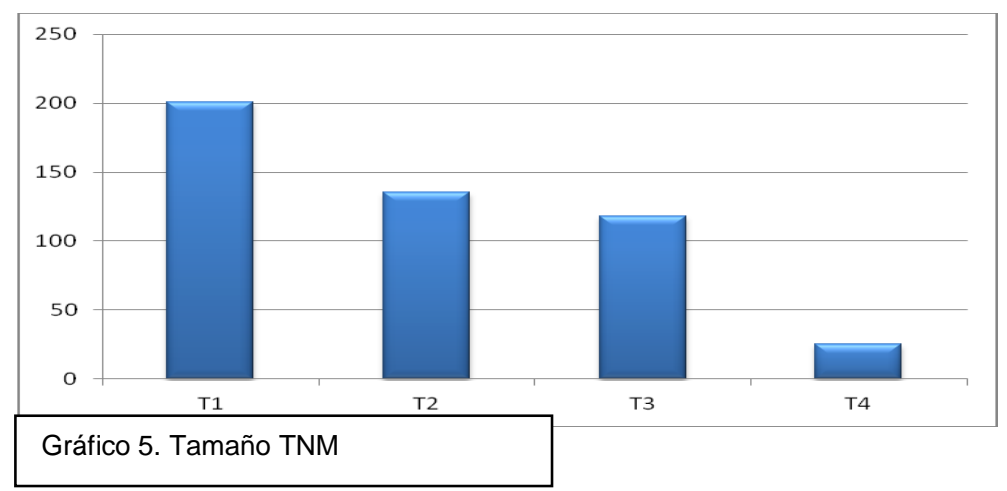

La proporción de pacientes englobado en cada subtipo de esta clasificación tumoral se encuentra recogido en la tabla y gráfico superiores. Ambos muestran una mayor proporción de T1 (42\%), seguido de T2 (28,2\%) siendo los menos frecuentes los de mayor tamaño o T4 (5,2\%).

La M1 fue positiva únicamente en 6 casos, 1,3\% de la muestra. 


\subsubsection{Tamaño COMS}

Tabla16. Descripción Tamaño COMS

\begin{tabular}{|ccc|}
\hline Tamaño & N & $\%$ \\
\hline Pequeño & 116 & 24,2 \\
\hline Mediano & 283 & 59,1 \\
\hline Grande & 80 & 16,7 \\
\hline Total & 479 & 100,0 \\
\hline
\end{tabular}

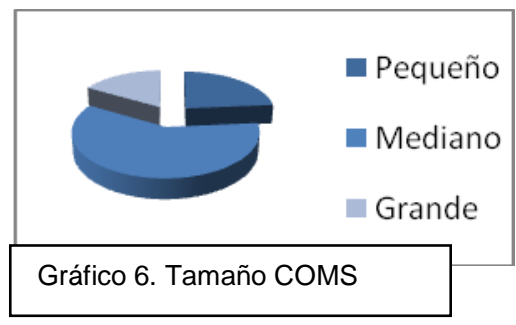

En coherencia con lo ocurrido con la anterior clasificación, la menor parte de la muestra se englobó en la subclasificación establecida por el COMS de tumores grandes, representando únicamente un $16,7 \%$ de la muestra total. En cambio los tumores medianos fueron los más números contando con un $59,1 \%$ de la muestra total.

1.10.3. Diámetro Máximo Tumoral:

Tabla 17. Diámetro Máximo Tumoral

\begin{tabular}{|ccc|}
\hline Tamaño & $\mathbf{N}$ & $\%$ \\
\hline$<10$ & 235 & 49,1 \\
\hline $10-16$ & 194 & 40,5 \\
\hline$>16$ & 50 & 10,4 \\
\hline Total & 479 & 100,0 \\
\hline
\end{tabular}

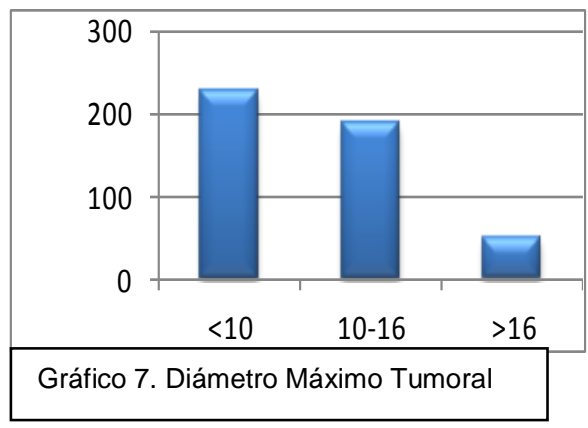

No ocurrió menos con esta tercera subclasificación tumoral en la cual los tumores $>16$ ocupan un porcentaje muy escaso $(10,4 \%)$ respecto al $40,5 \%$ y al $49,1 \%$ de la muestra que representaron los tumores de $10-16$ y $<10$ respectivamente. 


\subsection{TRATAMIENTO}

1.11.1. Tipos de tratamiento.

Tabla 18. Tratamientos

\begin{tabular}{|c|c|c|}
\hline Tratamientos & $\mathbf{N}$ & $\%$ \\
\hline TTT & 4 & 0,8 \\
\hline Observación & 172 & 36,4 \\
\hline Braquiterapia + TTT & 16 & 3,4 \\
\hline RTE protones & 6 & 1,3 \\
\hline Braquiterapia & 189 & 40 \\
\hline Enucleación & 86 & 18,2 \\
\hline Total & 473 & 100 \\
\hline Otros & 7 & \\
\hline Total & 480 & \\
\hline
\end{tabular}

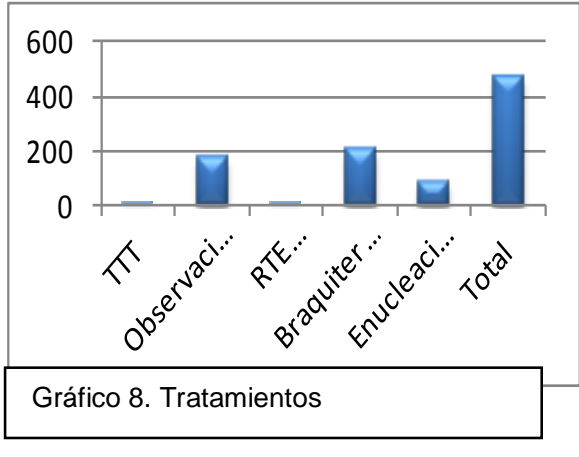

Existen múltiples terapéuticas posibles en el tratamiento del melanoma uveal siendo los más empleados la braquiterapia en el $40 \%$ de los casos, seguido de la observación que se llevó a cabo en el 36,4\% de los casos y de la enucleación en el 18,2\%.

1.11.2. Recidiva tras tratamiento conservador.

Tabla 19. Recidiva tras Tratamiento Conservador

\begin{tabular}{|ccc|}
\hline Tratamiento & N & $\%$ \\
\hline NO & 378 & 97,67 \\
\hline SI & 9 & 2,33 \\
\hline Total & 387 & 100,0 \\
\hline
\end{tabular}

Tras recibir tratamiento conservador, solo un 2,33\% de los 387 pacientes que fueron sometidos a tratamientos han recaído durante el seguimiento. 
1.11.3. Motivos de enucleación secundaria:

Tabla 20. Motivos de Enucleación Secundaria

\begin{tabular}{|ccc|}
\hline Motivos & N & $\%$ \\
\hline Recidiva & 9 & 45,0 \\
\hline Efectos secundarios & 11 & 55,0 \\
\hline Total & 20 & 100,0 \\
\hline
\end{tabular}

Las enucleaciones que se llevaron a cabo de manera secundaria y no como tratamiento primario tumoral fueron en un $45 \%$ de los casos causadas por una recidiva y en un $55 \%$ por efectos secundarios derivados de tratamientos conservadores.

\subsection{METÁSTASIS.}

1.12.1. Al diagnóstico

Tabla 21. Metástasis al Diagnóstico

\begin{tabular}{|ccc|}
\hline Metástasis & N & $\%$ \\
\hline No & 465 & 98,7 \\
\hline Si & 6 & 1,3 \\
\hline Total & 469 & 100,0 \\
\hline
\end{tabular}

Como se puede observar también la tabla 21 de diagnóstico de extensión sistémico, solo 6 pacientes $(1,3 \%)$ fueron diagnosticados como metastásicos en el momento del diagnóstico. 
1.12.2. Fallecimientos

Tabla 22. Fallecimientos

\begin{tabular}{|c|ccc|}
\hline Fallecido & & N & $\%$ \\
\hline No & & 402 & 83,7 \\
\hline Si & Melanoma & 39 & 8,1 \\
& Otra & 33 & 6,9 \\
\hline & No Conocida & 6 & 1,3 \\
\hline & Total & 78 & 16,3 \\
\hline
\end{tabular}

Un $16,3 \%$ de los pacientes han fallecido durante el seguimiento, únicamente $8,1 \%$ por causa del melanoma uveal.

\subsection{HISTOPATOLOGÍA.}

1.13.1. Medidas

Tabla 23. Anatomía Patológica

\begin{tabular}{|c|c|c|c|c|}
\hline Medida & Media(DS) & Mediana & Mínimo & Máximo \\
\hline Base & $13,95(3,78)$ & 14 & 5 & 24 \\
\hline Altura & $8,04(3,93)$ & 8 & 2 & 17 \\
\hline
\end{tabular}

Las medidas tomadas sobre la pieza quirúrgica fueron una base media de 13,95 $(3,78)$ y una altura media de $8,04(3,93)$. 
1.13.2. Localización:

Tabla 24. Localización Borde Anterior AP

\begin{tabular}{|ccc|}
\hline Localización & N & $\%$ \\
\hline Iris & 9 & 1,9 \\
\hline Malla Trabecular & 13 & 2,7 \\
\hline Cuerpo C. & 38 & 7,9 \\
\hline Ora-Ecuador & 52 & 10,8 \\
\hline Ecuador & 66 & 13,8 \\
\hline Ecua-Papila & 85 & 17,7 \\
\hline
\end{tabular}

La localización tumoral en la pieza de anatomía patológica se describe en la tabla superior siendo la localización más frecuente la localización entre ecuador y papila con un $17,7 \%$ de los casos y la menos numerosa los tumores localizados en iris $(1,9 \%)$.

1.13.3. Localización tumoral:

Tabla 25. Localización Tumoral

\begin{tabular}{|ccc|}
\hline Localización & $\mathbf{N}$ & $\%$ \\
\hline CC & 30 & 30 \\
\hline Resto & 70 & 70 \\
\hline Total & 100 & 100 \\
\hline
\end{tabular}

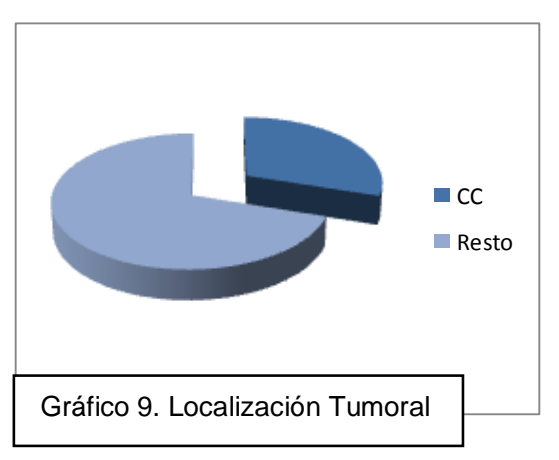

Estratificando la localización tumoral en cuerpo ciliar vs resto la afectación de cuerpo ciliar solo se encontró en $30 \%$ de los casos analizados. 
1.13.4. Clasificación celular:

Tabla 26. Clasificación Celular

\begin{tabular}{|ccc|}
\hline Tipo & N & $\%$ \\
\hline Fusiforme & 36 & 34,3 \\
\hline Mixto & 41 & 39,1 \\
\hline Epiteliode & 27 & 25,7 \\
\hline N.C. & 1 & 1,0 \\
\hline Total & 105 & 100,0 \\
\hline
\end{tabular}

En cuanto al tipo celular del cual se compone cada tumor se objetivó que el tipo celular más abundante fue el mixto $(39,1 \%)$ seguido del fusiforme $(34,3 \%)$, siendo el tipo epitelioide el menos frecuente $(25,7 \%)$.

\subsubsection{Características Anatomopatológicas:}

La tabla 27 resume varias de las características anatomopatológicas de las piezas quirúrgicas de las enucleaciones realizadas.

Se apreció invasión de nervio óptico en 18 pacientes (3,7\%), venas vorticosas en 9 pacientes $(1,9 \%)$ desprendimiento de retina en $38(8,1 \%)$, una marcada inflamación en 3 pacientes $(3,12 \%)$, marcada pigmentación en 33 pacientes $(33 \%)$ y necrosis en $>50 \%$ en 5 pacientes $(4,9 \%)$. 
Tabla 27. Características AP

\begin{tabular}{|c|c|c|}
\hline Características & N & $\%$ \\
\hline Tipo I.Difuso & 25 & $24,3(103)$ \\
\hline M.Bruch & 65 & $63,1(103)$ \\
\hline Invasión Retina & 39 & $37,9(103)$ \\
\hline D. Retina & 39 & $37,9(103)$ \\
\hline Cl.Tumorales Vitreo & 11 & $10,7(103)$ \\
\hline Venas Vorticosas & 9 & $8,7(103)$ \\
\hline Invasion Canal Emisario & 39 & $37,9(103)$ \\
\hline Yuxtapapilar & 39 & $37,9(103)$ \\
\hline Inv. N. Óptico & 18 & $17,5(103)$ \\
\hline
\end{tabular}

Sin llegar a superficie $\quad 44 \quad 42,7(103)$

\begin{tabular}{|c|c|c|}
\hline $\begin{array}{c}\text { Extensión a Superficie } \\
\text { escleral }\end{array}$ & 6 & $5,8(103)$ \\
\hline Sin transección & 3 & $2,9(103)$ \\
\hline $\begin{array}{c}\text { Con residuo orbitario } \\
\text { presumible }\end{array}$ & 7 & $6,8(103)$ \\
\hline Mínima & 78 & $81,25(96)$ \\
\hline Moderada & 15 & $15,625(96)$ \\
\hline Marcada & 3 & $3,125(96)$ \\
\hline Mínima & 15 & $15(100)$ \\
\hline Moderada & 52 & $52(100)$ \\
\hline Marcada & 33 & $33(100)$ \\
\hline$<10 \%$ & 27 & $26,5(102)$ \\
\hline $10-50 \%$ & 14 & $13,7(102)$ \\
\hline$>50 \%$ & 5 & $4,9(102)$ \\
\hline
\end{tabular}




\section{SUPERVIVENCIA.}

\subsection{SUPERVIVENCIA GLOBAL.}

Durante el seguimiento de 58,59 meses se han registrado 78 muertes de manera global, es decir, por melanoma y otras enfermedades.

Tiempo medio de supervivencia fue de 170,72 meses con un IC 95\% (157,4; 184,04).

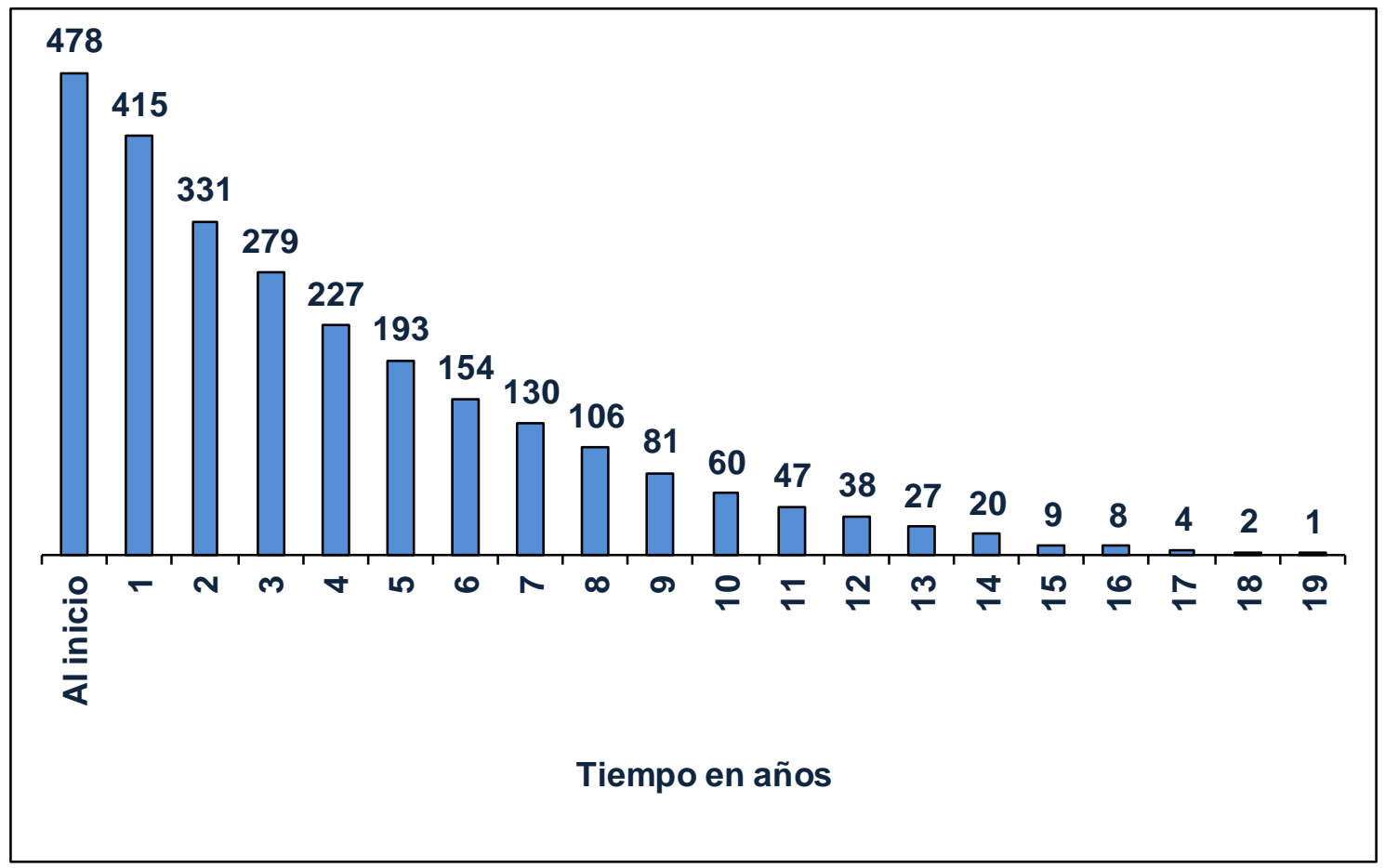

Gráfico 10. Seguimiento

El gráfico10 muestra el tiempo de seguimiento de los pacientes, así hay 478 pacientes al inicio del seguimiento, 193 con 5 años de seguimiento, 60 pacientes con 10 años, 9 pacientes con 15 años y un único paciente con 19 años de seguimiento. 
La probabilidad de sobrevivir (ps) se encuentra recogida en la gráfica 11, siendo a los 5 años es del $80,6 \%$, del $70 \%$ a los 10 años y de $58,6 \%$ a los 15 años.

\section{Función de supervivencia}

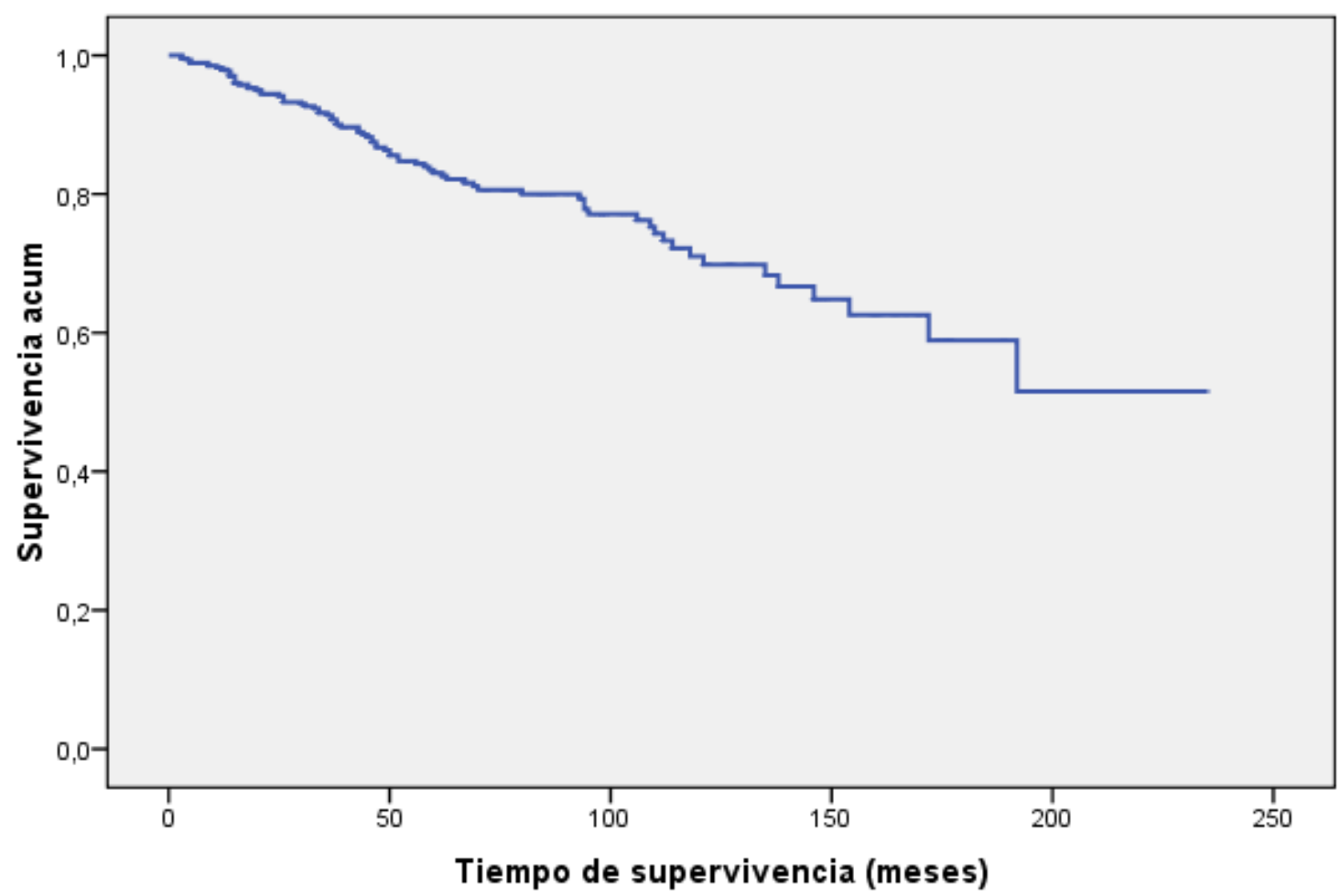

\begin{tabular}{|c|c|c|c|c|c|c|c|c|c|c|c|c|c|c|c|c|c|c|c|c|}
\hline Tiempo & $\begin{array}{c}\mathbf{A l} \\
\text { inicio }\end{array}$ & $\mathbf{1}$ & $\mathbf{2}$ & $\mathbf{3}$ & $\mathbf{4}$ & $\mathbf{5}$ & $\mathbf{6}$ & $\mathbf{7}$ & $\mathbf{8}$ & $\mathbf{9}$ & $\mathbf{1 0}$ & $\mathbf{1 1}$ & $\mathbf{1 2}$ & $\mathbf{1 3}$ & $\mathbf{1 4}$ & $\mathbf{1 5}$ & $\mathbf{1 6}$ & $\mathbf{1 7}$ & $\mathbf{1 8}$ & $\mathbf{1 9}$ \\
\hline $\mathbf{N}$ & 480 & 416 & 332 & 280 & 227 & 193 & 154 & 130 & 106 & 81 & 60 & 47 & 38 & 27 & 20 & 9 & 8 & 4 & 2 & 1 \\
\hline $\mathbf{p s}$ & 98,2 & 94,4 & 91,6 & 86,7 & 83,4 & 80,6 & 80 & 77,4 & 76,6 & 71,3 & 70 & 66,8 & 62,8 & 62,8 & 58,6 & 58,6 & 49,6 & 49,6 & 49,6 & 49,6 \\
\hline
\end{tabular}

Gráfico 11. Supervivencia a Global. 


\subsection{SUPERVIVENCIA ESPECÍFICA}

De los 78 fallecidos durante el periodo del seguimiento de la muestra, 39 de ellos lo han hecho por causa del melanoma.

El tiempo medio de supervivencia de esta muestra fue de 207,4 meses con un IC al 95\% $(199,13: 216,75)$.

La probabilidad de supervivencia a los 5 años es del $87,7 \%$, a los 10 años del $85,5 \%$ y a los 15 años continua siendo del $85,5 \%$.

\section{Función de supervivencia}

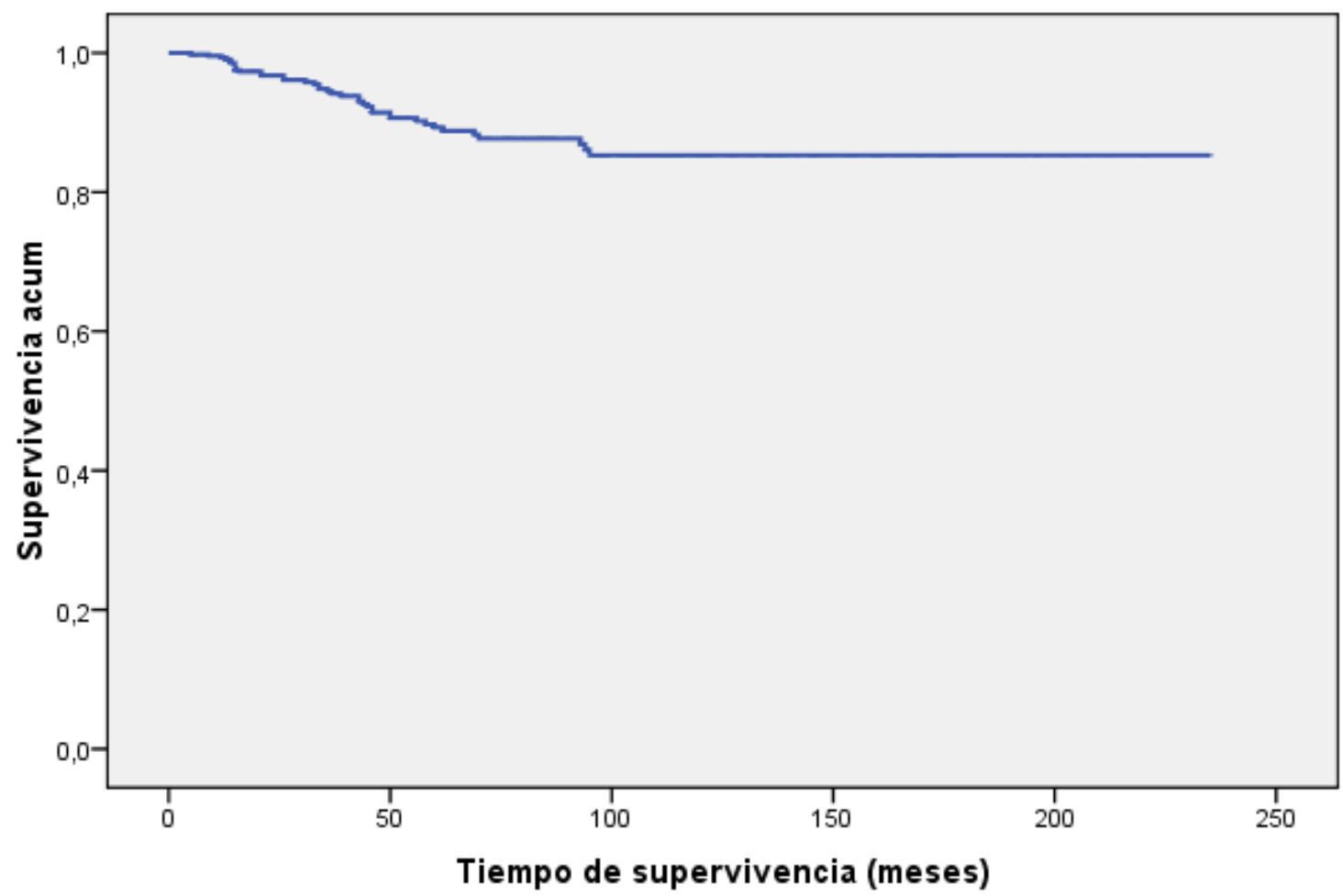

\begin{tabular}{|c|c|c|c|c|c|c|c|c|c|c|c|c|c|c|c|c|c|c|c|c|}
\hline $\begin{array}{c}\text { Tiempo } \\
\text { (años) }\end{array}$ & $\begin{array}{c}\text { Al } \\
\text { inicio }\end{array}$ & $\mathbf{1}$ & $\mathbf{2}$ & $\mathbf{3}$ & $\mathbf{4}$ & $\mathbf{5}$ & $\mathbf{6}$ & $\mathbf{7}$ & $\mathbf{8}$ & $\mathbf{9}$ & $\mathbf{1 0}$ & $\mathbf{1 1}$ & $\mathbf{1 2}$ & $\mathbf{1 3}$ & $\mathbf{1 4}$ & $\mathbf{1 5}$ & $\mathbf{1 6}$ & $\mathbf{1 7}$ & $\mathbf{1 8}$ & $\mathbf{1 9}$ \\
\hline $\mathbf{N}$ & 480 & 416 & 332 & 280 & 227 & 193 & 154 & 130 & 106 & 81 & 60 & 47 & 38 & 27 & 20 & 9 & 8 & 4 & 2 & 1 \\
\hline ps & 99,6 & 96,7 & 94,8 & 91,5 & 89,9 & 87,7 & 87,7 & 85,5 & 85,5 & 85,5 & 85,5 & 85,5 & 85,5 & 85,5 & 85,5 & 85,5 & 85,5 & 85,5 & 85,5 & 85,5 \\
\hline
\end{tabular}

Gráfico12. Supervivencia Específica. 


\subsection{SUPERVIVENCIA SEGÚN SEXO}

\section{Funciones de supervivencia}

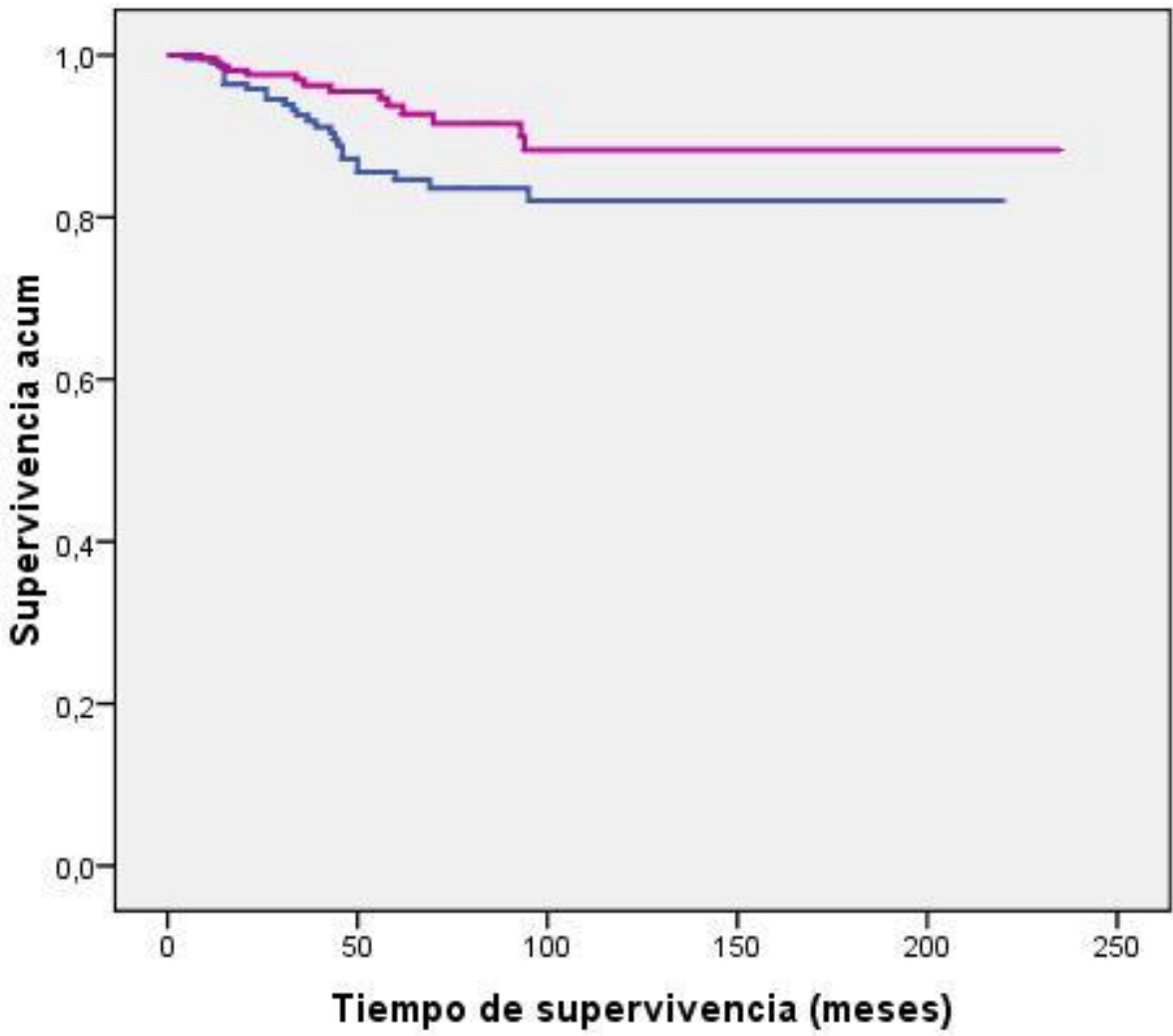

\begin{tabular}{|c|c|c|c|c|c|c|c|c|c|c|c|c|c|c|c|c|c|c|c|c|c|}
\hline \multicolumn{2}{|c|}{$\begin{array}{l}\text { Tiempo } \\
\text { (años) }\end{array}$} & $\begin{array}{c}\mathrm{Al} \\
\text { inicio }\end{array}$ & 1 & 2 & 3 & 4 & 5 & 6 & 7 & 8 & 9 & 10 & 11 & 12 & 13 & 14 & 15 & 16 & 17 & 18 & 19 \\
\hline \multirow{2}{*}{ Hombre } & $\mathrm{N}$ & 233 & 201 & 158 & 136 & 107 & 93 & 78 & 65 & 53 & 40 & 28 & 22 & 19 & 13 & 9 & 4 & 3 & 2 & 1 & \\
\hline & ps & 99,54 & 95,73 & 92,53 & 87,35 & 85,62 & 83,64 & 83,64 & 82,23 & 82,23 & 82,23 & 82,23 & 82,23 & 82,23 & 82,23 & 82,23 & 82,23 & 82,23 & 82,23 & 82,23 & \\
\hline \multirow{2}{*}{ Mujer } & $\mathrm{N}$ & 247 & 215 & 174 & 144 & 120 & 100 & 76 & 65 & 53 & 41 & 32 & 25 & 19 & 14 & 11 & 5 & 5 & 2 & 1 & 1 \\
\hline & ps & 99,57 & 97,53 & 96,91 & 95,47 & 93,75 & 91,65 & 91,65 & 88,59 & 88,59 & 88,59 & 88,59 & 88,59 & 88,59 & 88,59 & 88,59 & 88,59 & 88,59 & 88,59 & 88,59 & 88,59 \\
\hline
\end{tabular}

Gráfico 13. Supervivencia Sexo.

Tabla 28. Sexo

\begin{tabular}{cc|cc|}
\hline Sexo & Media & Inferior & Superior \\
\hline Hombre & 187,921 & 178,227 & 199,615 \\
\hline Mujer & 214,174 & 203,367 & 224,981 \\
\hline \multicolumn{3}{c}{ p-valor:0,044 } \\
\hline
\end{tabular}

Tabla 29. Cox Sexo.

\begin{tabular}{c|c|c|c|c} 
& & & \multicolumn{2}{|c}{$95,0 \%$ IC para HR } \\
\cline { 4 - 5 } Sexo & $p$-valor & HR & Inferior & Superior \\
\hline $\begin{array}{l}\text { Mujer vs } \\
\text { Hombre }\end{array}$ & 0,049 & 0,518 & 0,269 & 0,996 \\
\hline
\end{tabular}


En el estudio de la supervivencia especifica respecto al sexo se observó una supervivencia media para el hombre de 187,921 meses con IC al 95\% (178,227:199,615) y de 214,174 meses para la mujer con un IC 95\% (203,367:224,981). Las diferencias en la supervivencia media según sexo son estadísticamente significativas ( $p$-valor $=0,044$ ).

La probabilidad de sobrevivir a los 5 años fue de 83,64\% y $91,65 \%$; a los 10 años de $82,23 \%$ y de $88,59 \%$ y a los 15 años de $82,23 \%$ y $88,59 \%$ para el hombre y la mujer respectivamente.

En cuanto al modelo de regresión de Cox univariante, con un $p$-valor $=0,049$ y siendo su HR=0,518 IC 95\% (0,269:0,996), nos indica que el hombre tiene dos veces más riesgo de fallecer por melanoma que la mujer, siendo estas diferencias estadísticamente significativas. 


\subsection{SUPERVIVENCIA SEGÚN EDAD}

\section{Funciones de supervivencia}

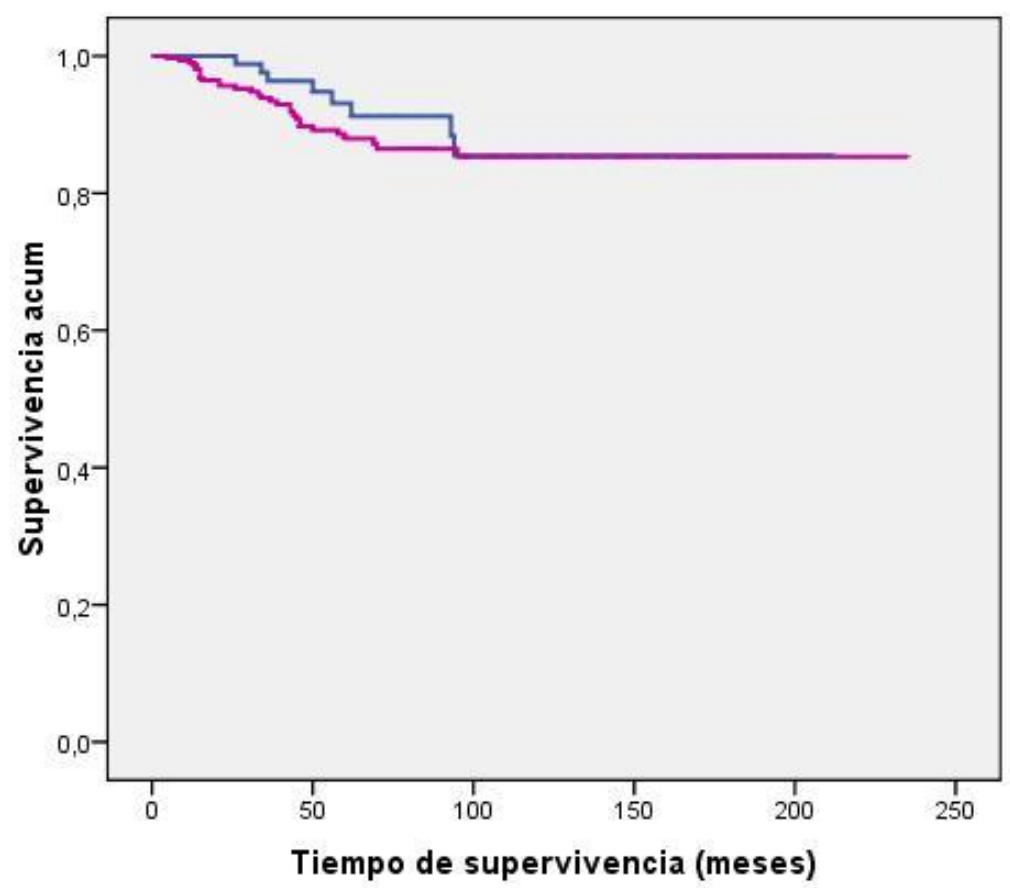

Edad

$\neg<50$ años

$\neg>50$ años

\begin{tabular}{|c|c|r|r|r|r|r|r|r|r|r|r|r|r|r|r|r|r|r|r|r|r|}
\hline $\begin{array}{c}\text { Tiempo } \\
\text { (años) }\end{array}$ & $\begin{array}{c}\text { Al } \\
\text { inicio }\end{array}$ & 1 & 2 & 3 & 4 & 5 & 6 & 7 & 8 & 9 & 10 & 11 & 12 & 13 & 14 & 15 & 16 & 17 & 18 & 19 \\
\hline \begin{tabular}{c}
$<$ \\
\multirow{2}{*}{$\begin{array}{c}\text { años } \\
\text { añ }\end{array}$}
\end{tabular} & $\mathrm{N}$ & 116 & 103 & 90 & 78 & 64 & 51 & 41 & 34 & 30 & 24 & 19 & 14 & 11 & 8 & 6 & 3 & 3 & 2 & \\
\hline & $\mathrm{ps}$ & 100,00 & 100,00 & 97,65 & 96,28 & 92,99 & 90,99 & 90,99 & 85,48 & 85,48 & 85,48 & 85,48 & 85,48 & 85,48 & 85,48 & 85,48 & 85,48 & 85,48 & 85,48 & & \\
\hline $\begin{array}{l}> \\
\text { >ños }\end{array}$ & $\mathrm{N}$ & 364 & 313 & 242 & 202 & 163 & 142 & 113 & 96 & 76 & 57 & 41 & 33 & 27 & 19 & 14 & 6 & 5 & 2 & 2 & 1 \\
\hline
\end{tabular}

Gráfico 14. Edad

Tabla 30. Edad

\begin{tabular}{cccc|}
\hline Edad & Media & Inferior & Superior \\
\hline$<50$ & 190,673 & 176,618 & 204,728 \\
\hline$>=50$ años & 206,608 & 197,028 & 216,188 \\
\hline \multicolumn{3}{c}{$p$-valor:0,219 } \\
\hline
\end{tabular}

\section{IC(95\%)}

Tabla31. Cox Edad

\begin{tabular}{c|c|c|c|c}
\hline \multirow{2}{*}{ Edad } & \multirow{2}{*}{ p-valor } & HR & \multicolumn{2}{|c}{$95,0 \%$ IC para HR } \\
\cline { 4 - 5 } & & & Inferior & Superior \\
\hline $\begin{array}{c}\text { años vs. } \\
<50 \text { años }\end{array}$ & 0,376 & 1,420 & 0,653 & 3,091 \\
& & & & \\
\hline
\end{tabular}


El estudio de la supervivencia según la variable edad estratificada en dos grupos cuyo punto de corte es de 50 años no resulto estadísticamente significativa ( $p$-valor $=0,219)$.

La media de supervivencia de ambos grupos fue de 190,673 IC 95\% $(176,618: 204,728)$ para el grupo menores de 50 años y de 206,608 IC 95\% $(197,028: 216,188)$ para el grupo de pacientes mayores o iguales a 50 años.

La probabilidad de sobrevivir de estos pacientes se encuentra recogida en el gráfico 14 , donde se puede observar que la probabilidad de sobrevivir a los 5, 10 y 15 años para el grupo de edad menor fue de 90,99\%, 85,48\% y 85,48\% respectivamente. En los iguales o mayores de 50 años la probabilidad de sobrevivir a los 5, 10 y 15 años es de un $86,65 \%$, $85,58 \%$ y $85,58 \%$ respectivamente.

La regresión de Cox univariante para los grupos de edad indicaría que el grupo de pacientes mayor o igual a 50 años tienen 1,42 veces más riesgo de morir que el grupo de pacientes menor de 50 años. Estos resultados no son estadísticamente significativos ( $p$ valor=0,376, con una $\mathrm{HR}=1,42 \mathrm{IC} 95 \%(0,653: 3,091)$. 


\subsection{SUPERVIVENCIA SEGÚN COLOR DEL IRIS}

\section{Funciones de supervivencia}

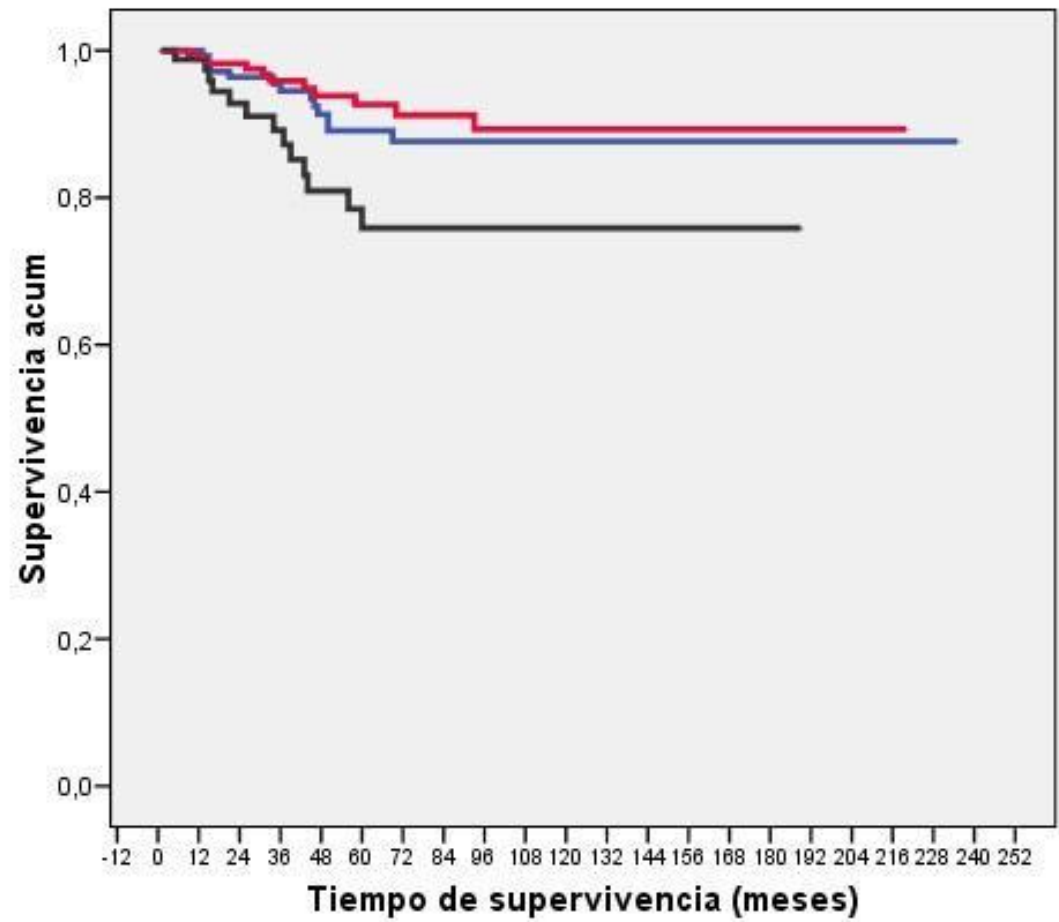

BPA Color del iris

IMarrón

IVerd-avell

חAzul-gris

Tiempo de supervivencia (meses)

\begin{tabular}{|c|c|c|c|c|c|c|c|c|c|c|c|c|c|c|c|c|c|c|c|c|c|}
\hline \multicolumn{2}{|c|}{$\begin{array}{l}\text { Tiempo } \\
\text { (años) }\end{array}$} & $\begin{array}{c}\mathrm{Al} \\
\text { inicio }\end{array}$ & 1 & 2 & 3 & 4 & 5 & 6 & 7 & 8 & 9 & 10 & 11 & 12 & 13 & 14 & 15 & 16 & 17 & 18 & 19 \\
\hline \multirow[b]{2}{*}{ Marrón } & $\mathrm{N}$ & 166 & 146 & 119 & 102 & 84 & 71 & 58 & 48 & 39 & 30 & 21 & 17 & 16 & 11 & 10 & 4 & 4 & 2 & 1 & 1 \\
\hline & ps & 100,00 & 96,30 & 95,43 & 91,41 & 89,08 & 87,71 & 87,71 & 87,71 & 87,71 & 87,71 & 87,71 & 87,71 & 87,71 & 87,71 & 87,71 & 87,71 & 87,71 & 87,71 & 87,71 & 87,71 \\
\hline \multirow{2}{*}{$\begin{array}{l}\text { Verd- } \\
\text { avell }\end{array}$} & $\mathrm{N}$ & 196 & 171 & 136 & 110 & 89 & 78 & 62 & 51 & 46 & 35 & 28 & 22 & 16 & 11 & 7 & 4 & 4 & 2 & 1 & \\
\hline & ps & 99,46 & 98,17 & 95,80 & 93,90 & 92,78 & 91,46 & 91,46 & 89,60 & 89,60 & 89,60 & 89,60 & 89,60 & 89,60 & 89,60 & 89,60 & 89,60 & 89,60 & 89,60 & 89,60 & \\
\hline \multirow{2}{*}{ Azul- } & $\mathrm{N}$ & 85 & 74 & 54 & 46 & 36 & 30 & 25 & 22 & 15 & 11 & 7 & 5 & 4 & 4 & 2 & 1 & & & & \\
\hline & ps & 98,75 & 2,77 & 13 & 0,84 & 78,42 & 5,62 & 75,62 & 75,62 & 75,62 & 75,62 & 75,62 & 75,62 & 75,62 & 75,62 & 75,62 & 75,62 & & & & \\
\hline
\end{tabular}

Gráfico15. Color de iris

\begin{tabular}{|cccc|}
\hline Tabla 32. Color Iris & \multicolumn{2}{c}{ IC $(95 \%)$} \\
\hline Color & Media & Inferior & Superior \\
\hline Marrón & 210,788 & 198,256 & 223,319 \\
\hline Verd-avell & 201,752 & 191,180 & 212,324 \\
\hline Azul-gris & 151,836 & 133,860 & 169,812 \\
\hline \multicolumn{3}{|c}{ p-valor:0,018 } \\
\hline
\end{tabular}

\begin{tabular}{c|c|c|c|c|}
\multicolumn{5}{|c}{ Tabla 33. Cox Color Iris } \\
\hline Color & p-valor & HR & Inferior & Superior \\
\cline { 4 - 5 } & Marrón \\
(Ref.) & 0,024 & & & \\
Verd- \\
$\begin{array}{c}\text { avell } \\
\text { Azul-gris }\end{array}$ & 0,515 & 0,0466 & 0,343 & 1,710 \\
& 0,044 & 2,202 & 1,021 & 4,752
\end{tabular}


La media de supervivencia para el color de iris marrón es de 210, 788 meses IC al 95\% (198,256:223,19). En el color verde avellana fue de 201,752 meses IC al 95\% $(191,180: 212,324)$ y en el color azul-gris de 151,836 meses IC al 95\% (133,860:169,812). Las diferencias entre las supervivencias medias de los tres grupos del color del iris son estadísticamente singificativas, $\mathrm{p}$-valor=0,018.

La probabilidad de sobrevivir a los 5, 10 y 15 años se encuentra recogida en el gráfico 15. Así, la probabilidad de fallecer a los 5 años es de $87,71 \%, 91,46 \%$ y 75,62\% para el color de ojos marrón, verde avellana y azul-gris respectivamente.

En el modelo de regresión de Cox univariante, se ha tomado como referencia el color del iris marrón. Los pacientes que pertenecen al grupo de verde-avellana presentan un menor riesgo de fallecer por melanoma, obtienen un HR de 0,766 IC95\%(0,343; 1,710$)$ el cual no es estadísticamente significativo. En cambio, el color de iris azul-gris presenta 2,202 veces más riesgo de fallecer por esta causa IC95\%(1,012;4,752) con un p-valor de 0,044 . 


\subsection{SUPERVIVENCIA SEGÚN TAMAÑO TUMORAL}

\subsubsection{Tamaño TNM.}

\section{Funciones de supervivencia}

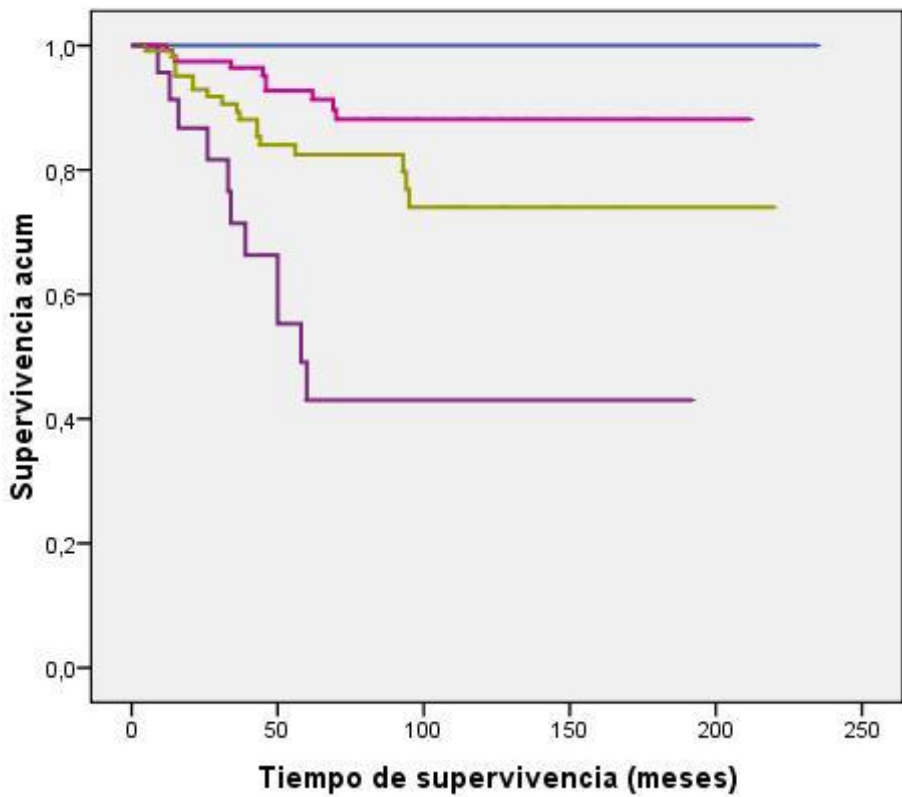

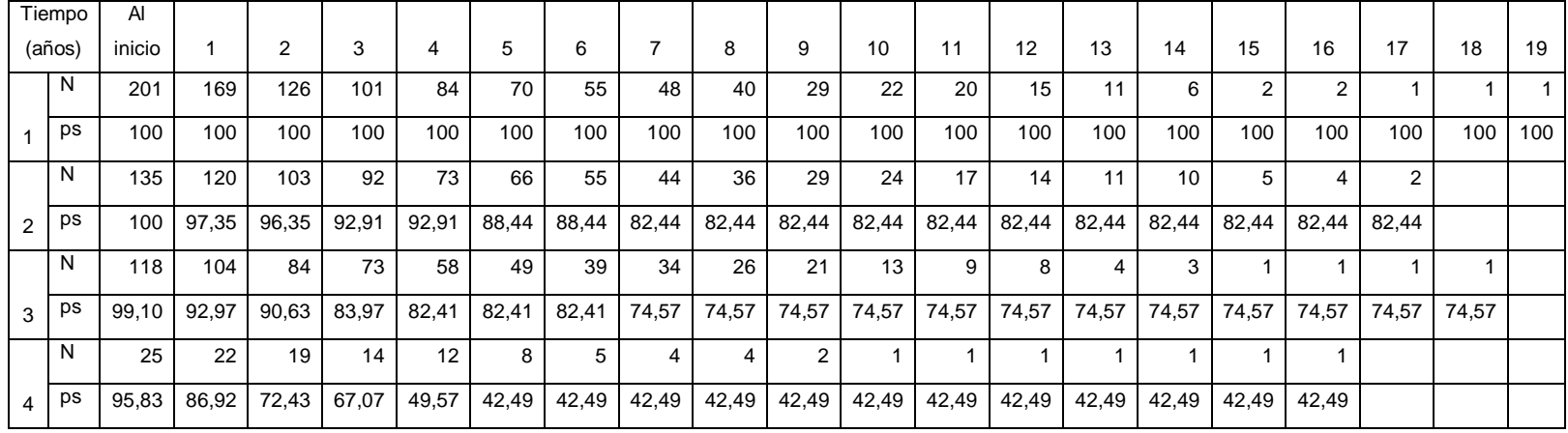

Gráfico16.TNM

\begin{tabular}{|c|c|c|c|}
\hline \multicolumn{2}{|c|}{ Tabla34. TNM } & \multicolumn{2}{|c|}{$\mathrm{IC}(95 \%)$} \\
\hline$T$ & Media & Inferior & Superior \\
\hline 1 & - & - & - \\
\hline 2 & 192,33 & 180,74 & 203,92 \\
\hline 3 & 176,08 & 157,71 & 194,45 \\
\hline 4 & 103,74 & 68,56 & 138,916 \\
\hline & &, 001 & \\
\hline
\end{tabular}

Tabla 35. Cox TNM

\begin{tabular}{c|c|c|c|c}
\hline$T$ & \multirow{2}{*}{$\mathrm{p}$-valor } & \multirow{2}{*}{ HR } & \multicolumn{2}{|c}{$95,0 \%$ IC para HR } \\
\cline { 4 - 5 } & & & Inferior & Superior \\
\hline 2(Ref) & $<0,001$ & & & \\
3 & 0,040 & 2,251 & 1,039 & 4,878 \\
4 & $<0,001$ & 7,171 & 3,039 & 16,925 \\
\hline
\end{tabular}


La supervivencia media para esta variable en cada una de sus subclasificaciones se encuentra recogida en la tabla 34, así para el tamaño T2 tiene una supervivencia media de 192,33 meses IC al 95\% (180,740:203,926), el T3 de 176,088 meses IC al $95 \%$ 157,716:194,45), el T4 fue de 103,74 meses IC al 95\% (103,74:138,916).Estas diferencias son estadísticamente significativas, $p$-valor $<0,001$.

La probabilidad de sobrevivir a los 5 años es del 100\%,88,44\%, $82,41 \%$ y $42,49 \%$ para los tamaños T1, T2, T3 y T4 respectivamente.

En la regresión de Cox, se tomó el tamaño T2 como referencia ( $p$-valor<0,001). La clasificación T3 presentó un HR de 2,251 IC al 95\% (1,039:4,878). En el tamaño T4 su HR fue de 7,171 IC al 95\% (3,039:16,925).

Esto nos indica que el riesgo de fallecer por melanoma es de 2,251 y 7,17 veces más mayor en las clasificaciones T3 y T4 respectivamente con respecto a la clasificación T2, siendo todos los resultados estadísticamente significativos. 


\subsubsection{Tamaño COMS.}

\section{Funciones de supervivencia}

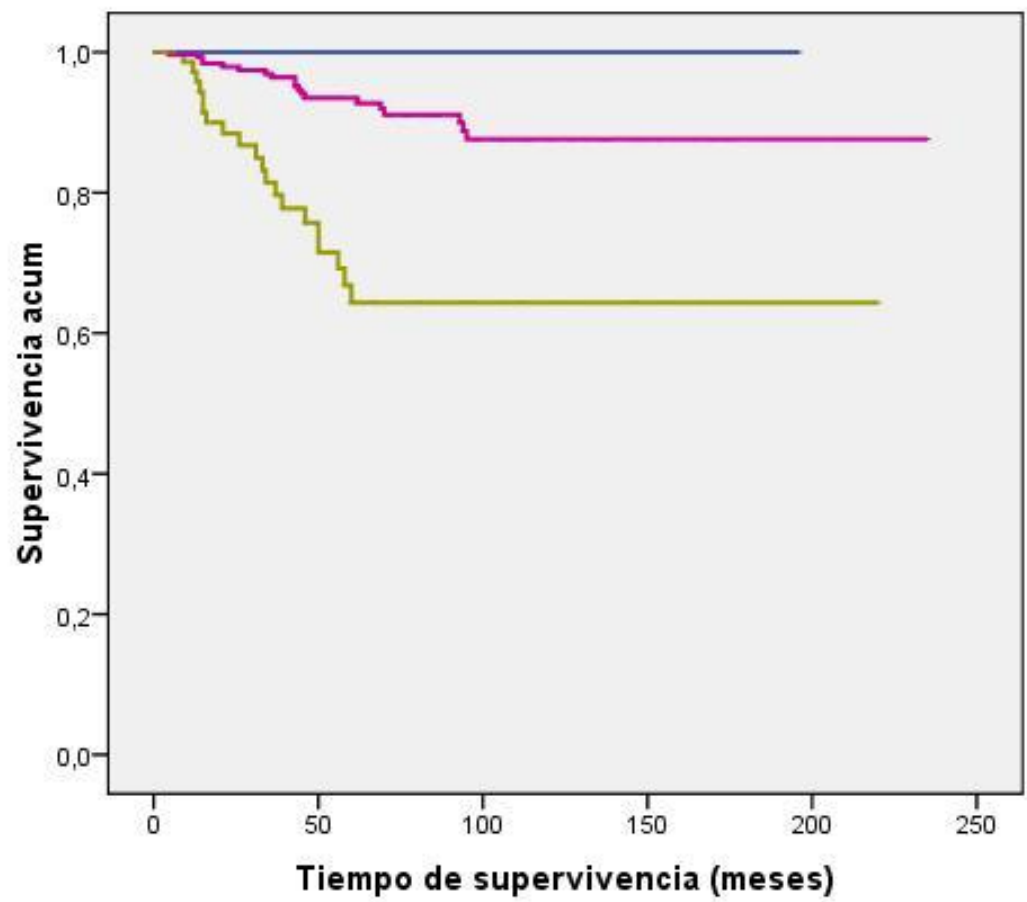

Tamaño COMS

$\neg$ Pequeño

$\rightarrow$ Mediano

$\rightarrow$ Grande

\begin{tabular}{|c|c|c|c|c|c|c|c|c|c|c|c|c|c|c|c|c|c|c|c|c|c|}
\hline \multicolumn{2}{|c|}{$\begin{array}{l}\text { Tiempo } \\
\text { (años) }\end{array}$} & $\begin{array}{c}\text { Al } \\
\text { inicio }\end{array}$ & 1 & 2 & 3 & 4 & 5 & 6 & 7 & 8 & 9 & 10 & 11 & 12 & 13 & 14 & 15 & 16 & 17 & 18 & 19 \\
\hline \multirow[b]{2}{*}{ Pequeño } & $N$ & 116 & 91 & 68 & 49 & 40 & 32 & 24 & 22 & 17 & 14 & 11 & 9 & 8 & 6 & 3 & 1 & 1 & & & \\
\hline & ps & 100,0 & 100,0 & 100,0 & 100,0 & 100,0 & 100,0 & 100,0 & 100,0 & 100,0 & 100,0 & 100,0 & 100,0 & 100,0 & 100,0 & 100,0 & 100,0 & 100,0 & & & \\
\hline \multirow{2}{*}{ Mediano } & $N$ & 283 & 254 & 208 & 185 & 151 & 134 & 110 & 91 & 74 & 56 & 40 & 31 & 23 & 17 & 14 & 6 & 5 & 3 & 1 & 1 \\
\hline & ps & 99,63 & 97,92 & 96,93 & 93,53 & 93,53 & 91,25 & 91,25 & 87,99 & 87,99 & 87,99 & 87,99 & 87,99 & 87,99 & 87,99 & 87,99 & 87,99 & 87,99 & 87,99 & 87,99 & 87,99 \\
\hline \multirow[b]{2}{*}{ ande } & $N$ & 80 & 70 & 56 & 46 & 36 & 27 & 20 & 17 & 15 & 11 & 9 & 7 & 7 & 4 & 3 & 2 & 2 & 1 & 1 & \\
\hline & ps & 98,68 & 88,29 & 81,63 & 75,86 & 66,81 & 64,02 & 64,02 & 64,02 & 64,02 & 64,02 & 64,02 & 64,02 & 64,02 & 64,02 & 64,02 & 64,02 & 64,02 & 64,02 & 64,02 & \\
\hline
\end{tabular}

\section{Gráfico17. Tamaño COMS}

Tabla 36. COMS

\begin{tabular}{|cccc|}
\hline Tamaño & Media & Inferior & Superior \\
\hline Pequeño & - & - & - \\
\hline Mediano & 212,833 & 203,182 & 222,484 \\
\hline Grande & 154,009 & 130,175 & 177,843 \\
\hline & \multicolumn{3}{c}{$p$-valor $<0,001$} \\
\hline
\end{tabular}

Tabla 37. Cox COMS

\begin{tabular}{ccccc} 
Tamaño & p-valor & HR & \multicolumn{2}{c}{$95,0 \%$ IC para HR } \\
Mediano & & & Inferior & Superior \\
vs & $<0,001$ & 4,339 & 2,313 & 8,141 \\
Grande & & & & \\
\end{tabular}


Otra variable utilizada para la clasificación del tamaño del tumor es la COMS, que al igual que en los resultados obtenidos en el TNM presenta diferencias en la supervivencia media de los pacientes ya sean clasificados en pequeños, mediano o grandes y estas diferencias son estadísticamente significativas, p-valor $<0,001$.

La media de supervivencia para el tamaño mediano fue de 212,833 meses IC al $95 \%(203,182: .222,484)$ y para el tamaño grande fue de 154,009 meses IC al $95 \%$ ( $130,175: 177,843)$

La probabilidad de sobrevivir a los 5 años es de 100\%, 91,25\% y 64,02\% para los tamaños pequeño, mediano y grande respectivamente.

En cuanto al modelo de regresión de Cox univariante se obtiene un HR 4,339 con un IC $95 \%(2,313: 8,141)$ lo que nos indica que los pacientes con tumores grandes tienen el 4,339 veces más riesgo de fallecer por melanoma que los tumores medianos $(p<0,001)$. 


\subsubsection{Diámetro Máximo Tumoral.}

\section{Funciones de supervivencia}

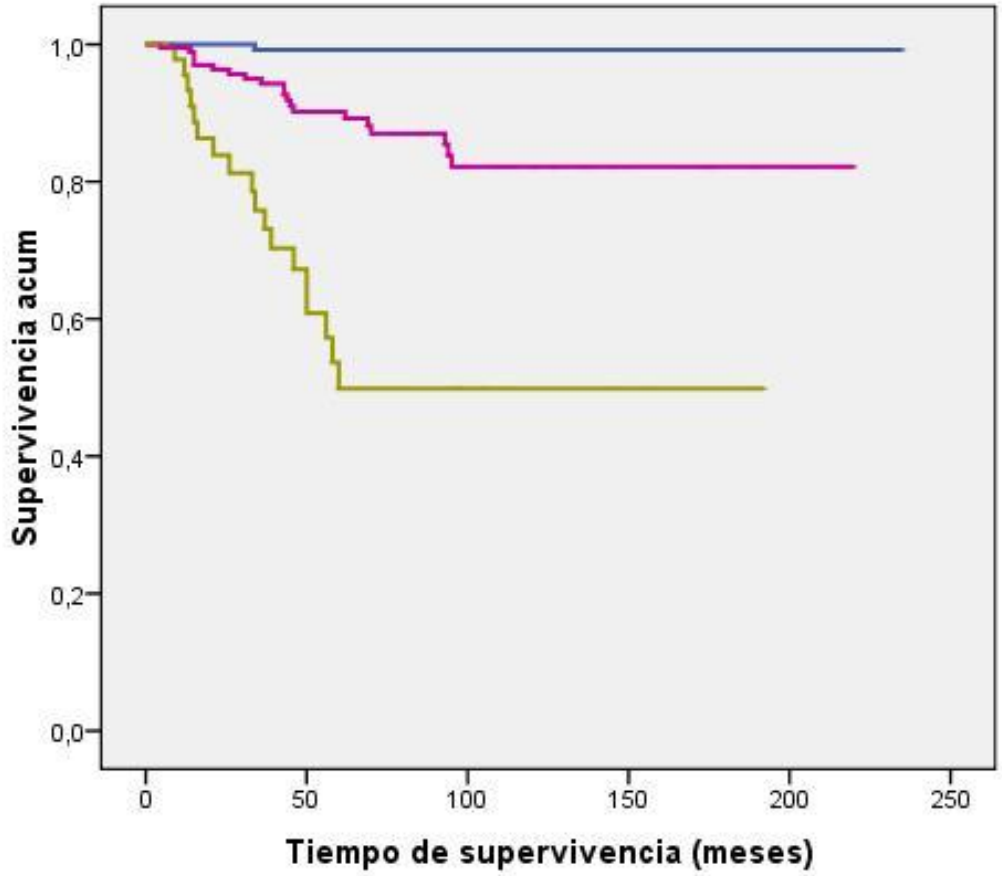

Tamaño máximo

$\neg$ Pequeño

$\neg$ Mediano

- TGrande

\begin{tabular}{|c|c|c|c|c|c|c|c|c|c|c|c|c|c|c|c|c|c|c|c|c|c|}
\hline \multicolumn{2}{|c|}{$\begin{array}{l}\text { Tiempo } \\
\text { (años) }\end{array}$} & $\begin{array}{c}\mathrm{Al} \\
\text { inicio }\end{array}$ & 1 & 2 & 3 & 4 & 5 & 6 & 7 & 8 & 9 & 10 & 11 & 12 & 13 & 14 & 15 & 16 & 17 & 18 & 19 \\
\hline \multirow[b]{2}{*}{$<10$} & $\mathrm{~N}$ & 235 & 201 & 153 & 122 & 98 & 83 & 67 & 57 & 47 & 36 & 27 & 25 & 20 & 14 & 8 & 4 & 4 & 2 & 1 & 1 \\
\hline & ps & 100,00 & 100,00 & 99,28 & 99,28 & 99,28 & 99,28 & 99,28 & 99,28 & 99,28 & 99,28 & 99,28 & 99,28 & 99,28 & 99,28 & 99,28 & 99,28 & 99,28 & 99,28 & 99,28 & 99,28 \\
\hline \multirow[b]{2}{*}{$10-16$} & $\mathrm{~N}$ & 194 & 170 & 145 & 130 & 108 & 96 & 76 & 64 & 50 & 41 & 30 & 19 & 15 & 12 & 11 & 4 & 3 & 2 & 1 & \\
\hline & ps & 99,45 & 96,34 & 94,95 & 90,28 & \begin{tabular}{|l|}
90,28 \\
\end{tabular} & 87,18 & 87,18 & 82,72 & 82,72 & 82,72 & 82,72 & 82,72 & 82,72 & 82,72 & 82,72 & 82,72 & 82,72 & 82,72 & 82,72 & \\
\hline \multirow[b]{2}{*}{$>16$} & $N$ & 50 & 44 & 34 & 28 & 21 & 14 & 11 & 9 & 9 & 4 & 3 & 3 & 3 & 1 & 1 & 1 & 1 & & & \\
\hline & ps & 97,89 & 83,91 & 76,16 & 67,38 & \begin{tabular}{|l|l|}
53,56 \\
\end{tabular} & 49,44 & 49,44 & 49,44 & 49,44 & 49,44 & 49,44 & 49,44 & 49,44 & 49,44 & 49,44 & 49,44 & 49,44 & & & \\
\hline
\end{tabular}

Gráfico 18. Tamaño Máximo Tumoral

Tabla 38. Tamaño

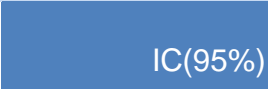

\begin{tabular}{|c|ccc|}
\hline $\begin{array}{c}\text { Tamaño } \\
\text { Pequeño }\end{array}$ & Media & Inferior & Superior \\
\hline $\begin{array}{c}10-16 \\
\text { Mediano }\end{array}$ & 190,427 & 178,280 & 202,574 \\
\hline $\begin{array}{c}>16 \\
\text { Grande }\end{array}$ & 113,633 & 87,129 & 140,136 \\
\hline
\end{tabular}

Tabla 39. Cox. Tamaño Máximo

\begin{tabular}{|c|c|c|c|c|}
\hline \multirow[t]{2}{*}{ Tamaño } & \multirow{2}{*}{ p-valor } & \multirow[t]{2}{*}{ HR } & \multicolumn{2}{|c|}{$\begin{array}{c}95,0 \% \text { IC para } \\
\text { HR }\end{array}$} \\
\hline & & & Inferior & Superior \\
\hline $\begin{array}{c}\text { Pequeño } \\
\text { (Ref.) }\end{array}$ & $<0,001$ & & & \\
\hline Mediano & 0,004 & 19,79 & 2,655 & 147,529 \\
\hline Grande & $<0,001$ & 85,85 & 11,458 & 643,239 \\
\hline
\end{tabular}

\footnotetext{
$-81-$ 
Para el diámetro máximo tumoral $<10$ la media de supervivencia fue de 233,417 meses IC al 95\% (230,328:236,507), el tamaño 10-16 fue de 190,427 meses IC al 95\%

$(178,280: 202,574)$ el $>16$ fue de 113,633 meses IC al 95\% $(87,129: 140,136)$.Las diferencias son estadísticamente significativas con un $\mathrm{p}$-valor $<0,001$.

La probabilidad de sobrevivir a los 5 años es del $99,28 \%, 87,18 \%$ y $49,44 \%$ para los tamaños $<10,10-16$ y $>16$ respectivamente.

En cuanto a la regresión de Cox, se tomó el tamaño $<10$ como referencia $(p-$ valor $<0,001)$ y respecto a él se compararon el resto de tamaños, siendo todos ellos estadísticamente significativos. El tamaño 10-16 presentó un HR de 19,792 IC al 95\% $(2,655: 147,529)$, lo que indica un riesgo 19 veces superior de fallecer por melanoma uveal que el tamaño <10. El tamaño $>16$ presentó un HR de 85,851 con un IC al 95\% $(11,458: 643,239)$, lo que supone un riesgo 85 veces superior a fallecer de melanoma uveal que el tamaño $<10$. 


\subsection{SUPERVIVENCIA SEGÚN INVASIÓN CUERPO CILIAR}

Funciones de supervivencia

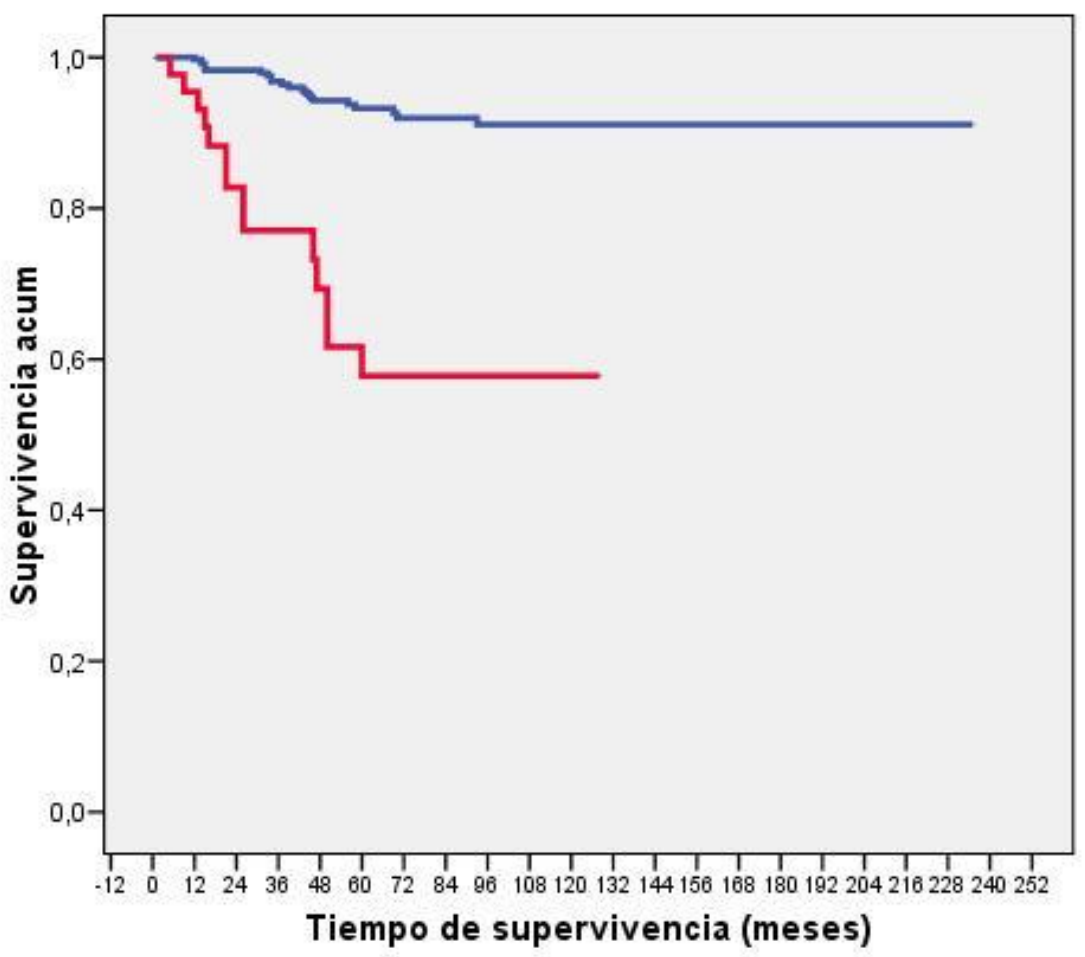

Invasión cuerpo ciliar

חNO

$\neg \mathrm{SI}$

\begin{tabular}{|c|c|c|c|c|c|c|c|c|c|c|c|c|c|c|c|c|c|c|c|c|c|}
\hline \multicolumn{2}{|c|}{$\begin{array}{c}\text { Tiempo } \\
\text { (años) }\end{array}$} & $\begin{array}{c}\mathrm{Al} \\
\text { inicio }\end{array}$ & 1 & 2 & 3 & 4 & 5 & 6 & 7 & 8 & 9 & 10 & 11 & 12 & 13 & 14 & 15 & 16 & 17 & 18 & 19 \\
\hline \multirow{2}{*}{$\mathrm{NO}$} & $\mathrm{N}$ & 428 & 370 & 297 & 251 & 207 & 175 & 141 & 121 & 102 & 78 & 58 & 47 & 38 & 27 & 20 & 9 & 8 & 4 & 2 & 1 \\
\hline & ps & 100 & 98 & 97 & 94 & 93 & 92 & 92 & 91 & 91 & 91 & 91 & 91 & 91 & 91 & 91 & 91 & 91 & 91 & 91 & 91 \\
\hline \multirow[b]{2}{*}{ SI } & $\mathrm{N}$ & 46 & 41 & 30 & 24 & 18 & 16 & 11 & 8 & 4 & 3 & 2 & & & & & & & & & \\
\hline & ps & 96 & 83 & 77 & 70 & 62 & 58 & 58 & 58 & 58 & 58 & 58 & & & & & & & & & \\
\hline
\end{tabular}

Gráfico19. Invasión Cuerpo Ciliar

Tabla 40. Invasión

\begin{tabular}{|ccc|c|}
\hline Invasión & \multicolumn{1}{c|}{ Media } & Inferior & Superior \\
\hline NO & 218,178 & 211,120 & 225,235 \\
\hline SI & 87,740 & 71,167 & 104,313 \\
\hline & \multicolumn{2}{|c|}{$p$-valor $<0,001$} & \\
\hline
\end{tabular}

Tabla41. Cox Invasión C. Ciliar

\begin{tabular}{|ccccc|}
\hline Invasión & p-valor & HR & \multicolumn{2}{c}{$95,0 \%$ IC para HR } \\
& & & Inferior & Superior \\
\hline T.Invasión & $<0,001$ & 6,925 & 3,515 & 13,645 \\
(SI vs NO) & & & &
\end{tabular}


Con respecto a la invasión de cuerpo ciliar se observó una supervivencia media de 218,178 meses IC al 95\% $(211,120: 225,235)$ para los pacientes sin invasión y de 87,740 meses para los pacientes con invasión con un IC 95\% (71,167:104,313). Las diferencias en la supervivencia media entre ambos grupos son estadísticamente significativas ( $p$-valor $<0,001)$.

La probabilidad de sobrevivir a los 5 años fue de $92 \%$ y $58 \%$ y a los 10 años de $91 \%$ y de $58 \%$ para el grupo sin y con invasión de cuerpo ciliar respectivamente.

En cuanto al modelo de regresión de Cox univariante se obtiene un HR 6,925 con un IC 95\% $(3,515: 13,645)$ lo que nos indica que los pacientes con invasión de cuerpo ciliar tienen el 6,9 veces más riesgo de fallecer por melanoma que los que no tienen invasión $(p<0,001)$. 


\subsection{SUPERVIVENCIA SEGÚN LA LOCALIZACIÓN YUXTAPAPILAR}

\section{Funciones de supervivencia}

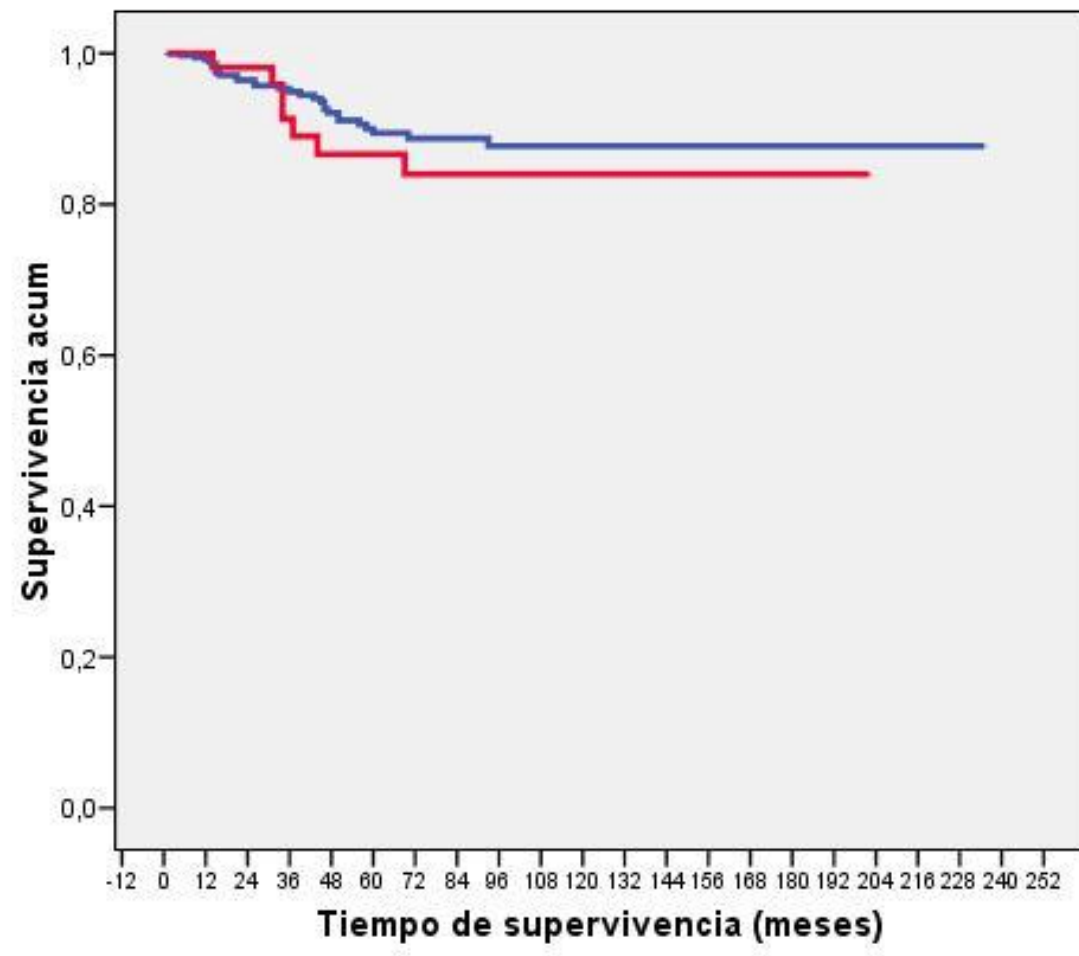

Tumor yuxtapapilar

-nNO

$\rightarrow \mathrm{SI}$

Tiempo de supervivencia (meses)

\begin{tabular}{|c|c|c|c|c|c|c|c|c|c|c|c|c|c|c|c|c|c|c|c|c|c|}
\hline \multicolumn{2}{|c|}{$\begin{array}{l}\text { Tiempo } \\
\text { (años) }\end{array}$} & $\begin{array}{c}\text { Al } \\
\text { inicio }\end{array}$ & 1 & 2 & 3 & 4 & 5 & 6 & 7 & 8 & 9 & 10 & 11 & 12 & 13 & 14 & 15 & 16 & 17 & 18 & 19 \\
\hline \multirow{2}{*}{ NO } & $\mathrm{N}$ & 411 & 354 & 278 & 234 & 188 & 158 & 122 & 105 & 85 & 66 & 47 & 35 & 28 & 19 & 13 & 7 & 6 & 4 & 2 & 1 \\
\hline & ps & 99,48 & 96,38 & 95,26 & 92,15 & 90,04 & 88,76 & 88,76 & 87,84 & 87,84 & 87,84 & 87,84 & 87,84 & 87,84 & 87,84 & 87,84 & 87,84 & 87,84 & 87,84 & 87,84 & 87,84 \\
\hline \multirow{2}{*}{ SI } & $\mathrm{N}$ & 61 & 55 & 48 & 40 & 36 & 33 & 31 & 24 & 21 & 15 & 13 & 12 & 10 & 8 & 7 & 2 & 2 & & & \\
\hline & ps & 100,00 & 98,08 & 91,61 & 86,91 & 86,91 & 84,24 & 84,24 & 84,24 & 84,24 & 84,24 & 84,24 & 84,24 & 84,24 & 84,24 & 84,24 & 84,24 & 84,24 & & & \\
\hline
\end{tabular}

Gráfico 20. Tumor Yuxtapapilar

\begin{tabular}{|crrr|}
\hline \multicolumn{2}{|c|}{ Tabla 42. Yuxtapapilar } & \multicolumn{2}{|c|}{ IC $(95 \%)$} \\
\hline Yuxtapa. & Media & Inferior & Superior \\
\hline NO & 211,30 & 202,93 & 219,68 \\
\hline SI & 175,91 & 158,11 & 193,71 \\
\hline & \multicolumn{3}{|c}{$p$-valor $=0,502$} \\
\hline
\end{tabular}

Tabla 43. Cox Yuxtapapilar.

\begin{tabular}{|ccccc|}
\hline Yuxtapapila & p-valor & HR & \multicolumn{2}{c|}{$95,0 \%$ IC para HR } \\
& & & Inferior & Superior \\
\hline $\begin{array}{c}\text { Yuxtapapilar } \\
\text { (SI vs NO) }\end{array}$ & 0,482 & 1,34 & 0,589 & 3,076 \\
\hline
\end{tabular}


Analizando la supervivencia respecto a la variable de tumor yuxtapapilar se observó una supervivencia media para el grupo de pacientes que no presentó tumores yuxtapapilar fue de de 211,30 meses IC al 95\% (202,93:219,69) y de 175,91 meses para el grupo que si presentó es te tipo de tumor con un IC 95\% $(158,11.193,71)$. Las diferencias entre ambos grupos no son estadísticamente significativas ( $p$-valor $=0,502$ ).

La probabilidad de sobrevivir a los 5 años fue de $88,76 \%$ y $84,24 \%$; a los 10 años de $88,76 \%$ y de $84,24 \%$ para el grupo sin y con tumor yuxtapapilar respectivamente.

En la regresión de Cox, se obtuvo un $\mathrm{HR}=1,346$ con un IC $95 \%(0,589: 3,076)$ lo que indica que los pacientes con tumor yuxtapapilar tienen un riesgo 1,3 veces mayor de fallecer por melanoma que los pacientes que no tienen tumor yuxtapapilar, esta asociación no es estadísticamente significativa. 


\subsection{SUPERVIVENCIA SEGÚN EXTENSIÓN EXTRAOCULAR.}

\section{Funciones de supervivencia}

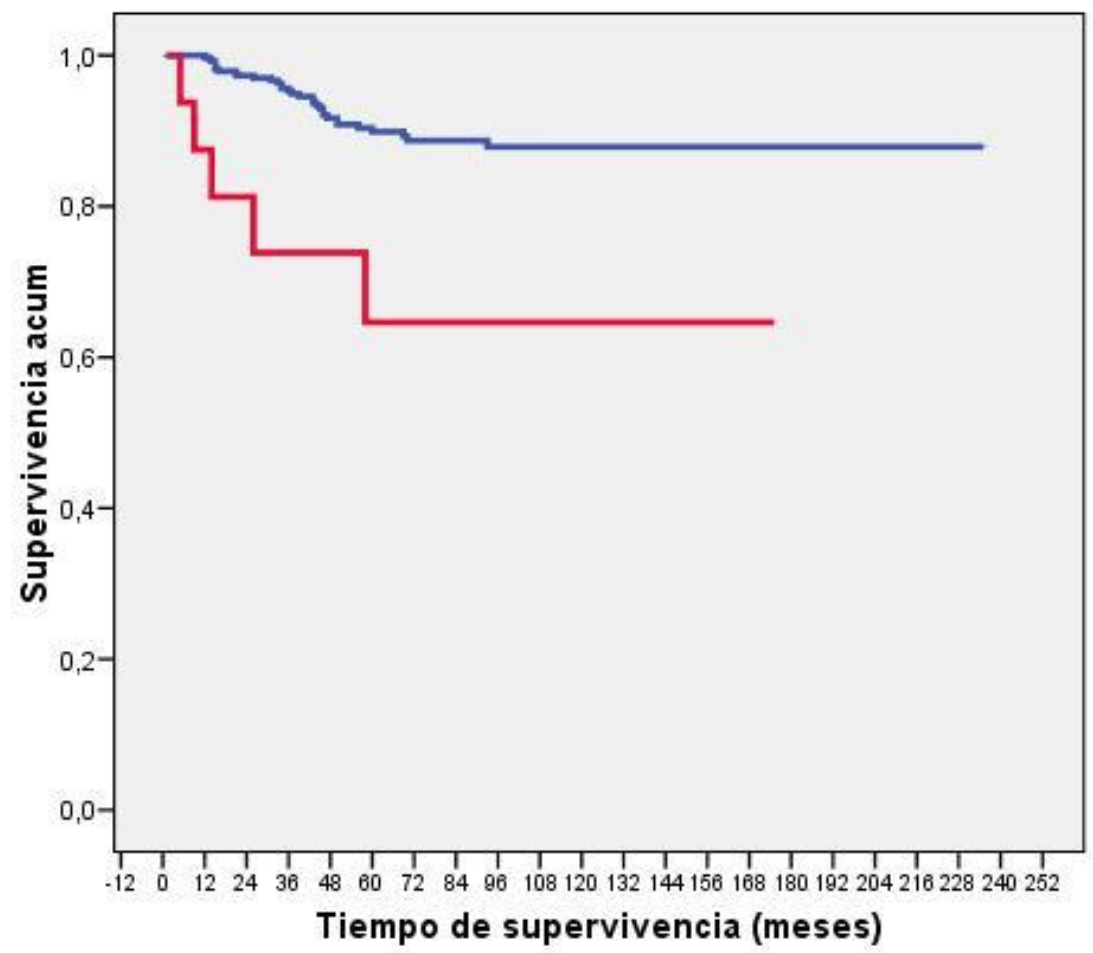

Extensión extraocular

- No

$-7 \mathrm{SI}$

\begin{tabular}{|c|c|c|c|c|c|c|c|c|c|c|c|c|c|c|c|c|c|c|c|c|c|}
\hline \multicolumn{2}{|c|}{$\begin{array}{l}\text { Tiempo } \\
\text { (años) }\end{array}$} & $\begin{array}{c}\text { Al } \\
\text { inicio }\end{array}$ & 1 & 2 & 3 & 4 & 5 & 6 & 7 & 8 & 9 & 10 & 11 & 12 & 13 & 14 & 15 & 16 & 17 & 18 & 19 \\
\hline \multirow{2}{*}{ NO } & $\mathrm{N}$ & 461 & 401 & 320 & 269 & 218 & 186 & 147 & 124 & 101 & 79 & 58 & 45 & 36 & 25 & 18 & 9 & 8 & 4 & 2 & 1 \\
\hline & $\%$ & 100,00 & 97,26 & 95,63 & 91,78 & 90,43 & 88,81 & 88,81 & 88,02 & 88,02 & 88,02 & 88,02 & 88,02 & 88,02 & 88,02 & 88,02 & 88,02 & 88,02 & 88,02 & 88,02 & 88,02 \\
\hline \multirow{2}{*}{ SI } & $\mathrm{N}$ & 17 & 14 & 11 & 10 & 9 & r & 7 & 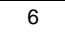 & 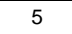 & 2 & 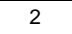 & 2 & 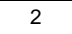 & 2 & 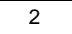 & & & & & \\
\hline & $\%$ & 87,88 & 1,12 & 3,74 & 73,74 & 5,07 & 65,07 & 5,07 & 65,07 & 65,07 & 65,07 & 5,07 & 65,07 & 65,07 & 65,07 & 65,07 & & & & & \\
\hline
\end{tabular}

Gráfico 21. Extensión Extraocular

\begin{tabular}{|c|cc|c|}
\hline \multicolumn{2}{|c|}{ Tabla 44. Extensión } & \multicolumn{2}{c|}{ IC(95\%) } \\
\hline Extraocular & Media & Inferior & Superior \\
\hline NO & 211,734 & 203,970 & 219,497 \\
\hline SI & 122,129 & 84,157 & 160,101 \\
\hline & $p-v a l o r<0,001$ & \\
\hline
\end{tabular}

Tabla 45. Cox Extensión Extraocular

\begin{tabular}{c|c|c|c|c}
\hline Extensión & p-valor & HR & \multicolumn{2}{|c}{$95,0 \%$ IC para HR } \\
\cline { 3 - 4 } & & Inferior & Superior \\
\hline $\begin{array}{c}\text { E.extraocular } \\
\text { (Si vs No) }\end{array}$ & 0,003 & 4,180 & 1,628 & 10,735 \\
\hline
\end{tabular}


En la extensión extraocular se observó una supervivencia media de 211,734 meses IC al 95\% $(203,1970: 219,497)$ en el grupo de si y de 122,129 meses en el que no presentan dicha extensión con un IC 95\% $(84,157: 160,101)$. Las diferencias entre ambos grupos son estadísticamente significativas ( $p$-valor $<0,001$ ).

La probabilidad de sobrevivir a los 5 años fue de $88,81 \%$ y $65,07 \%$ y a los 10 años de $88,02 \%$ y de $65,07 \%$ para el grupo sin extensión y con extensión extraocular respectivamente.

En cuanto al modelo de regresión de Cox, resulto estadísticamente significativa, con un p-valor $<0,003$, siendo su HR 4,180 con un IC 95\% (1,628:10,735). Esto nos indica que los pacientes con extensión extraocular tienen 4,1 veces más riesgo de fallecer por melanoma que los que no. 


\subsection{SUPERVIVENCIA SEGÚN TAMAÑO HISTOLÓGICO}

\section{Funciones de supervivencia}

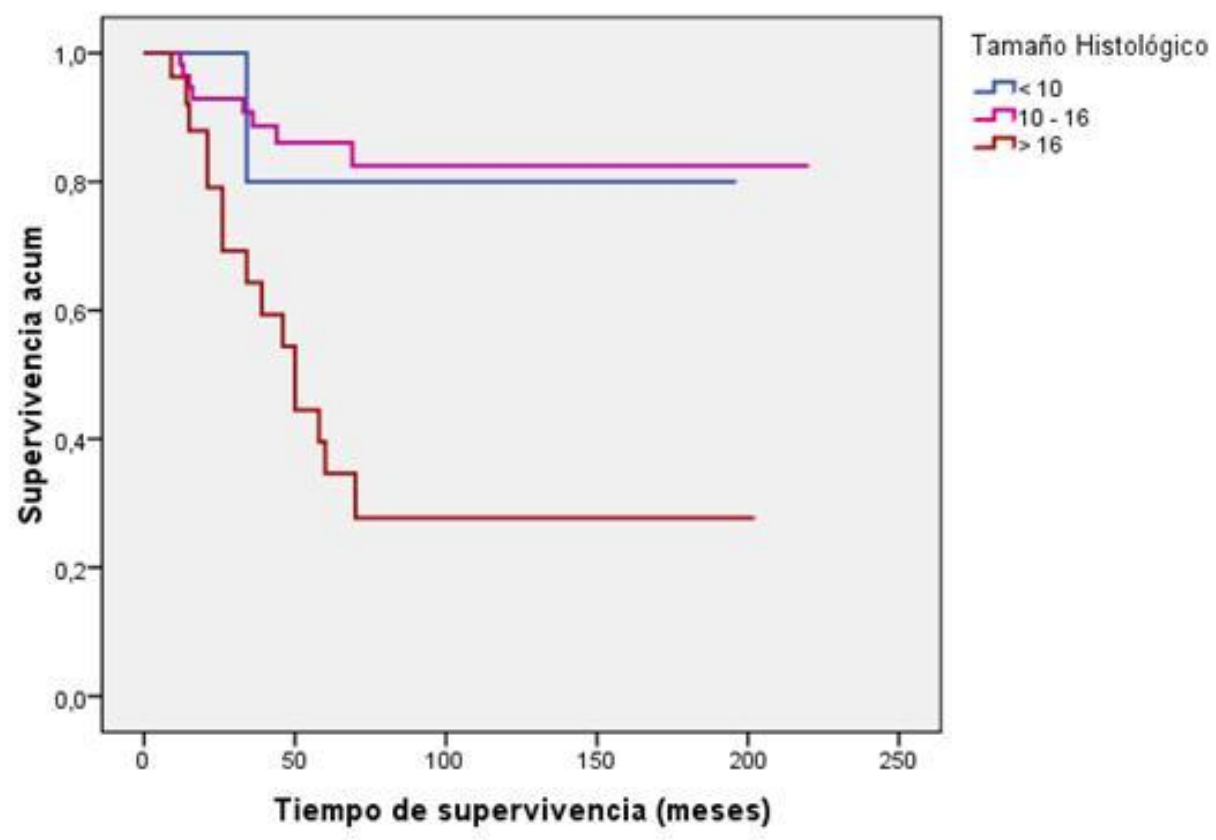

\begin{tabular}{|c|c|c|c|c|c|c|c|c|c|c|c|c|c|c|c|c|c|c|c|c|}
\hline \multicolumn{2}{|c|}{ Año } & $\begin{array}{l}\text { Al } \\
\text { inicio }\end{array}$ & 1 & 2 & 3 & 4 & 5 & 6 & 7 & 8 & 9 & 10 & 11 & 12 & 13 & 14 & 15 & 16 & 17 & 18 \\
\hline \multirow[b]{2}{*}{$<10$} & $\mathrm{~N}$ & 10 & 9 & 5 & 4 & 4 & 4 & 4 & 4 & 4 & 2 & 2 & 2 & 2 & 2 & 1 & 1 & 1 & & \\
\hline & ps & 100,0 & 100,0 & 80,0 & 80,0 & 80,0 & 80,0 & 80,0 & 80,0 & 80,0 & 80,0 & 80,0 & 80,0 & 80,0 & 80,0 & 80,0 & 80,0 & 80,0 & & \\
\hline \multirow[b]{2}{*}{$10-16$} & $\mathrm{~N}$ & 62 & 57 & 49 & 42 & 31 & 25 & 23 & 19 & 16 & 11 & 11 & 10 & 10 & 8 & 7 & 2 & 2 & 1 & 1 \\
\hline & ps & 100,0 & 92,7 & 90,7 & 85,9 & 85,9 & 82,4 & 82,4 & 82,4 & 82,4 & 82,4 & 82,4 & 82,4 & 82,4 & 82,4 & 82,4 & 82,4 & 82,4 & 82,4 & 82,4 \\
\hline \multirow[b]{2}{*}{$>16$} & $\mathrm{~N}$ & 29 & 25 & 18 & 13 & 11 & 8 & 4 & 4 & 3 & 2 & 1 & 1 & 1 & 1 & 1 & 1 & 1 & & \\
\hline & ps & 96,4 & 80,0 & 65,9 & 55,7 & 40,5 & 28,9 & 28,9 & 28,9 & 28,9 & 28,9 & 28,9 & 28,9 & 28,9 & 28,9 & 28,9 & 28,9 & 28,9 & & \\
\hline
\end{tabular}

Gráfica 22. Tamaño Histológico

\begin{tabular}{|c|c|c|c|}
\hline \multicolumn{2}{|c|}{$\begin{array}{c}\text { Tabla 46. Tamaño } \\
\text { Histológico }\end{array}$} & \multicolumn{2}{|c|}{$\mathrm{IC}(95 \%)$} \\
\hline Tamaño & Media & Inferior & Superior \\
\hline$<10$ & 163,600 & 106,800 & 220,400 \\
\hline $10-16$ & 187,499 & 166,569 & 208,429 \\
\hline$>16$ & 83,424 & 50,117 & 116,732 \\
\hline
\end{tabular}

\begin{tabular}{|ccccc|}
\hline \multicolumn{5}{|c|}{ Tabla47. Cox Tamaño Histológico } \\
\hline Tamaño & p-valor & HR & \multicolumn{2}{c|}{ 95,0\% IC para HR } \\
\hline <10 (REF) & 0 & & & \\
oct-16 & 0,937 & 1,087 & 0,136 & 8,705 \\
$>16$ & 0,09 & 5,789 & 0,762 & 43,976 \\
\hline
\end{tabular}


La supervivencia media en la variable realizada sobre la pieza de anatomía patológica en cada una de sus subclasificaciones se encuentra recogida en la tabla 46, así para el tamaño <10 la supervivencia media fue de 163,600 meses IC al 95\% ( 106,800:220,400), el tamaño 10-16 fue de 1187,499 meses IC al 95\% (166,569:208,429) y el >16 fue de 84,424 meses IC al 95\% (50,117:116,732).Las diferencias obtenidas entre los tres tamaño son estadísticamente significativas con un $p$-valor $<0,001$.

La probabilidad de sobrevivir a los 5 años es del $80 \%, 82,4 \%$ y $28,9 \%$ para los tamaños $<10,10-16$ y $>16$ respectivamente.

En cuanto a la regresión de Cox, se tomó el tamaño $<10$ como referencia ( $p$ valor $<0,001)$ y respecto a él se compararon el resto de tamaños. El tamaño 10-16 presentó un p-valor $=0,937$ y una HR de 1,087 con un IC al 95\% $(0,136: 8,705)$, lo que nos indica que no existen diferencias en el riesgo que tienen de fallecer por melanoma uveal los pacientes de tamaño 10-16 con respecto al tamaño $<10$. En el grupo del tamaño $>16$ se obtuvo un HR de 5,78 con un IC al 95\% (0,762:4,976), en este caso los pacientes tienen un riesgo 5,7 veces superior a fallecer de melanoma uveal que el tamaño $<10$. En ninguno de los dos grupos estos resultados son estadísticamente significativos. 


\subsection{SUPERVIVENCIA SEGÚN TIPO CELULAR.}

\section{Funciones de supervivencia}

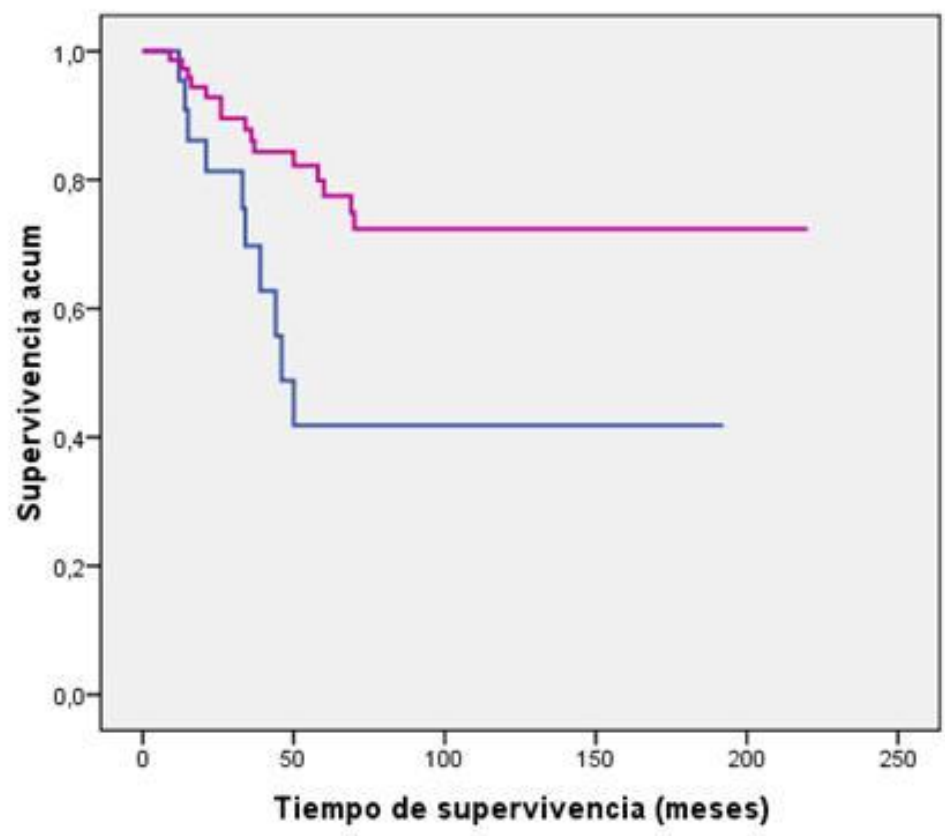

Clasificación

$\neg$ Epiteloide

$\rightarrow$ Resto

\begin{tabular}{|c|c|c|c|c|c|c|c|c|c|c|c|c|c|c|c|c|c|c|c|c|}
\hline \multicolumn{2}{|l|}{ Año } & $\begin{array}{c}\mathrm{Al} \\
\text { inicio }\end{array}$ & 1 & 2 & 3 & 4 & 5 & 6 & 7 & 8 & 9 & 10 & 11 & 12 & 13 & 14 & 15 & 16 & 17 & 18 \\
\hline \multirow{2}{*}{ Epiteloide } & $\mathrm{N}$ & 27 & 22 & 17 & 11 & 7 & 5 & 4 & 4 & 4 & 3 & 3 & 3 & 3 & 2 & 2 & 1 & 1 & & \\
\hline & ps & 100 & 81 & 71 & 50 & 43 & 43 & 43 & 43 & 43 & 43 & 43 & 43 & 43 & 43 & 43 & 43 & 43 & & \\
\hline \multirow{2}{*}{ Resto } & $\mathrm{N}$ & 77 & 72 & 58 & 51 & 41 & 34 & 28 & 23 & 19 & 12 & 11 & 10 & 10 & 9 & 7 & 3 & 3 & 1 & 1 \\
\hline & ps & 99 & 93 & 88 & 84 & 80 & 72 & 72 & 72 & 72 & 72 & 72 & 72 & 72 & 72 & 72 & 72 & 72 & 72 & 72 \\
\hline
\end{tabular}

Gráfico 23. Tipo Celular

\begin{tabular}{|cccc|}
\hline \multicolumn{2}{|c|}{ Tabla 48. Tipo Celular } & \multicolumn{2}{c|}{ IC(95\%) } \\
\hline Tipo celular & Media & Inferior & Superior \\
\hline Epiteloide & 99,594 & 61,062 & 138,126 \\
\hline Resto & 170,38 & 148,49 & 192,282 \\
\hline & \multicolumn{2}{|c|}{$p$-valor $=0,007$} \\
\hline
\end{tabular}

Tabla 49. Tipo Celular Histológico

\begin{tabular}{|ccccc} 
TIPO & & \multicolumn{3}{c}{$95,0 \%$ IC para HR } \\
$\begin{array}{c}\text { Celular } \\
\text { Epiteloide }\end{array}$ & p-valor & HR & Inferior & Superior \\
vs. resto & 0,011 & 2,9 & 1,3 & 6,4 \\
\hline
\end{tabular}


Con respecto al tipo celular, se observó una supervivencia media de 99,594 meses con IC al 95\% $(61,062: 138,126)$ para los pacientes con predominio celular epitelioide y de 170,38 meses para el resto con un IC 95\% (148,49:192,282). Las diferencias halladas entre ambos grupos son estadísticamente significativas ( $p$-valor $=0,007$ ).

La probabilidad de sobrevivir a los 5 años fue de $43 \%$ y $72 \%$ y a los 10 años de $43 \%$ y de $72 \%$ para el grupo epitelioide y el resto respectivamente.

En cuanto al modelo de regresión de Cox, se obtienen un HR=2,9 con un IC 95\% $(1,3: 6,4)$ lo que indica que los pacientes con células epitelioides tiene 2,9 veces mayor riesgo de fallecer por melanoma que los que no tienen ese tipo celular ( $p$-valor=0,011). 


\subsection{SUPERVIVENCIA SEGÚN LOCALIZACIÓN TUMORAL HISTOPATOLÓGICA.}

\section{Funciones de supervivencia}

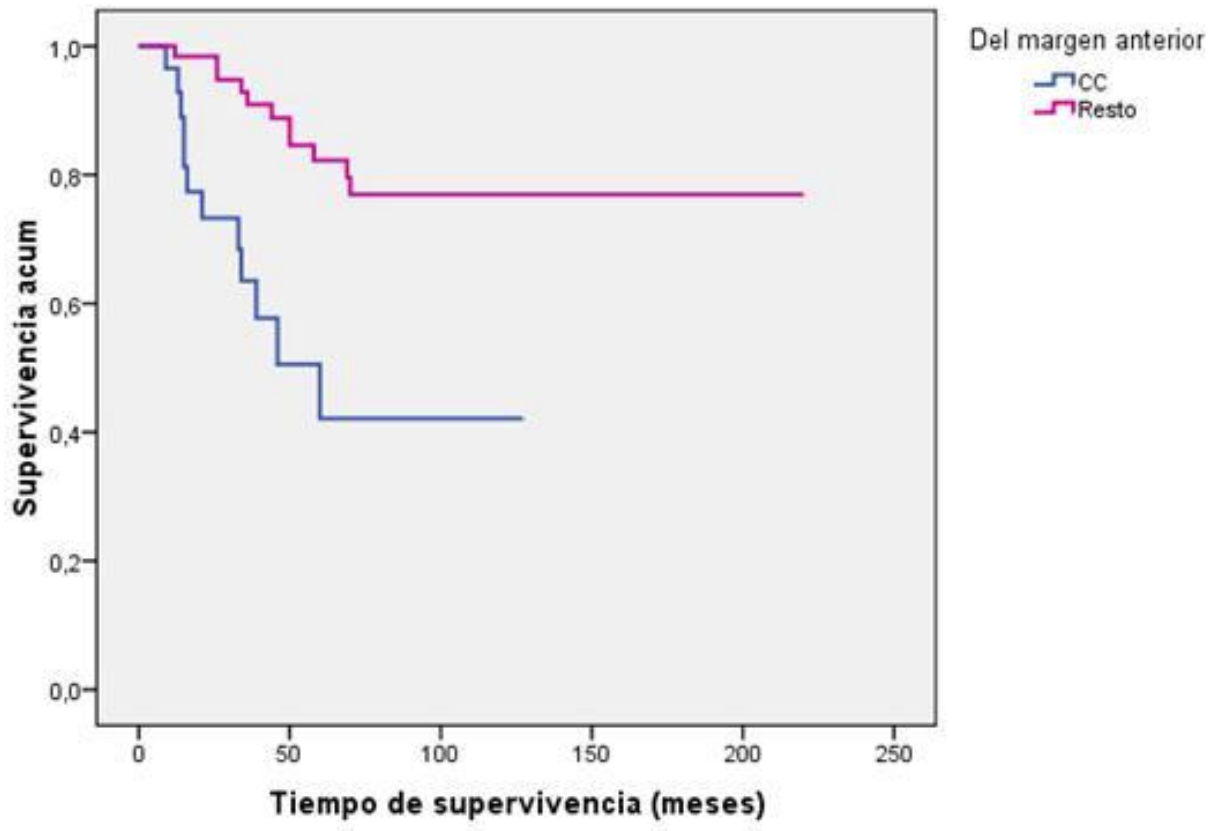

\begin{tabular}{|c|c|c|c|c|c|c|c|c|c|c|c|c|c|c|c|c|c|c|c|c|}
\hline \multicolumn{2}{|c|}{ Año } & $\begin{array}{c}\mathrm{Al} \\
\text { inicio }\end{array}$ & 1 & 2 & 3 & 4 & 5 & 6 & 7 & 8 & 9 & 10 & 11 & 12 & 13 & 14 & 15 & 16 & 17 & 18 \\
\hline \multirow{2}{*}{ CC } & $\mathrm{N}$ & 30 & 27 & 18 & 13 & 6 & 6 & 4 & 3 & 1 & 1 & 1 & & & & & & & & \\
\hline & ps & 97 & 74 & 65 & 53 & 53 & 43 & 43 & 43 & 43 & 43 & 43 & & & & & & & & \\
\hline \multirow{2}{*}{ Resto } & $\mathrm{N}$ & 70 & 63 & 56 & 48 & 42 & 34 & 29 & 24 & 22 & 14 & 13 & 13 & 13 & 11 & 9 & 4 & 4 & 1 & 1 \\
\hline & ps & 1 & 96 & 92 & 88 & 82 & 77 & 77 & 77 & 77 & 77 & 77 & 77 & 77 & 77 & 77 & 77 & 77 & 77 & 77 \\
\hline
\end{tabular}

Gráfico 24.Localización tumoral

\begin{tabular}{|c|c|c|c|}
\hline \multicolumn{2}{|c|}{$\begin{array}{c}\text { Tabla 50. Localización } \\
\text { tumoral }\end{array}$} & \multicolumn{2}{|c|}{ IC(95\%) } \\
\hline Localización & Media & Inferior & Superior \\
\hline $\mathrm{CC}$ & 71,344 & 49,316 & 93,371 \\
\hline Resto & 179,837 & 158,762 & 200,912 \\
\hline
\end{tabular}

Tabla 51. Localización Tumoral

\begin{tabular}{lcccc} 
Localización & p-valor & HR & \multicolumn{2}{c}{$95,0 \%$ IC para HR } \\
& & & Inferior & Superior \\
CC vs. resto & 0,001 & 4,2 & 1,8 & 9,7
\end{tabular}

p-valor $<0,001$ 
Atendiendo a la localización tumoral se observó una supervivencia media de 71,344 meses con IC al 95\% (49,316:93,371) para los pacientes localizados en cuerpo ciliar y de 179,837 meses para el resto de pacientes con un IC 95\% $(158,762: 200,912)$ con un pvalor $<0,001$.

La probabilidad de sobrevivir a los 5 años fue de $43 \%$ y $77 \%$ y a los 10 años de $43 \%$ y de $77 \%$ para el grupo localizado en cuerpo ciliar respecto al resto.

En la regresión de Cox ( $p$-valor<0,001), se obtiene un HR de 4,2 con un IC 95\% $(1,8: 9,7)$ lo que indica que los pacientes con tumores localizados en cuerpo ciliar tiene el 4,2 veces mayor riesgo de fallecer por melanoma que los pacientes con tumores en otras localizaciones. 


\subsection{SUPERVERVIVENCIA SEGUN TRATAMIENTOS}

\section{Funciones de supervivencia}

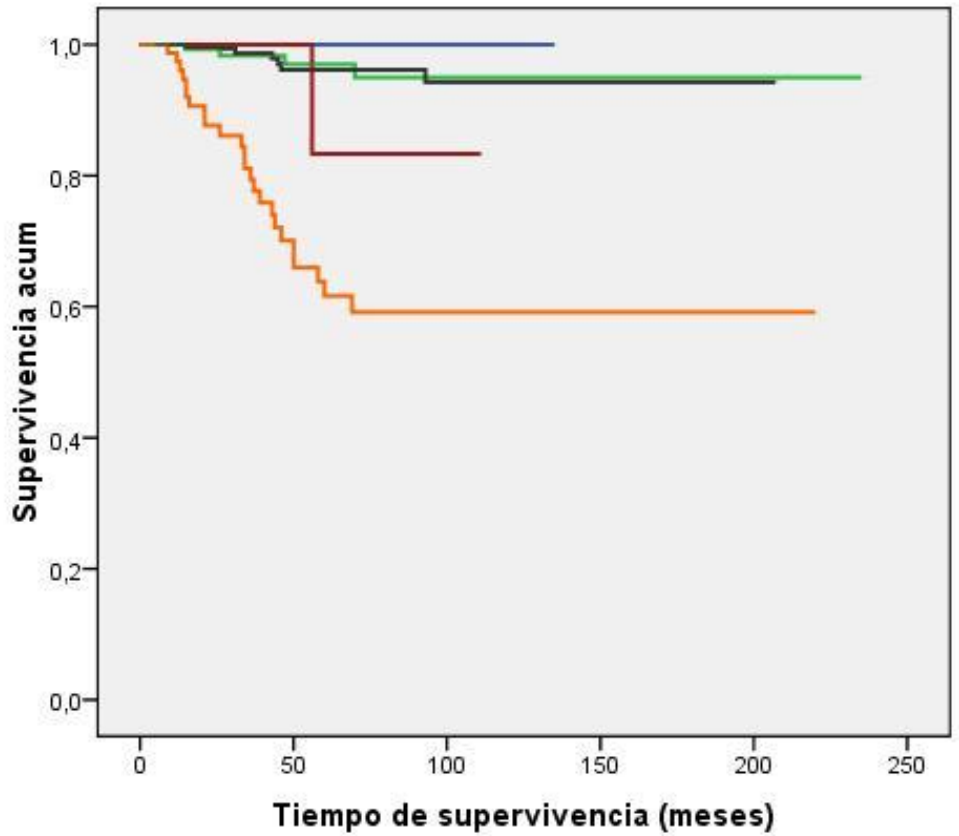

TRATAMIENTO

ITTT

MObservación

IRTE protones

IBraquiterapia

rEnucleación

\begin{tabular}{|c|c|c|c|c|c|c|c|c|c|c|c|c|c|c|c|c|c|c|c|c|c|}
\hline \multicolumn{2}{|c|}{ AÑOS } & Al inicio & 1 & 2 & 3 & 4 & 5 & 6 & 7 & 8 & 9 & 10 & 11 & 12 & 13 & 14 & 15 & 16 & 17 & 18 & 19 \\
\hline & $\mathbf{N}$ & 4 & 4 & 4 & 4 & 3 & 2 & 2 & 1 & 1 & 1 & 1 & 1 & & & & & & & & \\
\hline TाT & ps & 100 & 100 & 100 & 100 & 100 & 100 & 100 & 100 & 100 & 100 & 100 & 100 & & & & & & & & \\
\hline \multirow[b]{2}{*}{ Observ. } & $\mathbf{N}$ & 172 & 143 & 111 & 87 & 72 & 58 & 47 & 42 & 37 & 31 & 25 & 22 & 17 & 13 & 9 & 5 & 4 & 2 & 1 & 1 \\
\hline & ps & 100 & 99 & 98,2 & 97 & 97 & 95 & 95 & 95 & 95 & 95 & 95 & 95,2 & 95 & 95,2 & 95 & 95,2 & 95 & 95 & 95,2 & 95 \\
\hline \multirow[b]{2}{*}{ Proton } & $\mathbf{N}$ & 6 & 6 & 6 & 6 & 6 & 5 & 5 & 4 & 4 & 1 & & & & & & & & & & \\
\hline & ps & 100 & 100 & 100 & 100 & 83 & 83 & 83 & 83 & 83 & 83 & & & & & & & & & & \\
\hline \multirow[b]{2}{*}{$B Q$} & $\mathbf{N}$ & 203 & 183 & 150 & 132 & 110 & 98 & 75 & 62 & 47 & 36 & 23 & 14 & 11 & 5 & 3 & 1 & 1 & 1 & & \\
\hline & ps & 100 & 99 & 98,7 & 96 & 96 & 96 & 96 & 95 & 95 & 95 & 95 & 94,5 & 95 & 94,5 & 95 & 94,5 & 95 & 95 & & \\
\hline \multirow[b]{2}{*}{ Enucl. } & $\mathbf{N}$ & 86 & 75 & 58 & 48 & 34 & 29 & 24 & 20 & 17 & 12 & 11 & 10 & 10 & 9 & 8 & 3 & 3 & 1 & & \\
\hline & ps & 99 & 87 & 81 & 70 & 64 & 59 & 59 & 59 & 59 & 59 & 59 & 59 & 59 & 59 & 59 & 59 & 59 & 59 & & \\
\hline
\end{tabular}

Gráfico 25. Tratamientos.

Tabla 52. Tratamientos

\begin{tabular}{|cccc|}
\hline Tratamiento & Media & Inferior & Superior \\
\hline Observación & 225,61 & 216,26 & 234,95 \\
\hline RTE protones & 101,83 & 85,43 & 118,23 \\
\hline Braquiterapia & 198,33 & 191,38 & 205,27 \\
\hline Enucleación & 144,98 & 121,18 & 168,78 \\
\hline & p-valor<0,001 & \\
\hline
\end{tabular}

Tabla 53. Tratamientos

\begin{tabular}{cccccc} 
Tratamientos & p-valor & HR & \multicolumn{2}{c}{$95,0 \%$ IC para HR } \\
Inferior & Superior \\
\hline Observación (Ref) & 0 & & & \\
Braquiterapia & 0,944 & 1,046 & 0,295 & 3,709 \\
Enucleación & 0 & 11,632 & 4,035 & 33,527
\end{tabular}


La media de supervivencia para la variable de tratamientos se encuentra recogida en la tabla 52, así para la observación este resultado fue de 225,61 meses con un IC al 95\% $(216,26: 234,95)$, para el grupo de pacientes tratados con braquiterapia fue de 198,33 meses con un IC al 95\% (191,38:205,27) y para los pacientes enucleados fue de 144,98 meses con un IC al 95\% (121,18:168,78).Las diferencias obtenidas son estadísticamente significativas con un $p$-valor $<0,001$.

La probabilidad de supervivencia a los 5 años es del 95\%, 96\% y 58\% para los tratamientos de observación, braquiterapia y enucleación respectivamente.

En cuanto a la regresión de Cox, se tomó la observación como referencia ( $p$ valor $<0,001)$ y respecto a él se compararon el resto de tratamientos. El tratamiento de braquiterapia presentó un p-valor $=0,944$ y una HR de 1,046 con un IC al 95\% $(0,295: 3,709)$, lo que indica que no presenta diferencias con respecto a la observación en el fallecimiento por melanoma. El grupo de pacientes tratados con enucleación ( $p$ valor<0,001) presentó un HR de 11,632 con un IC al 95\% (4,035:33,527), lo que muestra un riesgo 11,6 veces superior a fallecer de melanoma uveal que los pacientes en observación. 


\subsection{EL MODELO DE REGRESIÓN MULTIVARIANTE:}

\begin{tabular}{|c|c|c|c|c|c|}
\hline \multicolumn{2}{|c|}{ Tabla 54. Multivariante Cox } & \multirow[b]{2}{*}{ p-valor. } & \multirow[b]{2}{*}{$\mathrm{HR}$} & \multicolumn{2}{|c|}{$95,0 \%$ IC para HR } \\
\hline & & & & Inferior & Superior \\
\hline & Hombre & 0,579 & 0,810 & 0,386 & 1,703 \\
\hline & agnóstico & 0,037 & 1,029 & 1,002 & 1,056 \\
\hline & ьо ciliar (SI/NO) & 0,006 & 2,885 & 1,362 & 6,108 \\
\hline Tam & (Grande/Mediano) & 0,003 & 3,142 & 1,491 & 6,624 \\
\hline \multirow{3}{*}{ 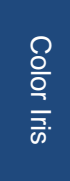 } & Marrón (Ref.) & 0,034 & & & \\
\hline & Verde-avellana & 0,555 & 1,295 & 0,549 & 3,056 \\
\hline & Azul-gris & 0,013 & 2,794 & 1,243 & 6,283 \\
\hline
\end{tabular}

Observando el modelo de regresión multivariante de Cox, ajustado por edad y sexo, podemos ver como presentarían un peor pronóstico pacientes con tumores grandes (HR $3,14)$, invasión del cuerpo ciliar (HR 2,88) y color de iris azul-gris (HR 2,79). 


\section{DISCUSIÓN}

En la actualidad no disponemos de datos en materia de supervivencia de pacientes españoles diagnosticados de melanoma uveal. Las series publicadas hasta el momento referentes al estudio de la supervivencia se basan en poblaciones estadounidenses o nórdicas, poblaciones muy diferentes a las nuestras por motivos raciales, de pigmentación y de latitud geográfica.

Estas diferencias fueron las principales causas para impulsar este estudio que ha mostrado diferencias epidemiológicas con respecto a una de las características más relacionadas con la aparición del melanoma, el color del iris, y una mayor supervivencia específica de la población española respecto a las series previamente publicadas en la literatura. La muestra estudiada tiene un predominio de mujeres con un color de iris oscuro, siendo más frecuente el color verde avellana. La mayoría se localizan en la coroides, siendo detectados tras dar síntomas visuales pero con tamaños medios, lo que permite la realización de tratamientos conservadores como la braquiterapia que es el más utilizado. Sin embargo, los factores pronósticos conocidos y estudiados en la muestra, han resultado similares a publicaciones previas (mayor tamaño e invasión de cuerpo ciliar) añadiendo el color azul del iris que había sido sugerido anteriormente de probable valor pronóstico, pero no demostrado como se observa en los resultados del presente estudio. 


\section{MÉTODO ESTADÍSTICO}

Se pueden emplear diferentes tipos estadísticos para el estudio de la supervivencia, el más conocido y usado es el método de Kaplan-Meier. La característica distintiva del análisis con este método es que la proporción acumulada que sobrevive se calcula para el tiempo de supervivencia individual de cada paciente y no se agrupan los tiempos de supervivencia en intervalos. Por esta razón es especialmente útil para estudios que utilizan un número pequeño de pacientes.

La validez de este método se basa en dos suposiciones:

- Las personas que se retiran del estudio tienen un destino parecido a las que quedan.

- El período de tiempo durante el cual una persona entra en el estudio no tiene efecto independiente en la respuesta.

Un problema fundamental en el estudio de la supervivencia de este tipo tumoral es que los estudios realizados hasta el momento se basan en su amplia mayoría en datos relativos a la supervivencia global, mortalidad global, y los que muestran datos al respecto de supervivencia causa-especifica, lo hacen utilizando diferentes métodos estadísticos, lo que complica la relación y comparación de los datos.

Los trabajos más relevantes en cuanto al tamaño muestral y seguimiento de los pacientes, que se han usado como referencia para este estudio, utilizan el método de Kaplan Meier, lo que se convirtió en otra de las razones para seleccionar este método de análisis.

Además, los factores pronósticos, no son independientes, y su estudio individual puede hacer que se le atribuyan un poder predictivo incorrecto. Es basándose en este problema por lo que Mc Lean, autor de los artículos más relevantes respecto a factores pronósticos, escribió un editorial en 1988 recomendando el uso de estudios multivariantes como la regresión de COX para analizar las variables pronósticas en materia de supervivencia. Además, ofrece valores de "Hazar Ratio" (HR) que nos orientan en cuanto de relevante es una variable en el pronóstico de la enfermedad a estudio. ${ }^{111}$ Esto permitirá un mejor análisis de datos en supervivencia, pudiendo así realizar una mejor comparación con los trabajos publicados hasta el momento.

- 99 - $\quad$ Estudio de la supervivencia en pacientes con Melanoma Uveal de una Unidad Referencial de Tumores Intraoculares. 2013 


\section{LIMITACIONES Y FORTALEZAS}

La principal fortaleza de este estudio es su seguimiento medio de 58,59 meses, aproximadamente cinco años (60 meses) de una serie de 480 pacientes diagnosticados y tratados por melanoma uveal, homogeneos en raza (caucásica no nórdica) y con un diseño prospectivo de recogida de datos que comienza en 1992. Este dato es tan relevante porque este estudio presenta una de las mayores series de pacientes con melanomas uveales publicadas en nuestro pais.

El seguimiento de los pacientes ha sido exahustivo, con pérdidas mínimas (por debajo del $1 \%$ ). Esto ha sido posible gracias a que en una publicación previa de este mismo grupo, en la que se analizó el perfil global de la muestra con datos de supervivencia global y especifica en 500 pacientes $^{34}$, observamos que los resultados podrian estar sesgados, tanto por los pacientes con tumores de iris ( mortalidad < $3 \%$ ) como por aquellos pacientes que no habian sido seguidos en nuestra unidad porque una vez confirmado el diagnóstico, se habian realizado el tratamiento en su ciudad de origen, hecho por el que han sido excluidos del estudio. Por lo tanto, ademas de ser una de las mayores series en poblacion no caucásica no nordica o norteamericana, se conoce la situación clínica de practicamente la totalidad de los pacientes al cierre del estudio.

El diagnóstico ha sido estandarizado y ajustado a los criterios establecidos por la comunidad científica internacional y representa el único estudio publicado hasta la fecha con casi 500 pacientes en España en materia de supervivencia, lo que hace que estos datos tengan un gran interés para el abordaje de los pacientes en nuestro medio, ya que hasta ahora, los pacientes estaban siendo informados con datos procedentes de poblaciones diferentes.

Una de las críticas que se puede realizar al estudio es la falta de demostración histopatologica del diagnostico del tumor, hecho poco habitual en oncologia general. En las series de melanomas uveales, tan solo en los pacientes sometidos a enucleación se obtiene la confirmación anatomopatológica, que como se ha descrito actualmente son menos de un tercio de los casos. Sin embargo el estudio mas riguroso desde el punto de vista científico y con mayor muestra y seguimiento de pacientes, lo hace de la misma forma porque previemente demostró que la precisión diagnóstica por expertos oncologos oculares es mayor del $99,5 \%{ }^{7}$. Este hecho ha sido reconocido por la sociedad Americana de Braquiterapia $^{6}$ que admite en sus protocolos el tratamiento de tumores con braquiterapia sin biopsia de confirmación diagnóstica previa. 


\section{CRITERIOS DE EXCLUSIÓN}

Los pacientes recogidos en la base de datos de esta unidad hasta diciembre de 2012 fueron 551, de los cuales se excluyeron 71 por diferentes causas: enucleación en centro de origen, segunda opinión, reciente diagnóstico y tumores de iris.

El haber excluido a las enucleaciones en centro de referencia puede hacer que nuestra muestra contenga un mayor porcentaje de tratamientos conservadores y por ello de tumores medianos/pequeños. Los pacientes enucleados corresponden en la mayor parte de los casos a tumores grandes y por ello de peor pronóstico. Pero este hecho no influye en el análisis de la supervivencia ya que la muestra de tumores grandesy/o enucleados con seguimiento que se analiza en el estudio es de un tamaño suficiente para que los datos sean valorables.

La exclusión de la muestra de tumores de iris se realizó debido a su comportamiento clínico diferente a los melanomas de coroides y cuerpo ciliar, con unas cifras de mortalidad a los 5 años muy bajas (inferior al 3\%), lo que hace que de manera habitual sean excluidos de los estudios de supervivencia. ${ }^{52}$ 


\section{PERFIL GENERAL DE LA MUESTRA}

\subsection{CARACTERÍSTICAS EPIDEMIOLÓGICAS:}

La raza caucásica de un país no nórdico o norteamericano representa prácticamente en la totalidad de los 480 casos que componen la muestra (tan solo 1 hispano de origen mejicano). No existen datos publicados en el momento actual que estudien la supervivencia de una población tan homogénea como la que presenta este trabajo. El estudio realizado por Virgili et al $^{112}$ para el análisis de la supervivencia de los pacientes europeos, recoge datos de países de Europa del norte y en menor medida de Europa del sur pero no la estudia según sus características raciales, siendo por tanto este trabajo el primero en estudiar este tipo de población.

En esta muestra, se observa una leve tendencia a la mayor incidencia en mujeres. Desde el punto de vista epidemiológico, la edad media de diagnóstico observada en la serie estudiada fue de 62,07 años; si tenemos es cuenta el sexo, se puede apreciar que los varones afectos son ligeramente más jóvenes que las mujeres, 61,59 y 62,53 años respectivamente. Datos muy similares a los publicados por Singh $(2011)^{113}$ en población americana donde la edad media era de 62 años. La predilección por el sexo femenino $(51.17 \%)$ detectada en este estudio, se ha podido observar también en el estudio recientemente publicado por Caminal et al ${ }^{114}$ y en la población israelí publicada por Péer ${ }^{115}$, pero contrasta con el predominio masculino de series norteamericana (Singh) ${ }^{113}$ en la cual la incidencia de género en varones fue del 4.9 IC 95\% (4.6-5.2) en contraposición a la incidencia en mujeres que fue de 3.7 IC 95\% (3.5-3.9). En la población estudiada por Virgili en una muestra de 6673 pacientes europeos ${ }^{116} 2896$ era varones, mostrando también un leve predominio de los varones sobre las mujeres.

El color del iris como posible factor de riesgo de desarrollo de melanoma ha sido estudiado en varios trabajos. En la serie estudiada se observa una mayor frecuencia en el grupo verde-avellana $(43,8 \%)$, seguido de marrón $(37,3 \%)$. Estos datos corroboran los previamente publicados por Muiños en el $2009{ }^{41}$ y contrastan con las series nórdicas y estadounidenses, donde el color azul es el color más prevalente como muestra el estudio de Regan ${ }^{117}$ en el cual de una muestra de 1162 pacientes, 553 presentaban color de iris azul o gris. Singh en el 2004 buscó la relación entre iris claros, exposición solar y aparición de melanoma sin encontrar una significación clara al respecto ${ }^{118}$. El hecho de que en la 
muestra del presente estudio el color de iris más relacionado con la aparición de melanoma uveal sea el verde/avellana (43,8\%), puede explicarse debido a la distinta distribución del color de los ojos en la población española, donde el porcentaje de ojos oscuros es bastante más elevado que en otras poblaciones previamente estudiadas, en las que la presencia de ojos claros en mucho más alta ${ }^{41}$.

\subsection{CARACTERÍSTICAS CLINICAS}

El $95 \%$ de los pacientes presentan tumores coroideos y la presencia de sintomatología visual como causa del diagnóstico supone aproximadamente el $60 \%$ de los casos, datos coherente con la distribución por tamaños en los que, entre el 50 y el $70 \%$ de los casos, dependiendo de la clasificación utilizada, (tablas15-17) fueron medianos/grandes, por lo tanto con presentación sintomática.

Damato et al ${ }^{119}$ en un estudio sobre población del Reino Unido en el que tratan de determinar la precocidad del diagnóstico y tratamiento de una serie de 304 pacientes en la que 244 (80\%) son diagnosticados cuando son medianos o grandes y por lo tanto sintomáticos. Esquelin y Kivela ${ }^{120}$ revisando 184 pacientes encuentran que el $87 \%$ de los pacientes debutaron con síntomas aunque la mayoría fueron de tamaño mediano. Estos autores atribuyen los resultados al retraso en el proceso de acceso a la unidad referencial donde se corrobora el diagnóstico y son tratados. Por lo tanto los resultados del presente estudio muestran que nuestros pacientes son diagnosticados en un momento de la evolución similar o incluso más precoz que en los trabajos comentados aunque hay que tener en cuenta que este dato puede estar sesgado por los pacientes excluidos.

Comparando la distribución de tamaños según la clasificación COMS con un estudio realizado en Israel sobre 558 pacientes ${ }^{115}$ encontramos una distribución similar a la nuestra con un $9 \%$ de melanomas pequeños, $64,5 \%$ de medianos y $17,9 \%$ de grandes (pérdida de $8,6 \%$ de datos), siendo nuestras cifras de $23 \%, 59,7 \%$ y $16,7 \%$ respectivamente.

En general se puede afirmar que sea cual sea la clasificación aplicada, los tumores pequeños y medianos representan aproximadamente el $75 \%$ de la muestra. A pesar de que la clasificación TNM es la más precisa, al contrario de lo que ocurre con el resto de los tumores, no es utilizada en la práctica diaria por su complejidad. En cambio, la clasificación estandarizada por tamaños aportada por el COMS es la más empleada en la práctica diaria por su comodidad, sencillez y la posibilidad de comparación de datos con los previamente publicados. En cambio, la más predictiva en cuanto a pronóstico de la enfermedad, y por 
ello la hemos incluido en el presente estudio, es la clasificación desarrollada por Mc Lean basada en el Diámetro Máximo Tumoral.

Respecto a la extensión el 3,6\% de los pacientes mostraron signos radiológicos de tumor extraocular y un 1,3\% signos de enfermedad sistémica. La extensión extraocular de los melanomas intraoculares es rara y la proporción varía desde el $2,5 \%$ al $28 \%$ dependiendo de los criterios utilizados para el diagnóstico: evidencia clínica (extensiones extraoculares anteriores o limitación de la motilidad ocular), técnicas de imagen o estudios histopatológicos. ${ }^{121}$ Los pacientes del presente estudio fueron en su mayor parte asintomáticos excepto 2 con extensiones orbitarias grandes que limitaron la motilidad o producían proptosis, y 3 con extensiones anteriores visibles en la exploración clínica; la mayoría fueron detectados y confirmados con técnicas de imagen en las que la resonancia magnética es más sensible que el TAC. Es un parámetro clínico muy importante ya que condiciona la selección del tratamiento y la técnica quirúrgica y es de reconocido valor pronóstico. Respecto a la extensión sistémica, no solo condiciona la realización del tratamiento sino que desgraciadamente no hay tratamiento eficaz.

\subsection{DISTRIBUCIÓN DE TRATAMIENTOS}

Analizando la distribución de los tratamientos primarios realizados (tabla18) se observa que tan sólo se realizó enucleación en 86 pacientes $(18,2 \%)$ incluidos en el estudio pero hay que tener en cuenta la infravaloración de este procedimiento en la muestra del estudio, debido a que en 34 de los pacientes excluidos se indicó este procedimiento pero fue realizado en su centro de origen.

La observación se realizó en 172 casos $(36,4 \%)$ de tumores de tamaño pequeño con dos o menos signos de actividad, o en pacientes con melanomas medianos o grandes que rechazaron el tratamiento. El estudio de la observación como alternativa terapéutica ha sido analizado recientemente por este mismo grupo de investigación, encontrando que es una alternativa para tumores pequeños inactivos sin signos de crecimiento, en los que menos del $5 \%$ crecen y son secundariamente tratados con braquiterapia (García Alvarez C La observación como alternativa terapéutica en los melanomas uveales. Tesis Doctoral, Universidad de Valladolid Mayo 2012).

Los tratamientos conservadores con braquiterapia epiescleral en su mayor parte, asociada o no a termoterapia transpupilar, y los pocos casos tratados con RTE con

- 104 - $\quad$ Estudio de la supervivencia en pacientes con Melanoma Uveal de una Unidad Referencial de Tumores Intraoculares. 2013 
protones o TTT suponen el $45,5 \%$ de la muestra consiguiendo el control local del tumor en el $97,67 \%$ de los casos ya que en el seguimiento sólo se encontraron 9 recidivas locales que fueron tratadas con enucleación de forma secundaria.

La escasez de casos tratados con RTE con protones se debe a que es una técnica no disponible en nuestro país, costosa tanto desde el punto de vista administrativo como económico y que se reserva a casos muy puntuales en los que el tamaño del tumor y/o la proximidad al nervio óptico junto con las condiciones visuales del ojo adelfo hacen prioritaria su indicación para conservar el globo ocular y la visión.

Los casos agrupados bajo el epígrafe de "otros tratamientos" son pacientes en los que se diagnosticaron metástasis sistémicas en el momento del diagnóstico y no se realizó tratamiento del tumor primario, y también se ha incluido el único caso de endoresección quirúrgica realizado en esta serie, y dos casos de exenteración orbitaria por presentarse con extensiones extraoculares orbitarias masivas.

Estos resultados siguen en la línea de los previamente publicados por este mismo grupo de investigación, que analizando 273 pacientes tratados en la unidad de tumores intraoculares entre 1992 y 2007, aproximadamente el 70\% fueron tratados con terapias conservadores enucleando de forma primaria tan solo a 80 , con una probabilidad de conservación del globo ocular a los 5 y 10 años del $88 \%$ y el $83 \%$ respectivamente. ${ }^{122}$

La comparación de estos datos con otros trabajos es complicada porque las series publicadas suelen clasificarse en función del tamaño u otras características clínicas, existiendo pocos trabajos de análisis consecutivos de pacientes; además hay que limitarse a las dos últimas décadas, ya que anteriormente, el tratamiento más difundido era la enucleación. Por otra parte, los tratamientos conservadores no tienen indicaciones absolutas; es decir, dependiendo de la tecnología disponible y las habilidades adquiridas un tumor de tamaño mediano puede ser tratado adecuadamente con RTE con protones, braquiterapia epiescleral, o resección quirúrgica mas radioterapia adyuvante.

En cuanto a la observación periódica, actualmente es un objeto de estudio ya que hay autores que proponen el tratamiento precoz de los tumores pequeños. Por lo tanto la selección del tratamiento es variable según los centros de referencia que se consulten. 
En la Tabla 55 se comparan los resultados del presente estudio con algunas series de diferentes centros de referencia en la que se observa en nuestro caso un mayor porcentaje de pacientes sometidos a observación, y el menor número de enucleaciones que probablemente sería muy parecido al resto de los centros si tenemos en cuenta los pacientes excluidos por realizarse el tratamiento en su centro de origen. También se puede observar la elevada proporción de pacientes tratados con RTE con protones en los que hay facilidades y disponibilidad para la realización de este tratamiento. Respecto a la resección quirúrgica del tumor, es una técnica muy compleja que requiere experiencia y se concentra aun en un número menor de centros.

Tabla 55: Comparación en la distribución de tratamientos.

\begin{tabular}{|c|c|c|c|c|c|c|c|}
\hline $\begin{array}{c}\text { AlonsoP } \\
\mathbf{2 0 1 3} \\
\text { CSUR } \\
\text { Valladolid }\end{array}$ & 480 & $<1 \%$ & $36,4 \%$ & $43,4 \%$ & $1,3 \%$ & $<1 \%$ & $18,2 \%$ \\
\hline $\begin{array}{c}\text { Frenkel } \\
\mathbf{2 0 0 9} \\
\text { Israel }\end{array}$ & 558 & $<1 \%$ & $4,5 \%$ & $74 \%$ & ---- & $2,5 \%$ & $17,9 \%$ \\
\hline $\begin{array}{c}\text { Damato } \\
\mathbf{2 0 0 4} \\
\text { Inglaterra }\end{array}$ & 1632 & $2,5 \%$ & --- & $31 \%$ & $16,7 \%$ & $14,7 \%$ & $35 \%$ \\
\hline $\begin{array}{c}\text { Singh } \\
\mathbf{2 0 1 1} \\
\text { USA }\end{array}$ & 4070 & ---- & ---- & $31,6 \%$ & $16,7 \%$ & $14,7 \%$ & $35 \%$ \\
\hline $\begin{array}{c}\text { Caminal } \\
\text { 2012 } \\
\text { CSUR.BCN }^{33}\end{array}$ & 155 & $1,9 \%$ & --- & $60,65 \%$ & $1,2 \%$ & $8,4 \%$ & $25,81 \%$ \\
\hline
\end{tabular}

\subsection{CARACTERÍSTICAS HISTOPATOLÓGICAS}

La histopatología ha jugado un papel crucial en el conocimiento de los melanomas de la uvea con una repercusión clínica muy importante ya que es a raíz de los trabajos 
procedentes del "Armed Forces Institute of Pathology" (L Zimmerman y I McLean) en las décadas de los 80 y 90 cuando se descubren las peculiaridades en la diseminación y enfermedad y el desarrollo de la enfermedad sistémica, y se comienzan a conocer factores pronósticos que determinan la probabilidad de que un paciente desarrolle metástasis. Estos factores son también recogidos en el protocolo de estudio de ojos enucleados del estudio multicéntrico americano de melanomas (COMS) junto con otras características que se han sugerido como de probable valor pronóstico ${ }^{2125}$.

Estas características histopatológicas son las que se han recogido prospectiva y sistemáticamente en la descripción y clasificación histopatológica de los ojos enucleados, para su posterior análisis (Anexo I).

Se han incluido todos los ojos enucleados como indicación primaria y también los enucleados secundariamente tras tratamiento conservador por recidiva local o por presentar complicaciones graves que condujeron a un ojo ciego y doloroso en el que la situación del tumor intraocular se hace difícil de evaluar (20 enucleaciones secundarias) . Se pensaron las ventajas e inconvenientes de la realización del análisis sin las enucleaciones secundarias, pero los factores pronósticos que se pretendían analizar en relación con la supervivencia, son independientes de si el tumor es primario o recidivado y se consideró adecuado el estudio de la muestra total.

Por lo tanto se analizaron los resultados histopatológicos con microscopía óptica de 106 ojos enucleados cuyos datos fueron recogidos en un protocolo prospectivo, con respecto a hallazgos de reconocido valor pronóstico. En el 30\% de los casos el tumor se originó en el cuerpo ciliar y en el $12,5 \%$ de los casos el borde anterior estuvo en cuerpo ciliar o por delante del mismo (tablas 24 y 25).

Para la clasificación del tipo celular (tabla 26) se utilizó la de Callender modificada por McLean y Zimmerman en 1983 desde el Registro de Patologia del instituto de las Fuerzas Armadas de Washington y que ha sido asumida internacionalmente para la interpretación de estos tumores intraoculares ${ }^{126}$. Esta clasificación simplifica las seis categorías previas en tres (fusiforme, epitelioide y mixto) en base a su valor pronóstico que demostraron posteriormente en un estudio de más de 4500 pacientes con un seguimiento mayor de 40 años (McLean 1995). Según esta clasificación, los resultados del presente estudio muestran que el $25 \%$ de los tumores fueron epitelioides, siendo los más frecuentes de tipo mixto $(39,1 \%)$.

\footnotetext{
- 107 - $\quad$ Estudio de la supervivencia en pacientes con Melanoma Uveal de una Unidad Referencial de Tumores Intraoculares. 2013
} 
Entre las características microscópicas que han sido sugeridas como de posible valor pronóstico merece la pena destacar (tabla 27) el bajo pocentaje de invasiones de venas vorticosas $(1,9 \%)$ y de nervio óptico $(3,7 \%)$.

Con respecto de la extensión extaescleral hay que tener en cuenta que más de un $84 \%$ de los casos tenían algún grado de invasión de la esclera. Este hecho se correlaciona clínicamente con la aparición de la característica ecográfica de "excavación coroidea" que está mostrando la presencia de células tumorales en esta estructura. También hay que tenerlo muy presente cuando se realizan tratamientos de estos tumores (por pequeños que sean) con sistemas de diferentes tipos de láseres transpupilares, que no llegan a ser efectivos en estas células intraesclerales. Sin embargo, tan sólo 7 pacientes mostraron signos de presumible residuo orbitario tumoral $(6,8 \%)$ que sistemáticamente fueron sometidos a radioterapia externa adyuvante en la cavidad orbitaria con el objetivo de prevenir posibles recidivas locales (pre o post enucleación). ${ }^{77} 46$

A pesar de que la actividad mitótica es un indicador pronóstico importante, no se ha analizado en este estudio debido a la falta de homogeneidad en la recogida de los datos; en los primeros años, se registró el número de mitosis en 10 campos de gran aumento según su aspecto morfológico; posteriormente se realizaron marcadores como PC10 y más tarde el Ki67 para objetivar un porcentaje de proliferación celular. Por esta razón, no tenemos datos homogéneos pero en un futuro es posible recuperar las preparaciones y realizar las técnicas adecuadas en cortes en parafina de forma homogénea en cuando a metodología de tinción e interpretación.

Comparando estos resultados con la publicación del COMS $^{125}$ que analiza 1527 ojos enucleados con melanoma uveal incluidos en el estudio de tumores de tamaño grande y mediano, con el mismo criterio utilizado en este estudio, se puede observar que nuestra precisión diagnóstica es del $100 \%$, ya que en todos los ojos enucleados se confirmó el diagnóstico de melanoma frente al 99,7\% del estudio COMS en el que en 5 globos oculares el diagnóstico final fue de metástasis de adenocarcinoma o hemangioma. Sin embargo nuestra proporción de tumores epitelioides es notablemente mayor (25\% frente a tan solo un 5\%). Estos hechos pueden explicarse porque el estudio COMS incluyó tumores de tamaño mediano (que randomizaron a enucleación o braquiterapia) en los que cabe alguna posibilidad de error diagnóstico, y que generalmente se asocian a tipos celulares menos agresivos.

\footnotetext{
- 108 - $\quad$ Estudio de la supervivencia en pacientes con Melanoma Uveal de una Unidad Referencial de Tumores Intraoculares. 2013
} 


\section{SUPERVIVENCIA Y FACTORES PRONÓSTICOS:}

\subsection{SUPERVIVENCIA GLOBAL Y ESPECÍFICA}

El objetivo prioritario del estudio ha sido analizar la supervivencia de los pacientes diagnosticados de melanoma uveal y compararla con la de estudios realizados en poblaciones diferentes a la nuestra, pero que emplean similares criterios de diagnóstico y clasificación clínica. Como ya se ha comentado anteriormente, es a partir del estudio metaanalítico de Diener-West et al que sistematiza la información hasta la fecha y aporta unas cifras de mortalidad a los 5 años que oscilan entre 16\% para tumores pequeños y $53 \%$ para tumores grandes, asumiéndose en general que el melanoma uveal es altamente agresivo. Estos datos son modificados por las publicaciones del COMS posteriormente que aporta cifras de mortalidad en tumores pequeños, medianos y grandes aproximadamente del $1 \%, 18-19 \%$ y $57-62 \%$ respectivamente.

En nuestro estudio de 480 pacientes con un seguimiento medio de 58,59 meses en los que 193 tienen un seguimiento igual o mayor de 5 años, se han registrado 78 muertes, con una supervivencia global media de 170,72 meses y una probabilidad de supervivencia a los 5 años del $80,6 \%$ y a los 10 años del $70 \%$.

Si analizamos la supervivencia específica, objeto del estudio, de los 78 fallecidos solo 39 murieron por metástasis del melanoma, presentando un tiempo medio de supervivencia de 207,4 meses, y una probabilidad de supervivencia a los 5 y 10 años del $87,7 \%$ y el $85,5 \%$ respectivamente. Los eventos ocurrieron durante los 7 primeros años del seguimiento, estabilizándose después la supervivencia hasta el fin del estudio, aunque este hecho puede estar influido por la disminución del número de pacientes seguidos a partir de los 10 años. Probablemente el incremento del periodo de seguimiento aportaría nuevos fallecimientos causados por la enfermedad metastásica.

Singh en $2011^{124}$, en un estudio realizado sobre 4070 pacientes seguidos entre el año 1973 al 2008 observó que la incidencia del melanoma uveal ha permanecido estable a lo largo de los años al igual que la supervivencia encontrando datos de supervivencia relativa los 5 años de $81,6 \%$. 


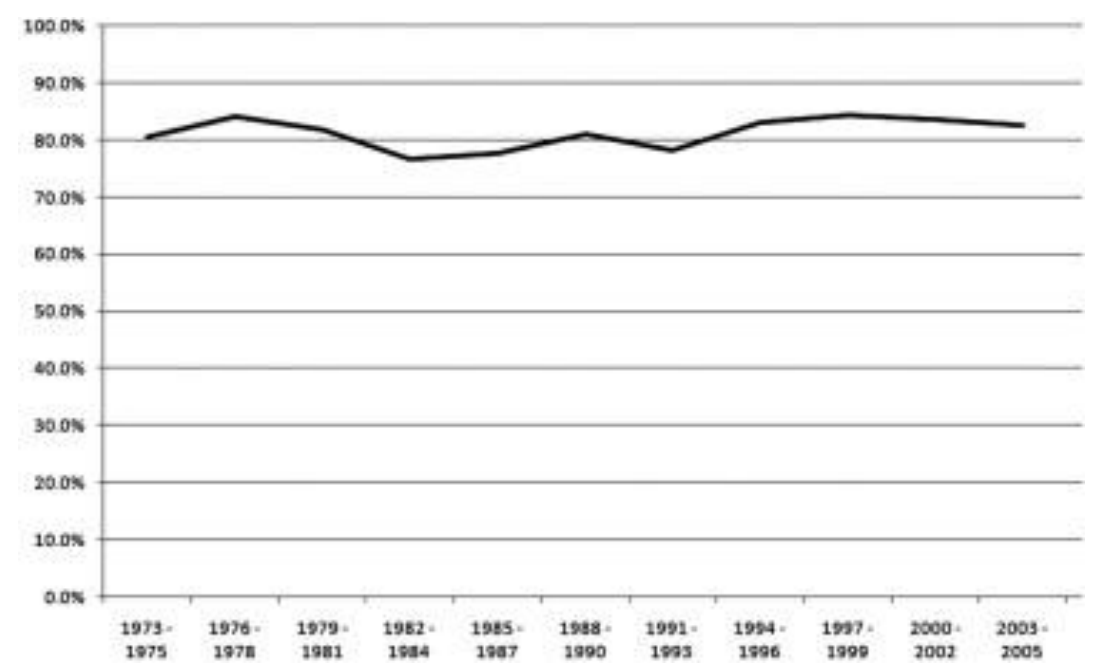

Singh 2011.Figure 3. Five-year relative survival rate with uveal melanoma, 1973-2006.

En uno de los pocos estudios realizados sobre población europea entre enero de 1983 hasta diciembre de $1994^{78}$, se reclutaron 5788 pacientes sobre los que se estudió la supervivencia de pacientes provenientes de 16 países europeos. En el caso de la muestra española, solo se encuentran casos aislados de Tarragona, Mallorca y navarra (38 en total de los 5788 pacientes incluidos en el estudio) por lo que los datos hallados en este trabajo no son representativos de nuestra población.

Los resultados hallados en cuanto a supervivencia muestran una supervivencia relativa de $63,3 \%$ para Europa del sur, cifras inferiores a las obtenidas por Singh en $2011^{124}$ y difícilmente comparable con los datos del presente trabajo por referirse a supervivencia relativa y no específica, datos de los que disponemos en este trabajo.

\begin{tabular}{|c|c|c|c|}
\hline Registry & $\begin{array}{l}\text { No. of } \\
\text { Cases }\end{array}$ & Registry & $\begin{array}{l}\text { No. of } \\
\text { Cases } \\
\end{array}$ \\
\hline United Kingdom & & Western European area & \\
\hline East Anglia & 149 & Bas Rhin & 57 \\
\hline Mersey & 146 & Calvados Gen & 32 \\
\hline Midlands & 208 & Eindhoven & 49 \\
\hline Oxford & 179 & Geneva & 21 \\
\hline Southwestern area & 537 & Latina & 13 \\
\hline Thames & 482 & Mallorca & 9 \\
\hline Trent & 370 & Navarra & 15 \\
\hline Wales & 200 & Parma & 22 \\
\hline Yorkshire & 275 & Ragusa & 5 \\
\hline Nordic area & & Saarland & 66 \\
\hline Denmark & 547 & Tarragona & 7 \\
\hline Finland & 350 & Turin & 33 \\
\hline Iceland & 14 & Tuscany & 47 \\
\hline Norway & 442 & Varese & 35 \\
\hline \multirow[t]{4}{*}{ Sweden } & 808 & Eastern European area & \\
\hline & & $\begin{array}{l}\text { Cracow } \\
\text { Estonia }\end{array}$ & $\begin{array}{r}51 \\
125\end{array}$ \\
\hline & & Slovakia & 345 \\
\hline & & Slovenia & 149 \\
\hline
\end{tabular}

\begin{tabular}{|c|c|c|}
\hline Variable & $\begin{array}{l}\text { No. of } \\
\text { Cases }\end{array}$ & $\begin{array}{l}\text { 5-Year Relative } \\
\text { Survival, \% } \\
\text { (95\% Confidence } \\
\text { Interval) }\end{array}$ \\
\hline Overall & 5788 & $68.9(67.4-70.4)$ \\
\hline \multicolumn{3}{|l|}{ Age, y } \\
\hline $15-54$ & 1681 & $79.0(77.0-81.1)$ \\
\hline $55-74$ & 2954 & $65.2(63.2-67.3)$ \\
\hline$\geq 75$ & 1153 & $58.8(54.1-63.4)$ \\
\hline \multicolumn{3}{|l|}{ Sex } \\
\hline Female & 2892 & $69.3(67.2-71.4)$ \\
\hline Male & 2896 & $68.5(66.3-70.7)$ \\
\hline \multicolumn{3}{|l|}{ Study period } \\
\hline 1983-1985 & 1384 & $69.1(66.0-72.2)$ \\
\hline 1986-1988 & 1455 & $69.2(66.2-72.2)$ \\
\hline 1989-1991 & 1486 & $68.2(65.2-71.2)$ \\
\hline 1992-1994 & 1463 & $69.1(66.0-72.1)$ \\
\hline \multicolumn{3}{|l|}{ Geographic region } \\
\hline United Kingdom & 2546 & $70.5(68.2-72.8)$ \\
\hline Nordic area & 2161 & $69.2(66.7-71.7)$ \\
\hline Western European area & 411 & $63.3(57.7-69.0)$ \\
\hline Eastern European area & 670 & $65.4(60.9-69.8)$ \\
\hline
\end{tabular}

Virgili et al. Table 1 y Table 2.Survival in patients with úveal melanoma in Europe.

\footnotetext{
$-110-$ Estudio de la supervivencia en pacientes con Melanoma Uveal de una Unidad Referencial de Tumores Intraoculares. 2013
} 
El estudio realizado por Pe'er et al $^{115}$ sobre 558 pacientes israelíes reclutados entre 1988 y 2007 muestra las características del melanoma uveal en este país. En cuanto al estudio del impacto de la enfermedad en la supervivencia del paciente encontramos datos de mortalidad relativa a los cinco años del $11,4 \%$, que son superiores a los obtenidos por Singh en $2011^{124}$ o por Virgili $2008^{78}$ y están más encaminados al aumento de supervivencia obtenido en este trabajo.

El trabajo recientemente publicado por Caminal et $\mathrm{al}^{33}$ sobre una serie de 155 pacientes, muestra unos datos referentes a supervivencia relativa a los cinco años del $90 \%$. Al igual que ocurre con el trabajo Israelí, obtienen una supervivencia superior a la obtenida en trabajos realizados sobre población de paises nórdicos o de EEUU. Estos datos van más acorde con los datos obtenidos en el presente trabajo aunque no puedan ser comparados por ser unos datos referentes a supervivencia específica y otros a supervivencia relativa.

En resumen, los datos de supervivencia específica obtenida en este trabajo muestran cifras superiores a los datos obtenidos en trabajos previamente publicados sobre población nórdica $^{112}$ o estadounidense ${ }^{124}$. En cambio, estos datos van más encaminados a los obtenidos por Pe'er et al o Caminal et al, mostrando cifras de supervivencia superiores aunque no comparables con los datos del presente estudio.

\subsection{SUPERVIVENCIA ESPECÍFICA SEGÚN SEXO, EDAD Y COLOR DEL IRIS}

Siendo estadísticamente significativo, la mujer con $91,65 \%$ presenta mejor supervivencia que el hombre que sólo alcanza el $83,64 \%$. Este hecho no se ha visto reflejado en ningún otro trabajo, siendo publicado recientemente por Caminal et $\mathrm{al}^{33}$ uno sobre 155 pacientes españoles en el cual también predominaban las mujeres pero la supervivencia era peor en estas.

Se ha publicado recientemente un estudio realizado por Damato ${ }^{28}$ sobre 3380 pacientes diagnosticados de melanoma de úvea de los cuales 1685 eran mujeres y 1695 eran hombres. El estudio concluyó que los melanomas suelen ser de mayor tamaño en hombres y más posteriores en las mujeres lo que puede influir en el peor pronóstico del las pacientes.

$\begin{array}{ll}\text { - } 111 \text { - } & \text { Estudio de la supervivencia en pacientes con Melanoma Uveal de una Unidad Referencial de Tumores Intraoculares. } \\ 2013\end{array}$ 
Acorde con el estudio realizado por Caminal, Graell et al en un estudio retrospectivo realizado sobre 303 pacientes diagnosticados de melanoma de úvea observaron mayor supervivencia de los hombres respecto a las mujeres en pacientes mayores de $50 a_{n}{ }^{29}$.

Ninguno de los estudios analizados muestran una supervivencia mayor para la mujer como hemos hallado en este trabajo, hecho que puede ser debido a la mayor proporción de mujeres en la muestra que puede estar relacionado con una mayor asistencia al médico por parte de este subgrupo de la población, lo que conllevaría un diagnóstico más temprano y por ello un mejor pronóstico de la enfermedad.

La edad es un factor que se ha sugerido que puede marcar diferencias con respecto al pronóstico del paciente, siendo los pacientes jóvenes los que presentan un mejor pronóstico. ${ }^{127}$

En el estudio se seleccióna un corte de edad que agrupara los pacientes más jóvenes que supuestamente podrían tener un mejor pronóstico a corto plazo, y que nos permitiera comparar con trabajos previos. Los resultados muestran una supervivencia a los cinco años del $90,99 \%$ en el grupo de pacientes menores de 50 años y de $86,65 \%$ en los mayores de 50 años. Aunque parece que efectivamente durante los primeros 5 años la supervivencia es mayor en el grupo de menores de 50 años, esta se iguala a partir del $7^{\circ}$ año.

McLean ${ }^{2}$, en su trabajo publicado en 1995, en el cual revisó 4518 pacientes estratificados en mayores de 55 años y menores de 55 años, no encontró diferencias significativas tras 40 años de seguimiento en la supervivencia de estos pacientes.

Graell y Caminal (2007) en uno de los escasos estudios en el que enrolaron a 303 pacientes diagnosticados y tratados de melanoma uveal, observaron que la media de edad de los pacientes fue de 60,09 años. La supervivencia en los pacientes menores de 50 años a los 2,5 y los 10 años de seguimiento fue de $91,41 \%, 81,83 \%$ y $61,45 \%$ respectivamente y la supervivencia de los pacientes mayores de 50 años fue del $90.86 \%, 73,18 \%$ y $58,28 \%$ no encontrando diferencias significativas entre esos grupos de $\operatorname{edad}^{29}$, al igual que los datos encontrados en el presente trabajo. 
En cambio, Shields et al, han publicado recientemente un trabajo realizado sobre 8033 pacientes diagnosticados de melanoma uveal y los han estratificado en tres grupos: 106 jóvenes (<20años), 4287 adultos (21-60 años) y 3640 ancianos (>60 años). En su estudio ha concluido que los jóvenes tienen una alta proporción de tumores de iris, los jóvenes y adultos tienen tumores con menor diámetro basal y menor número de metástasis y fallecimientos ${ }^{127}$

Los motivos por los que Shields ha encontrado diferencias en la supervivencia según la edad a diferencia de lo ocurrido en nuestro trabajo o el de Graell et al o Mc Lean, puede ser debido a varios factores. Por un lados las características raciales y geográficas de la muestra y por otro lado las posibles debilidades del estudio de Shields como por ejemplo que la muestra de ancianos es superior a la de adultos y mucho mayor que la de jóvenes.

En cuanto al estudio del color del iris, al estudiar la supervivencia de la muestra se observa una supervivencia menor para el color azul-gris que para el color oscuro de iris. La supervivencia a los cinco años es de $75,62 \%$ en el caso de los pacientes con color de iris azul-gris en comparación con la supervivencia del $91,46 \%$ a los 5 años que muestran los pacientes con color de iris verde avellana. Estos datos hablarían a favor de lo anteriormente publicado por Singh ${ }^{21118}$, el cual postuló que el color de iris azul es un factor pronóstico desfavorable para el melanoma de úvea.

Regan et al $^{117}$ en un estudio realizado sobre 1162 pacientes reclutados entre $1984 \mathrm{y}$ 1996 muestra un porcentaje de iris color azul-gris del 48\%. Este subgrupo a su vez presenta un HR de 1,9, lo que indica un riesgo casi dos veces superior de fallecer que los pacientes con iris de color oscuro. Este dato es muy similar al obtenido en este trabajo en el cual el HR es de 2,2 y certifica el color de iris como un factor de riesgo importante en los pacientes afectos de melanoma de úvea. 


\subsection{SUPERVIVENCIA ESPECÍFICA SEGÚN TAMAÑO TUMORAL}

El tamaño tumoral es el factor pronóstico principal en materia de supervivencia, estando reflejado en todos los estudios que a continuación se detallan que a mayor tamaño tumoral peor supervivencia media se encuentra.

Existen varias clasificaciones que atienden al tamaño tumoral, la clasificación TNM, la clasificación COMS y la clasificación según el Diámetro Máximo Tumoral. La más empleada por ser la más simple y estandarizada es la clasificación COMS, que divide a los tumores en pequeños, medianos y grandes. Sea cual sea la clasificación utilizada, todas muestran unas cifras de supervivencia menor cuanto mayor es el tumor. Así, los datos de supervivencia a los cinco años de los tumores pequeños, medianos y grandes son del $100 \%, 91,2 \%$ y $64 \%$ respectivamente.

McLean et al (1995) desde el Registro de Patología ocular del instituto de las Fuerzas Armadas de Washington, estudian durante más de 30 años la supervivencia de pacientes enucleados con respecto a características histopatológicas publicando estudios sobre más de 4000 pacientes, donde el tamaño tumoral es uno de los factores pronósticos más importante. De tal forma se obtienen datos de supervivencia del $78 \%$ en tumores pequeños (diámetro basal igual o menor a $10 \mathrm{~mm}$ o altura menor o igual a $3 \mathrm{~mm}$ ), mientras que en tumores medianos (diámetro basal entre 11 y $15 \mathrm{~mm}$ y altura entre 3 y $10 \mathrm{~mm}$ ) es del $55 \%$ y en tumores grandes (diámetro basal mayor o igual a $15 \mathrm{~mm}$ y altura mayor o igual a $10 \mathrm{~mm}$ ) es del $30 \%$. ${ }^{95}$

El artículo de Kujala, Mäkitie y Kivelä de Finlandia es relevante en el campo de la supervivencia del melanoma de coroides ya que no solo estudia la supervivencia relativa sino que también muestra el pronóstico de la enfermedad a largo plazo. ${ }^{98}$ En este estudio se observa la correlación de la supervivencia con el tamaño tumoral encontrando supervivencias a los 25 años de tratamiento de aproximadamente $18 \%, 52 \%$ y $59 \%$ para los tumores grandes, medianos y pequeños, respectivamente.

Basándose en la relevancia del tamaño tumoral en el impacto en la supervivencia, el COMS realizó varios estudios estratificando los pacientes según su tamaño tumoral: 
a) Tumores Pequeños:

Se realizó el seguimiento durante 14 años de 204 pacientes diagnosticados de melanoma de úvea de pequeño tamaño. La mortalidad global a los 5 años fue de $6 \%$ (27 fallecidos) y del $1 \%$ en mortalidad específica.

Este estudio llego a la conclusión de que la baja mortalidad de los tumores pequeños recomienda un tratamiento observacional en este tamaño tumoral ${ }^{75}$.

b) Tumores medianos:

En este estudio se analizó de nuevo la supervivencia global y específica de 1317 pacientes diagnosticados de melanoma de coroides de tamaño medio y tratados con enucleación o braquiterapia epiescleral.

El estudio no reveló diferencias entre la supervivencia obtenida según el tratamiento empleado. Así los datos obtenidos de la mortalidad global a los 5 años de seguimiento en el grupo de pacientes tratado con enucleación fueron de 19\% y de $18 \%$ para el grupo tratado con braquiterapia. En cuanto al estudio de la mortalidad específica los datos una vez más fueros similares para ambos grupos, siendo del $11 \%$ para los pacientes enucleados y del $8 \%$ para los pacientes tratados con braqutierapia. ${ }^{128} 129$

c) Tumores Grandes:

Para el estudio de la mortalidad en tumores grandes se llevó a cabo un estudio randomizado sobre 1003 pacientes diagnosticados de melanoma de úvea de tamaño grande que fueron sometidos a enucleación sola o precedida de Radioterapia.

La supervivencia obtenida a los cinco años fue de $72 \%$ para los pacientes únicamente sometidos a enucleación y de $74 \%$ para los pacientes que fueron tratados con Radioterapia previa. ${ }^{77}$

En 2004, el COMS realizo un nuevo estudio para analizar la supervivencia sobre esos 1003 pacientes estudiados previamente. Diez años después del estudio previo habían fallecido 576 pacientes, un $61 \%$ de ambos brazos de tratamiento. La mortalidad con confirmación histopatológica causada por enfermedad metastásica fue del $45 \%$ en el brazo de RT previa y de $40 \%$ en el de enucleación sola. ${ }^{130}$

Si comparamos todos los estudios arriba detallados, con los datos obtenidos en el presente trabajo podemos concluir que:

Si se compara con los datos obtenidos por COMS para cada tamaño, en el caso de los tumores pequeños, el COMS № $4^{75}$ obtiene una mortalidad global del $6 \%$ y una

- 115 - $\quad$ Estudio de la supervivencia en pacientes con Melanoma Uveal de una Unidad Referencial de Tumores Intraoculares. 2013 
mortalidad específica del $1 \%$. Estos datos son muy diferentes a la muestra estudiada en este trabajo ya que la supervivencia es del $100 \%$ por no fallecer durante todo el seguimiento ningún paciente con tumor pequeño. En el caso de los tumores medianos se realizaron dos estudios, el COMS №18 $8^{128}$ y el COMS №16 ${ }^{129}$, ambos demostraron datos de mortalidad entre $8-11 \%$, datos similares a los obtenidos en nuestro estudio.

En el caso de los tumores grandes, el COMS №10 ${ }^{77}$ mostró datos de supervivencia de $72 \%$, levemente superiores a las obtenidas en nuestra muestra, esto puede estar debido al escaso número de tumores grandes de los que disponemos en nuestro estudio.

\subsection{SUPERVIVENCIA ESPECÍFICA SEGÚN OTRAS CARACTEÍRSTICAS CLINICAS: INVASION DE CUERPO CILIAR, LOCALIZACIÓN YUXTAPAPILAR, EXTENSIÓN EXTRAOCULAR}

La invasión de cuerpo ciliar muestra una probabilidad de sobrevivir a los cinco años del $58 \%$ respecto a la probabilidad que presenta la muestra de pacientes que no presentan esta infiltración que es del 92\%.

Esta diferencia en la supervivencia obtenida en el presente estudio ya la explicó Gragoudas et al ${ }^{68}$ en su trabajo, en el cual postuló la invasión del cuerpo ciliar con un factor pronostico importante de diseminación a distancia tras estudiar a 510 pacientes seguidos desde 1975 a 1984.

Podemos concluir que la invasión del cuerpo ciliar es un factor pronóstico desfavorable y los datos obtenidos en este trabajo están acorde con los datos previamente publicados.

La extensión extraocular en un factor pronóstico estudiado por Sahammas et $\mathrm{al}^{44}$ que lo postulan como un factor de agresividad e indicador de progresión tumoral. En nuestra muestra, los pacientes con extensión extraocular tienen una probabilidad de supervivencia a los cinco años de $65,07 \%$ comparada con el $88,81 \%$ de la muestra que no la presenta.

La localización yuxtapapilar es un factor pronóstico importante ya que predice la invasión del nervio óptico con la clínica que ello conlleva en cuanto a disminución de visión y de las cifras de supervivencia. Los datos de supervivencia específica a los cinco años es de $88,76 \%$ y de $84,24 \%$ para los pacientes con y sin localización yuxtapapilar respectivamente. 
De los trabajos realizados hasta el momento el más importante es el realizado en Dinamarca sobre 157 pacientes entre los años 1942-2001 ${ }^{102}$, que estudian este factor pronóstico pero no encuentran repercusión alguna en el análisis multivariante. Estos datos son similares a los obtenidos en el presente trabajo, no siendo ni estadísticamente significativo ni mostrando una disminución de la supervivencia específica.

\subsection{SUPERVIVENCIA ESPECÍFICA SEGÚN CARACTERÍSTICAS HISTOPATOLOGICAS: TAMAÑO, TIPO CELULAR, LOCALIZACIÓN EN CUERPO CILIAR}

Las características histopatológicas analizadas como de valor pronóstico: tamaño, tipo celular, y localización del margen anterior son claramente significativas y acorde con la literatura publicada desde los años 70 . En este sentido no hay variaciones y desde los primeros trabajos de Jensen ${ }^{30}$ y Zimmerman ${ }^{20}$ los tumores grandes de tipo epitelioide y con borde anterior en o por delante del cuerpo ciliar tienen un pronóstico drásticamente peor que el resto.

Con los datos de la población estudiada respecto al tamaño, los pacientes con melanomas grandes (diámetro máximo $>16 \mathrm{~mm}$ ) tienen una probabilidad de supervivencia del $28,9 \%$ frente al $80 \%$ de los tumores pequeños (diámetro máximo $<10 \mathrm{~mm}$ ) presentando los primeros un riesgo 5,7 veces superior de fallecer a causa del melanoma uveal. Respecto al tipo celular, los tumores de tipo epitelioide presentan una supervivencia a los 5 años del $43 \%$ frente al $72 \%$ de los de otros tipos, con un riesgo de fallecer a causa del melanoma 2,9 veces mayor. En cuanto a la afectación del cuerpo ciliar, la supervivencia a los 5 años de los que alcanzan esta parte de la uvea es del $43 \%$ frente al $77 \%$ de los que su borde anterior se encuentra por detrás de la ora serrata, con un riesgo 4,2 veces mayor de desarrollar enfermedad sistémica.

Numerosos estudios posteriores a Jensen y Zimmerman han demostrado el indudable valor pronóstico del tamaño grande, el tipo celular epitelioide y la invasión del cuerpo ciliar demostrados histológicamente asociados a una pobre supervivencia del paciente ${ }^{13195}$ como se puede observar en los gráficos adjuntos. Estos factores no son independientes y una explicación para esta asociación es que los tumores grandes son de larga evolución, tienen más probabilidades de alcanzar el cuerpo ciliar y sufrir una transformación celular, por lo tanto más capacidad de desarrollar metástasis y diseminarse. Además se ha puesto de manifiesto la relación de estos factores "clásicos" con la 
existencia de alteraciones en los cromosomas 6 y 8 , y el perfil molecular Clase $2{ }^{26}$ por lo que en un futuro próximo se está proponiendo la realización de biopsias incluso a los pacientes tratados de forma conservadora para poder realizar con más precisión y de forma personalizada el estudio pronóstico del paciente.

\subsection{SUPERVIVENCIA ESPECÍFICA SEGÚN TRATAMIENTOS}

Se han realizado múltiples trabajos en los últimos años estudiando el impacto de los diversos tratamientos sobre la supervivencia del paciente diagnosticado de melanoma uveal. Todos ellos han concluido que no hay diferencia en materia de supervivencia sea cual sea el tratamiento empleado.

Basándose en la hipótesis establecida por Zimmerman, explicada con anterioridad en este texto, la Collaborative Ocular melanoma Study (COMS) realizó un estudio de 1003 pacientes comparando la supervivencia a 5 años en pacientes enucleados vs tratados con RTE neoadyuvante para evitar el pico de mortalidad a los dos años posteriores a la intervención quirúrgica. Se alcanzaron unas cifras de supervivencia mayor para el grupo de pacientes tratados con RT previa. (57\% vs $62 \%$ ) Se observaron diferencias significativas en la repartición de factores pronósticos entre los dos grupos, sobre todo de edad y diámetro tumoral. ${ }^{77}$ Una vez ajustados estos parámetros la supervivencia a 5 años resultó del $72 \%$ en pacientes tratados solo con enucleación y del $74 \%$ en pacientes que recibieron RTE previa, no siendo estadísticamente significativos. ${ }^{130}$

Se deduce de este estudio la importancia de la homogeneidad entre grupos para la correcta interpretación de los resultados.

En 1998 Augsburger et al $^{132}$ desarrollan un estudio retrospectivo de 237 pacientes, 140 de ellos tratados con enucleación y 97 tratados con braquiterapia, encontrándose mayor mortalidad a los 15 años en el grupo de pacientes enucleados. Sin embargo, estas diferencias se deben a los factores pronósticos asociados a cada grupo ya que eliminando estos factores de confusión se concluyó que la supervivencia a 15 años fue similar en ambos grupos de tratamiento.

Posteriormente, el COMS, intentando evitar la diferencia entre los dos brazos de estudio, llevo a cabo un estudio comparativo de 650 pacientes con melanoma de coroides de 2,5 a $10 \mathrm{~mm}$ de altura y menores de $16 \mathrm{~mm}$ de diámetro. Se comparó la supervivencia de dos brazos de tratamiento: enucleación Vs Braquiterapia epiescleral. Se observó un riesgo

- 118 - Estudio de la supervivencia en pacientes con Melanoma Uveal de una Unidad Referencial de Tumores Intraoculares. 2013 
de fallo de tratamiento a los 5 años del 10,3\% (requiriendo enucleación) y una vez más no se encontraron diferencias significativas en la supervivencia entre ambos tratamientos a excepción del beneficio de la conservación del globo ocular en la braquiterapia. ${ }^{31}$

Años después se realizó el mismo estudio pero analizando la supervivencia a 12 años. Es trabajo concluyo, al igual que en su estudio a los 5 años de seguimiento, que no se objetivaba ninguna diferencia en la supervivencia estudiada basada en el tratamiento seleccionado. ${ }^{76}$

En cuanto a estudios similares realizados en la población española se encuentran uno realizado en Cataluña ${ }^{133}$ (Caminal et al) y otro realizado en nuestro centro ${ }^{122}$ que arrojan los mismos datos que los publicados hasta el momento.

En cambio los datos hallados en este estudio, tienen una complicada interpretación. Los datos de supervivencia a los cinco años son de 100\% para los pacientes sometidos a TTT, 95\% para los pacientes tratados con observación, $83 \%$ para los pacientes tratados con protones, $96 \%$ para los pacientes sometidos a braquiterapia y del $59 \%$ para los pacientes enucleados.

Los datos obtenidos no son similares sea cual sea el tratamiento llevado a cabo como mostraban los trabajos arriba detallados ya que en el centro en el que se lleva a cabo este estudio los tumores pequeños se tratan con técnicas conservadoras y los tumores grandes, recidivas o complicaciones, se tratan con enucleación. Siendo esta última la que peores cifras de supervivencia muestra por esta causa.

Los pacientes tratados con Protones, por ser un número tan escaso, no son representativos, y muestran una supervivencia del 100\% al no haber fallecido ninguno durante el seguimiento.

La braquiterapia es la terapéutica más empleada, con unas cifras de supervivencia a los cinco años del $96 \%$, datos similares a los obtenidos en los estudios del COMS arriba detallados. 


\subsection{MODELO REGRESIÓN DE COX MULTIVARIANTE}

En el modelo multivariante de COX, ajustado por edad y sexo, se encontró peor pronóstico para los pacientes con tumores grandes, invasión del cuerpo ciliar y con color de iris azul-gris.

Este análisis ayuda a realizar un pronóstico más adecuado de estos pacientes teniendo en cuenta todos los factores clínicos e histopatológico de los que disponemos siendo todos ellos ajustados por la edad y el sexo de la muestra.

Siguiendo esta línea de trabajo un grupo de Liverpool ${ }^{134}$ ha creado una página web en la cual tras introducir los datos del paciente: edad, sexo y tamaño tumoral; se muestran los datos pronósticos teniendo en cuenta los datos obtenidos en los trabajos realizados y publicados hasta el momento en población estadounidense.

El presente trabajo nos ayudara a disponer de datos pronósticos aplicables a nuestra población, que posee características raciales y geográficas diferentes a las poblaciones previamente estudiadas y ello se ve reflejado en cifras de supervivencia específica superiores a las que se manejaban hasta el momento. 


\section{CONCLUSIONES}

- Con respecto a las características clínicas y epidemiológicas de la población estudiada se han encontrado diferencias con respecto a la raza; la muestra estudiada es homogénea compuesta por pacientes caucásicos no nórdicos en los cuales los melanomas son más frecuentes en mujeres y en iris de una tonalidad más oscura, (verde avellana) que los publicados en estudios previos. Se localizan en su amplia mayoría en la coroides, siendo detectados tras dar síntomas visuales pero en estadios poco avanzados, lo que permite tratamientos conservadores, siendo la braquiterapia el más empleado.

- La supervivencia específica es notablemente mejor que la global, probablemente asociado a la edad de diagnostico de esta neoplasia, y además superior a las previamente publicadas en series de países norteamericanos y nórdicos.

- Las mujeres presentan una supervivencia significativamente mayor que los hombres no encontrándose diferencias respecto a la edad mayor o menor de 50 años.

- Los factores clínicos con valor pronóstico relacionados con el riesgo de aparición de enfermedad sistémica son: el color azul de iris, el tamaño grande, cualquiera que sea la clasificación utilizada, la localización en cuerpo ciliar y la extensión extraocular. Los pacientes sometidos a enucleación presentan un peor pronóstico, hecho relacionado con que esta técnica se indica en tumores de tamaño grande y recidivas tumorales.

- Los factores histopatológicos con valor pronóstico son: el tamaño, el predominio de células epitelioides y la localización en cuerpo ciliar.

- Se observa una disminución de la mortalidad específica por melanoma comparada con otras series publicadas y la mayor parte de los factores con valor pronóstico son los ya señalados en las publicaciones, con la excepción del color de iris azul que había sido sugerido pero no demostrado previamente. 


\section{BIBLIOGRAFÍA}

1. Singh, A. D. \& Topham, A. Incidence of uveal melanoma in the United States: 19731997. Ophthalmology 110, 956-61 (2003).

2. McLean, I. W., Saraiva, V. S. \& Burnier, M. N. Pathological and prognostic features of uveal melanomas. Canadian journal of ophthalmology. Journal canadien d'ophtalmologie 39, 343-50 (2004).

3. Diener-West, M., Hawkins, B. S., Markowitz, J. A. \& Schachat, A. P. A review of mortality from choroidal melanoma. II. A meta-analysis of 5-year mortality rates following enucleation, 1966 through 1988. Archives of ophthalmology 110, 245-50 (1992).

4. Bell, D. J. \& Wilson, M. W. Choroidal melanoma: natural history and management options. Cancer control : journal of the Moffitt Cancer Center 11, 296-303

5. Bergman L, Seregard S, Nilsson B, Ringborg U, Lundell G, Ragnarsson-Olding B. Incidence of uveal melanoma in Sweden from 1960 to 1998. Investigative ophthalmology \& visual science 43, 2579-83 (2002).

6. Nag S, Quivey JM, Earle JD, Followill D, Fontanesi J, Finger PT; The American Brachitherapy Society Recomendations For Brachitherapy Of Uvela Melanomas. Radiation Oncology 56, 544-555 (2003).

7. Quality of life assessment in the collaborative ocular melanoma study: design and methods. COMS-QOLS Report No. 1. COMS Quality of Life Study Group. Ophthalmic epidemiology 6, 5-17 (1999).

8. Jampol LM, Moy CS, Murray TG, Reynolds SM, Albert DM, Schachat AP, Diddie KR, Engstrom RE Jr, Finger PT, Hovland KR, Joffe L, Olsen KR, Wells CG. The COMS randomized trial of iodine 125 brachytherapy for choroidal melanoma: IV. Local treatment failure and enucleation in the first 5 years after brachytherapy. COMS report no. 19. Ophthalmology 109, 2197-206 (2002).

9. Augsburger, J. J. \& Gamel, J. W. Clinical prognostic factors in patients with posterior uveal malignant melanoma. Cancer 66, 1596-600 (1990).

10. Hungerford, J. L. Management of ocular melanoma. British medical bulletin 51, 694716 (1995).

11. Damato, B. Developments in the management of uveal melanoma. Clinical \& experimental ophthalmology 32, 639-47 (2004).

12. Lommatzsch, P. K. \& Kirsch, I. H. 106Ru/106Rh plaque radiotherapy for malignant melanomas of the choroid. With follow-up results more than 5 years. Documenta ophthalmologica. Advances in ophthalmology 68, 225-38

13. Weber DC, Bogner J, Verwey J, Georg D, Dieckmann K, Escudé L, Caro M, Pötter R, Goitein G, Lomax AJ, Miralbell R. Proton beam radiotherapy versus fractionated 
stereotactic radiotherapy for uveal melanomas: A comparative study. International journal of radiation oncology, biology, physics 63, 373-84 (2005).

14. Damato, B., Groenewald, C., McGalliard, J. \& Wong, D. Endoresection of choroidal melanoma. The British journal of ophthalmology 82, 213-8 (1998).

15. Gass, J. D. Observation of suspected choroidal and ciliary body melanomas for evidence of growth prior to enucleation. Ophthalmology 87, 523-8 (1980).

16. Straatsma, B. R., Diener-West, M., Caldwell, R. \& Engstrom, R. E. Mortality after deferral of treatment or no treatment for choroidal melanoma. American journal of ophthalmology 136, 47-54 (2003).

17. Rietschel P, Panageas KS, Hanlon C, Patel A, Abramson DH, Chapman PB. Variates of survival in metastatic uveal melanoma. Journal of clinical oncology: official journal of the American Society of Clinical Oncology 23, 8076-80 (2005).

18. Singh, A. D. \& Borden, E. C. Metastatic uveal melanoma. Ophthalmology clinics of North America 18, 143-50, ix (2005).

19. Diener-West M, Reynolds SM, Agugliaro DJ, Caldwell R, Cumming K, Earle JD, Hawkins BS, Hayman JA, Jaiyesimi I, Jampol LM, Kirkwood JM, Koh WJ, Robertson DM, Shaw JM, Straatsma BR, Thoma J. Development of metastatic disease after enrollment in the COMS trials for treatment of choroidal melanoma: Collaborative Ocular Melanoma Study Group Report No. 26. Archives of ophthalmology 123, 1639-43 (2005).

20. Zimmerman, L. E., McLean, I. W. \& Foster, W. D. Does enucleation of the eye containing a malignant melanoma prevent or accelerate the dissemination of tumour cells. The British journal of ophthalmology 62, 420-5 (1978).

21. Singh, A. D., Bergman, L. \& Seregard, S. Uveal melanoma: epidemiologic aspects. Ophthalmology clinics of North America 18, 75-84, viii (2005).

22. Saornil, M. A. Iris colour and uveal melanoma. Canadian journal of ophthalmology. Journal canadien d'ophtalmologie 39, 448-52 (2004).

23. Shah, C. P., Weis, E., Lajous, M., Shields, J. A. \& Shields, C. L. Intermittent and chronic ultraviolet light exposure and uveal melanoma: a meta-analysis.

Ophthalmology 112, 1599-607 (2005).

24. Gragoudas ES, Egan KM, Seddon JM, Glynn RJ, Walsh SM, Finn SM, Munzenrider JE, Spar MD. Survival of patients with metastases from uveal melanoma. Ophthalmology 98, 383-9; discussion 390 (1991).

25. McLean, I. W., Foster, W. D. \& Zimmerman, L. E. Uveal melanoma: location, size, cell type, and enucleation as risk factors in metastasis. Human pathology 13, 123-32 (1982).

26. Damato B, Duke C, Coupland SE, Hiscott P, Smith PA, Campbell I, Douglas A, Howard P. Cytogenetics of uveal melanoma: a 7-year clinical experience. Ophthalmology 114, 1925-31 (2007). 
27. Singh, A. D., Damato, B., Howard, P. \& Harbour, J. W. Uveal melanoma: genetic aspects. Ophthalmology clinics of North America 18, 85-97, viii (2005).

28. Damato, B. E. \& Coupland, S. E. Differences in uveal melanomas between men and women from the British Isles. Eye (London, England) 26, 292-9 (2012).

29. Graell X, Caminal JM, Masuet C, Arias L, Rubio M, Pujol O, Roca G, Arruga J. [Age distribution of uveal melanoma and its relationship to survival]. Archivos de la Sociedad Española de Oftalmología 82, 343-7 (2007).

30. Jensen, O. A. Malignant melanomas of the human uvea: 25-year follow-up of cases in Denmark, 1943--1952. Acta ophthalmologica 60, 161-82 (1982).

31. Jampol LM, Moy CS, Murray TG, Reynolds SM, Albert DM, Schachat AP, Diddie KR, Engstrom RE Jr, Finger PT, Hovland KR, Joffe L, Olsen KR, Wells CG. The COMS randomized trial of iodine 125 brachytherapy for choroidal melanoma: IV. Local treatment failure and enucleation in the first 5 years after brachytherapy. COMS report no. 19. Ophthalmology 109, 2197-206 (2002).

32. Singh, A. D., Kalyani, P. \& Topham, A. Estimating the risk of malignant transformation of a choroidal nevus. Ophthalmology 112, 1784-9 (2005).

33. Caminal JM, Ribes J, Clèries R, Ibáñez N, Arias L, Piulats JM, Pera J, Gutierrez C, Arruga J. Relative survival of patients with uveal melanoma managed in a single center. Melanoma research 22, 271-7 (2012).

34. Vicente N, Saornil MA, García-Álvarez C, Almaraz A, Alonso Martinez P, FrutosBaraja JM, Lopez-Lara F. Melanoma uveal: características clínicas, tratamiento y supervivencia en una serie de 500 pacientes. Arch Soc Esp Oftal ( en prensa)

35. Strickland, D. \& Lee, J. A. Melanomas of eye: stability of rates. American journal of epidemiology 113, 700-2 (1981).

36. Yu, G.-P., Hu, D.-N., McCormick, S. \& Finger, P. T. Conjunctival melanoma: is it increasing in the United States? American journal of ophthalmology 135, 800-6 (2003).

37. Barzilai DA, Koroukian SM, Neuhauser D, Cooper KD, Rimm AA, Cooper GS.The sensitivity of Medicare data for identifying incident cases of invasive melanoma (United States). Cancer causes \& control: CCC 15, 179-84 (2004).

38. Egan, K. M., Seddon, J. M., Glynn, R. J., Gragoudas, E. S. \& Albert, D. M. Epidemiologic aspects of uveal melanoma. Survey of ophthalmology 32, 239-51

39. Hu, D.-N., Yu, G.-P., McCormick, S. A., Schneider, S. \& Finger, P. T. Populationbased incidence of uveal melanoma in various races and ethnic groups. American journal of ophthalmology 140, 612-7 (2005).

40. Kaneko, A. [Malignant ophthalmic tumors]. Nihon rinsho. Japanese journal of clinical medicine 51 Suppl, 1013-20 (1993). 
41. Muiños Díaz Y, Saornil MA, Almaraz A, Muñoz-Moreno MF, García C, Sanz R. Iris color: validation of a new classification and distribution in a Spanish populationbased sample. European journal of ophthalmology 19, 686-9

42. Yanoff, M. \& Zimmerman, L. E. Histogenesis of malignant melanomas of the uvea. II. Relationship of uveal nevi to malignant melanomas. Cancer 20, 493-507 (1967).

43. Singh AD, Donoso LA, Jackson L, Shields CL, De Potter $P$, Shields JA. Familial uveal melanoma: absence of constitutional cytogenic abnormalities in 14 cases. Archives of ophthalmology 114, 502-3 (1996).

44. Shammas, H. F. \& Watzke, R. C. Bilateral choroidal melanomas. Case report and incidence. Archives of ophthalmology 95, 617-23 (1977).

45. Singh, A. D., Shields, C. L., Shields, J. A. \& De Potter, P. Bilateral primary uveal melanoma. Bad luck or bad genes? Ophthalmology 103, 256-62 (1996).

46. López-Caballero C, Saornil-Alvarez MA, Blanco-Mateos G, Frutos-Baraja JM, LópezLara F, González-Sansegundo C. [Choroidal melanoma in ocular melanosis]. Archivos de la Sociedad Española de Oftalmología 78, 99-102 (2003).

47. Carreño E, Saornil MA, Garcia-Alvarez C, Lopez-Lara F, De Frutos-Baraja JM, Almaraz A.. Prevalence of ocular and oculodermal melanocytosis in Spanish population with uveal melanoma. Eye (London, England) 26, 159-62 (2012).

48. Bataille V, Sasieni P, Cuzick J, Hungerford JL, Swerdlow A, Bishop JA. Risk of ocular melanoma in relation to cutaneous and iris naevi. International journal of cancer. Journal international du cancer 60, 622-6 (1995).

49. Folberg, R. The familial occurrence of cutaneous melanoma, intraocular melanoma, and the dysplastic nevus syndrome. American journal of ophthalmology 96, 815-6 (1983).

50. Ohta, M. et al. Rarity of somatic and germline mutations of the cyclin-dependent kinase 4 inhibitor gene, CDK4I, in melanoma. Cancer research 54, 5269-72 (1994).

51. Bell, D. J. \& Wilson, M. W. Choroidal melanoma: natural history and management options. Cancer control : journal of the Moffitt Cancer Center 11, 296-303

52. Damato, B., Groenewald, C., McGalliard, J. \& Wong, D. Endoresection of choroidal melanoma. The British journal of ophthalmology 82, 213-8 (1998).

53. Pach JM, Robertson DM, Taney BS, Martin JA, Campbell RJ, O'Brien PC.Prognostic factors in choroidal and ciliary body melanomas with extrascleral extension. American journal of ophthalmology 101, 325-31 (1986).

54. Nag S, Quivey JM, Earle JD, Followill D, Fontanesi J, Finger PT; American Brachytherapy Society. The American Brachytherapy Society recommendations for brachytherapy of uveal melanomas. International journal of radiation oncology, biology, physics 56, 544-55 (2003). 
55. Lavinsky D, Belfort RN, Navajas E, Torres V, Martins MC, Belfort R Jr. Fundus autofluorescence of choroidal nevus and melanoma. The British journal of ophthalmology 91, 1299-302 (2007).

56. Scott, I. U., Murray, T. G. \& Hughes, J. R. Evaluation of imaging techniques for detection of extraocular extension of choroidal melanoma. Archives of ophthalmology 116, 897-9 (1998).

57. Verbeek, A. M., Thijssen, J. M., Cuypers, M. H., Brink, H. \& Deutman, A. F. Echographic classification of intraocular tumours. A 15-year retrospective analysis. Acta ophthalmologica 72, 416-22 (1994).

58. Boldt HC, Byrne SF, Gilson MM, Finger PT, Green RL, Straatsma BR, Simpson ER, Hawkins BS. Baseline echographic characteristics of tumors in eyes of patients enrolled in the Collaborative Ocular Melanoma Study: COMS report no. 29. Ophthalmology 115, 1390-7, 1397.e1-2 (2008).

59. Lorigan, J. G., Wallace, S. \& Mavligit, G. M. The prevalence and location of metastases from ocular melanoma: imaging study in 110 patients. AJR. American journal of roentgenology 157, 1279-81 (1991).

60. Servois V, Mariani P, Malhaire C, Petras S, Piperno-Neumann S, Plancher C, LevyGabriel C, Lumbroso-le Rouic L, Desjardins L, Salmon RJ.. Preoperative staging of liver metastases from uveal melanoma by magnetic resonance imaging (MRI) and fluorodeoxyglucose-positron emission tomography (FDG-PET). European journal of surgical oncology: the journal of the European Society of Surgical Oncology and the British Association of Surgical Oncology 36, 189-94 (2010).

61. Margo, C. E. The Collaborative Ocular Melanoma Study: an overview. Cancer control : journal of the Moffitt Cancer Center 11, 304-9

62. Hungerford, J. L. Management of ocular melanoma. British medical bulletin 51, 694 716 (1995).

63. Hykin, P. G., McCartney, A. C., Plowman, P. N. \& Hungerford, J. L. Postenucleation orbital radiotherapy for the treatment of malignant melanoma of the choroid with extrascleral extension. The British journal of ophthalmology 74, 36-9 (1990).

64. Lommatzsch, P. K. \& Kirsch, I. H. 106Ru/106Rh plaque radiotherapy for malignant melanomas of the choroid. With follow-up results more than 5 years. Documenta ophthalmologica. Advances in ophthalmology 68, 225-38

65. Moore, R. F. Choroidal Sarcoma Treated By The Intraocular Insertion of Radon Seeds. The British journal of ophthalmology 14, 145-52 (1930).

66. Nath R, Anderson LL, Luxton G, Weaver KA, Williamson JF, Meigooni AS. Dosimetry of interstitial brachytherapy sources: recommendations of the AAPM Radiation Therapy Committee Task Group No. 43. American Association of Physicists in Medicine. Medical physics 22, 209-34 (1995).

67. Gündüz K, Shields CL, Shields JA, Cater J, Freire JE, Brady LW. Radiation retinopathy following plaque radiotherapy for posterior uveal melanoma. Archives of ophthalmology 117, 609-14 (1999). 
68. Gragoudas ES, Goitein M, Verhey L, Munzenreider J, Suit HD, Koehler A. Proton beam irradiation. An alternative to enucleation for intraocular melanomas.

Ophthalmology 87, 571-81 (1980).

69. Zorlu, F., Selek, U. \& Kiratli, H. Initial results of fractionated CyberKnife radiosurgery for uveal melanoma. Journal of neuro-oncology 94, 111-7 (2009).

70. Langmann, G., Pendl, G., Klaus-Müllner, Papaefthymiou, G. \& Guss, H. Gamma knife radiosurgery for uveal melanomas: an 8-year experience. Journal of neurosurgery 93 Suppl 3, 184-8 (2000).

71. Weber DC, Bogner J, Verwey J, Georg D, Dieckmann K, Escudé L, Caro M, Pötter R, Goitein G, Lomax AJ, Miralbell R. Proton beam radiotherapy versus fractionated stereotactic radiotherapy for uveal melanomas: A comparative study. International journal of radiation oncology, biology, physics 63, 373-84 (2005).

72. Petersch, B., Bogner, J., Dieckmann, K., Pötter, R. \& Georg, D. Automatic real-time surveillance of eye position and gating for stereotactic radiotherapy of uveal melanoma. Medical physics 31, 3521-7 (2004).

73. Shields, C. L., Shields, J. A., Kiratli, H., De Potter, P. \& Cater, J. R. Risk factors for growth and metastasis of small choroidal melanocytic lesions. Ophthalmology 102 , 1351-61 (1995).

74. Seddon JM, Gragoudas ES, Egan KM, Glynn RJ, Howard S, Fante RG, Albert DM. Relative survival rates after alternative therapies for uveal melanoma.

Ophthalmology 97, 769-77 (1990).

75. Mortality in patients with small choroidal melanoma. COMS report no. 4. The Collaborative Ocular Melanoma Study Group. Archives of ophthalmology 115, 88693 (1997).

76. The COMS randomized trial of iodine 125 brachytherapy for choroidal melanoma: $\mathrm{V}$. Twelve-year mortality rates and prognostic factors: COMS report No. 28. Archives of ophthalmology 124, 1684-93 (2006).

77. The Collaborative Ocular Melanoma Study (COMS) randomized trial of preenucleation radiation of large choroidal melanoma II: initial mortality findings. COMS report no. 10. American journal of ophthalmology 125, 779-96 (1998).

78. Virgili G, Gatta G, Ciccolallo L, Capocaccia R, Biggeri A, Crocetti E, Lutz JM, Paci E. Survival in patients with uveal melanoma in Europe. Archives of ophthalmology 126, 1413-8 (2008).

79. Bedikian AY, Legha SS, Mavligit G, Carrasco CH, Khorana S, Plager C,

Papadopoulos N, Benjamin RS. Treatment of uveal melanoma metastatic to the liver: a review of the M. D. Anderson Cancer Center experience and prognostic factors. Cancer 76, 1665-70 (1995).

80. Kath R, Hayungs J, Bornfeld N, Sauerwein W, Höffken K, Seeber S. Prognosis and treatment of disseminated uveal melanoma. Cancer 72, 2219-23 (1993). 
81. Missotten, G. S. \& Keunen, J. E. E. Screening for uveal melanoma metastasis. Literature review. Bulletin de la Société belge d'ophtalmologie 13-22 (2004).at $<$ http://www.ncbi.nlm.nih.gov/pubmed/15682915>

82. Lane AM, Egan KM, Harmon D, Holbrook A, Munzenrider JE, Gragoudas ES. Adjuvant interferon therapy for patients with uveal melanoma at high risk of metastasis. Ophthalmology 116, 2206-12 (2009).

83. Diener-West M, Reynolds SM, Agugliaro DJ, Caldwell R, Cumming K, Earle JD, Hawkins BS, Hayman JA, Jaiyesimi I, Jampol LM, Kirkwood JM, Koh WJ, Robertson DM, Shaw JM, Straatsma BR, Thoma J. Development of metastatic disease after enrollment in the COMS trials for treatment of choroidal melanoma: Collaborative Ocular Melanoma Study Group Report No. 26. Archives of ophthalmology 123, 1639-43 (2005).

84. Kujala, E., Mäkitie, T. \& Kivelä, T. Very long-term prognosis of patients with malignant uveal melanoma. Investigative ophthalmology \& visual science 44, 4651-9 (2003).

85. Gordon-Thomson, C., Mason, R. S. \& Moore, G. P. Regulation of epidermal growth factor receptor expression in human melanocytes. Experimental dermatology 10, 321-8 (2001).

86. Kolandjian NA, Wei C, Patel SP, Richard JL, Dett T, Papadopoulos NE, Bedikian AY. Delayed Systemic Recurrence of Uveal Melanoma. American journal of clinical oncology (2012).doi:10.1097/COC.0b013e3182546a6b

87. Diener-West M, Reynolds SM, Agugliaro DJ, Caldwell R, Cumming K, Earle JD, Green DL, Hawkins BS, Hayman J, Jaiyesimi I, Kirkwood JM, Koh WJ, Robertson DM, Shaw JM, Thoma J. Screening for metastasis from choroidal melanoma: the Collaborative Ocular Melanoma Study Group Report 23. Journal of clinical oncology: official journal of the American Society of Clinical Oncology 22, 2438-44 (2004).

88. Eskelin, S., Pyrhönen, S., Summanen, P., Prause, J. U. \& Kivelä, T. Screening for metastatic malignant melanoma of the uvea revisited. Cancer 85, 1151-9 (1999).

90. Kivelä T, Suciu S, Hansson J, Kruit WH, Vuoristo MS, Kloke O, Gore M, HahkaKemppinen M, Parvinen LM, Kumpulainen E, Humblet Y, Pyrhönen S. Bleomycin, vincristine, lomustine and dacarbazine (BOLD) in combination with recombinant interferon alpha-2b for metastatic uveal melanoma. European journal of cancer (Oxford, England : 1990) 39, 1115-20 (2003).

91. Albert, D. M., Ryan, L. M. \& Borden, E. C. Metastatic ocular and cutaneous melanoma: a comparison of patient characteristics and prognosis. Archives of ophthalmology 114, 107-8 (1996).

92. Bedikian, A. Y., Papadopoulos, N., Plager, C., Eton, O. \& Ring, S. Phase II evaluation of temozolomide in metastatic choroidal melanoma. Melanoma research 13, 303-6 (2003).

93. Leyvraz S, Spataro V, Bauer J, Pampallona S, Salmon R, Dorval T, Meuli R, Gillet $M$, Lejeune F, Zografos L. Treatment of ocular melanoma metastatic to the liver by 
hepatic arterial chemotherapy. Journal of clinical oncology: official journal of the American Society of Clinical Oncology 15, 2589-95 (1997).

94. Carrasco $\mathrm{CH}$, Wallace S, Charnsangavej C, Papadopoulos NE, Patt YZ, Mavligit GM. Treatment of hepatic metastases in ocular melanoma. Embolization of the hepatic artery with polyvinyl sponge and cisplatin. JAMA : the journal of the American Medical Association 255, 3152-4 (1986).

95. McLean, I. W., Ainbinder, D. J., Gamel, J. W. \& McCurdy, J. B. Choroidal-ciliary body melanoma. A multivariate survival analysis of tumor location. Ophthalmology 102, 1060-4 (1995).

96. Kroll, S., Char, D. H., Quivey, J. \& Castro, J. A comparison of cause-specific melanoma mortality and all-cause mortality in survival analyses after radiation treatment for uveal melanoma. Ophthalmology 105, 2035-45 (1998).

97. Shammas, H. F. \& Blodi, F. C. Prognostic factors in choroidal and ciliary body melanomas. Archives of ophthalmology 95, 63-9 (1977).

98. Kujala, E., Mäkitie, T. \& Kivelä, T. Very long-term prognosis of patients with malignant uveal melanoma. Investigative ophthalmology \& visual science 44, 4651-9 (2003).

99. Gragoudas ES, Seddon JM, Egan KM, Polivogianis L, Hsieh CC, Goitein M, Verhey L, Munzenrider J, Austin-Seymour M, Urie M. Prognostic factors for metastasis following proton beam irradiation of uveal melanomas. Ophthalmology 93, 675-80 (1986).

100. Shammas, H. F. \& Blodi, F. C. Prognostic factors in choroidal and ciliary body melanomas. Archives of ophthalmology 95, 63-9 (1977).

101. Kaiserman I, Anteby I, Chowers I, Blumenthal EZ, Kliers I, Pe'er J. Postbrachytherapy initial tumour regression rate correlates with metastatic spread in posterior uveal melanoma. The British journal of ophthalmology 88, 892-5 (2004).

102. Lindegaard, J., Isager, P., Prause, J. U. \& Heegaard, S. Optic nerve invasion of uveal melanoma: clinical characteristics and metastatic pattern. Investigative ophthalmology \& visual science 47, 3268-75 (2006).

103. Lindegaard, J., Isager, P., Prause, J. U. \& Heegaard, S. Optic nerve invasion of uveal melanoma. APMIS : acta pathologica, microbiologica, et immunologica Scandinavica 115, 1-16 (2007).

104. Folberg R, Salomao D, Grossniklaus HE, Proia AD, Rao NA, Cameron JD.Recommendations for the reporting of tissues removed as part of the surgical treatment of common malignancies of the eye and its adnexa. The Association of Directors of Anatomic and Surgical Pathology. Human pathology 34, 114-8 (2003).

105. Folberg R, Rummelt V, Parys-Van Ginderdeuren R, Hwang T, Woolson RF, Pe'er J, Gruman LM. The prognostic value of tumor blood vessel morphology in primary uveal melanoma. Ophthalmology 100, 1389-98 (1993). 
106. Pe'er, J., Gnessin, H., Shargal, Y. \& Livni, N. PC-10 immunostaining of proliferating cell nuclear antigen in posterior uveal melanoma. Enucleation versus enucleation postirradiation groups. Ophthalmology 101, 56-62 (1994).

107. Char, D. H., Kroll, S. \& Phillips, T. L. Uveal melanoma. Growth rate and prognosis. Archives of ophthalmology 115, 1014-8 (1997).

108. De la Cruz, P. O., Specht, C. S. \& McLean, I. W. Lymphocytic infiltration in uveal malignant melanoma. Cancer 65, 112-5 (1990).

109. Blom DJ, Schurmans LR, De Waard-Siebinga I, De Wolff-Rouendaal D, Keunen JE, Jager MJ. HLA expression in a primary uveal melanoma, its cell line, and four of its metastases. The British journal of ophthalmology 81, 989-93 (1997).

110. McLean, I. W., Keefe, K. S. \& Burnier, M. N. Uveal melanoma. Comparison of the prognostic value of fibrovascular loops, mean of the ten largest nucleoli, cell type, and tumor size. Ophthalmology 104, 777-80 (1997).

111. McLean, I. W. \& Gamel, J. W. Cause-specific versus all-cause survival. Ophthalmology 105, 1989-90 (1998).

112. Virgili G, Gatta G, Ciccolallo L, Capocaccia R, Biggeri A, Crocetti E, Lutz JM, Paci E. Survival in patients with uveal melanoma in Europe. Archives of ophthalmology 126, 1413-8 (2008).

113. Singh, A. D., Turell, M. E. \& Topham, A. K. Uveal melanoma: trends in incidence, treatment, and survival. Ophthalmology 118, 1881-5 (2011).

114. Graell X, Caminal JM, Masuet C, Arias L, Rubio M, Pujol O, Roca G, Arruga, J. Age distribution of uveal melanoma and its relationship to survival. Arch Soc Esp 82, 343-347 (2007).

115. Frenkel, S., Hendler, K. \& Pe'er, J. Uveal melanoma in Israel in the last two decades: characterization, treatment and prognosis. The Israel Medical Association journal : IMAJ 11, 280-5 (2009).

116. Virgili G, Gatta G, Ciccolallo L, Capocaccia R, Biggeri A, Crocetti E, Lutz JM, Paci E; Incidence of uveal melanoma in Europe. Ophthalmology 114, 2309-15 (2007).

117. Regan, S., Judge, H. E., Gragoudas, E. S. \& Egan, K. M. Iris color as a prognostic factor in ocular melanoma. Archives of ophthalmology 117, 811-4 (1999).

118. Singh, A. D., Rennie, I. G., Seregard, S., Giblin, M. \& McKenzie, J. Sunlight exposure and pathogenesis of uveal melanoma. Survey of ophthalmology 49, 41928 (2004).

119. Damato, B. Detection of uveal melanoma by optometrists in the United Kingdom. Ophthal. Physiol. Opt. 21, 268-271 (2001).

120. Eskelin, S. \& Kivelä, T. Mode of presentation and time to treatment of uveal melanoma in Finland. The British journal of ophthalmology 86, 333-8 (2002). 
121. Blanco, G. Diagnosis and treatment of orbital invasion in uveal melanoma. Canadian journal of ophthalmology. Journal canadien d'ophtalmologie 39, 388-96 (2004).

122. García-Alvarez C, Muiños Y, Saornil MA, Almaraz A, López-Lara F, Frutos JM, Muñoz MF. [Ocular retention in patients with uveal melanoma managed by a multimodality approach]. Archivos de la Sociedad Española de Oftalmología 84, 145-9 (2009).

123. Damato, B. \& Lecuona, K. Conservation of eyes with choroidal melanoma by a multimodality approach to treatment: an audit of 1632 patients. Ophthalmology 111, 977-83 (2004).

124. Singh, A. D., Turell, M. E. \& Topham, A. K. Uveal melanoma: trends in incidence, treatment, and survival. Ophthalmology 118, 1881-5 (2011).

125. Histopathologic characteristics of uveal melanomas in eyes enucleated from the Collaborative Ocular Melanoma Study. COMS report no. 6. American journal of ophthalmology 125, 745-66 (1998).

126. McLean, I. W., Foster, W. D., Zimmerman, L. E. \& Gamel, J. W. Modifications of Callender's classification of uveal melanoma at the Armed Forces Institute of Pathology. American journal of ophthalmology 96, 502-9 (1983).

127. Shields, C. L., Kaliki, S., Furuta, M., Mashayekhi, A. \& Shields, J. A. Clinical spectrum and prognosis of uveal melanoma based on age at presentation in 8,033 cases. Retina (Philadelphia, Pa.) 32, 1363-72 (2012).

128. Diener-West M, Earle JD, Fine SL, Hawkins BS, Moy CS, Reynolds SM, Schachat AP, Straatsma BR. The COMS randomized trial of iodine 125 brachytherapy for choroidal melanoma, III: initial mortality findings. COMS Report No. 18. Archives of ophthalmology 119, 969-82 (2001).

129. Melia BM, Abramson DH, Albert DM, Boldt HC, Earle JD, Hanson WF, Montague P, Moy CS, Schachat AP, Simpson ER, Straatsma BR, Vine AK, Weingeist TA. Collaborative ocular melanoma study (COMS) randomized trial of I-125 brachytherapy for medium choroidal melanoma. I. Visual acuity after 3 years COMS report no. 16. Ophthalmology 108, 348-66 (2001).

130. Hawkins, B. S. The Collaborative Ocular Melanoma Study (COMS) randomized trial of pre-enucleation radiation of large choroidal melanoma: IV. Ten-year mortality findings and prognostic factors. COMS report number 24. American journal of ophthalmology 138, 936-51 (2004).

131. Damato, B. \& Coupland, S. E. A reappraisal of the significance of largest basal diameter of posterior uveal melanoma. Eye (London, England) 23, 2152-60; quiz 2161-2 (2009).

132. Augsburger, J. J., Corrêa, Z. M., Freire, J. \& Brady, L. W. Long-term survival in choroidal and ciliary body melanoma after enucleation versus plaque radiation therapy. Ophthalmology 105, 1670-8 (1998). 
133. Correa R, Pera J, Gómez J, Polo A, Gutiérrez C, Caminal JM, Modolell I, Navarro V, Guedea F. (125)I episcleral plaque brachytherapy in the treatment of choroidal melanoma: a single-institution experience in Spain. Brachytherapy 8, 290-6

134. Damato, B., Eleuteri, A., Taktak, A. F. G. \& Coupland, S. E. Estimating prognosis for survival after treatment of choroidal melanoma. Progress in retinal and eye research 30, 285-95 (2011). 
Modelo de Consentimiento Informado. 


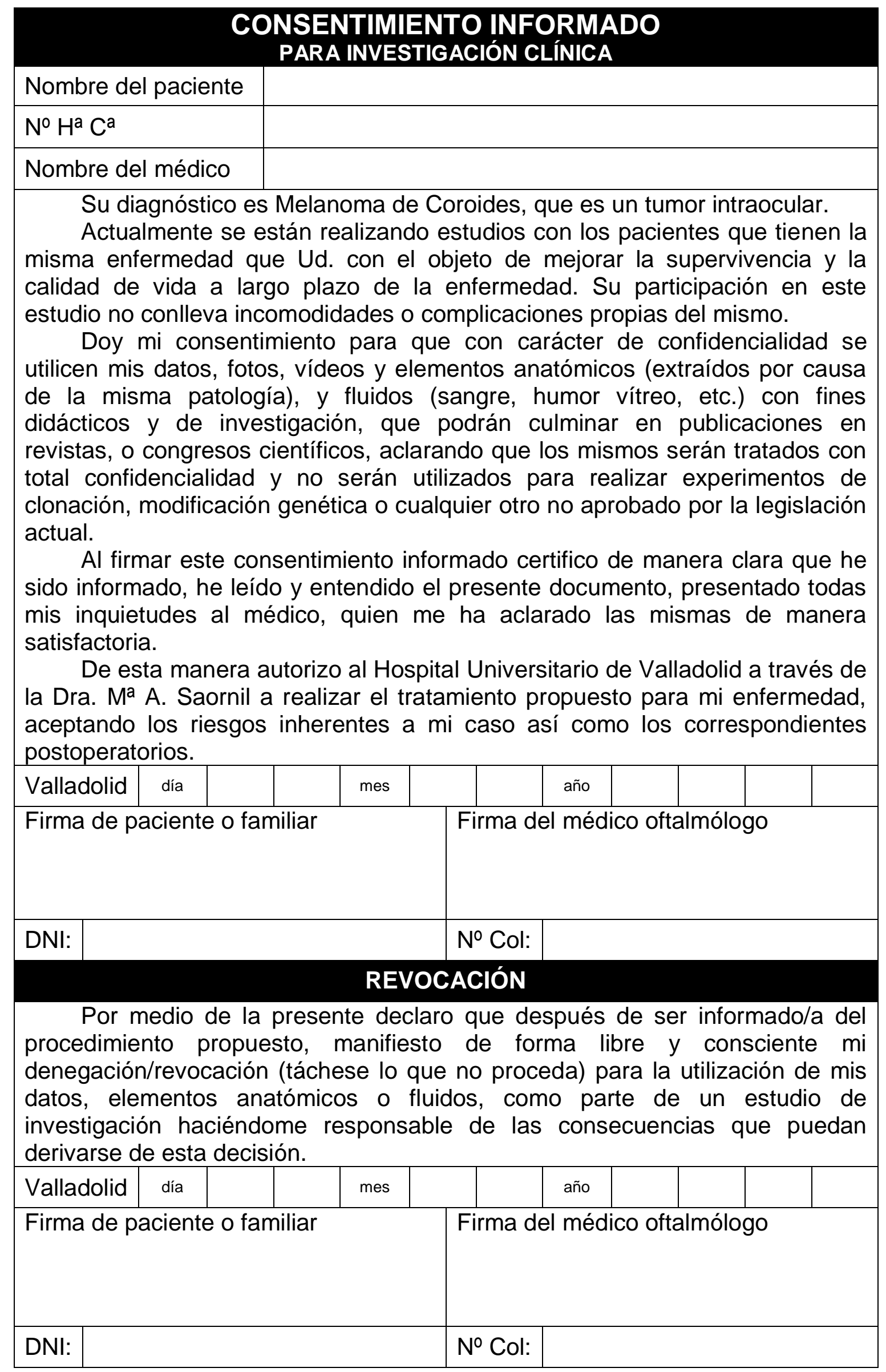


Modelo de formulario de recogida de datos. 


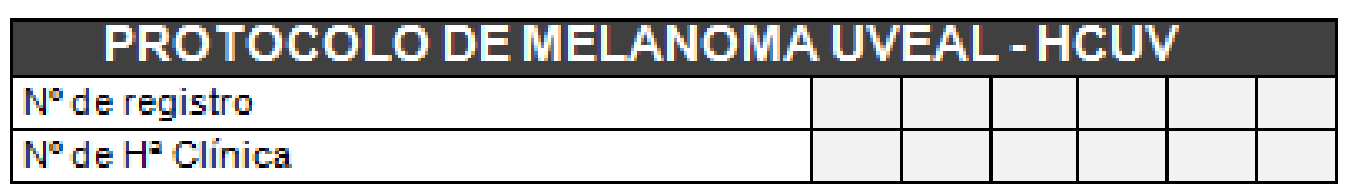

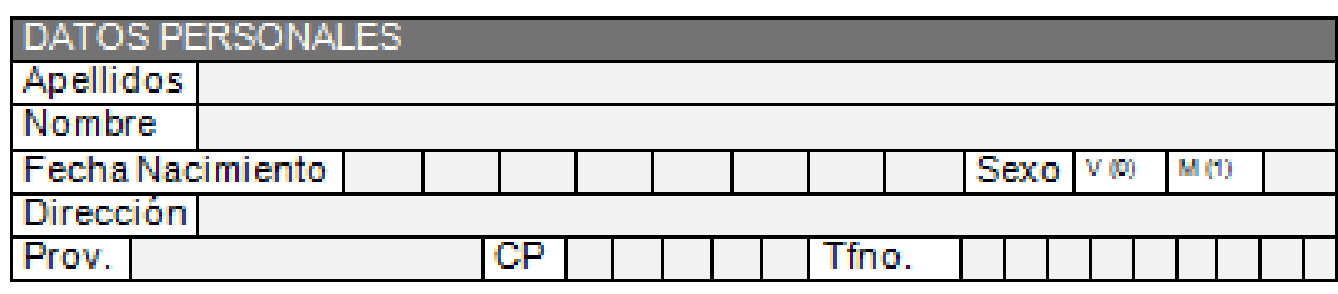

\begin{tabular}{|c|c|c|c|c|c|c|}
\hline \multicolumn{7}{|c|}{ ANTECEDENTES } \\
\hline \multicolumn{4}{|c|}{ Exposiciónsolar } & $>50 \%(1)$ & $<50 \%(0)$ & \\
\hline \multicolumn{4}{|c|}{ Cáncer cutáneo } & al (1) & No (10) & \\
\hline \multicolumn{4}{|c|}{ Otros cánceres } & $\mathbf{a}(1)$ & No (0) & \\
\hline \multicolumn{4}{|c|}{ Inmunosupresión } & a (1) & No (10) & \\
\hline \multicolumn{4}{|c|}{ Depresión (activa en tto) } & al (1) & Noo (10) & \\
\hline \multicolumn{4}{|c|}{ A. familiares de melanoma } & al (1) & No (10) & \\
\hline Tabaco & No (0) & $\leqslant 10(1)$ & $10-20(2)$ & $r 20(3)$ & Exatapa(4) & \\
\hline
\end{tabular}

\begin{tabular}{|c|c|c|c|c|c|c|}
\hline \multirow{2}{*}{\begin{tabular}{|l|} 
Patología \\
Ambliopía \\
\end{tabular}} & \multicolumn{2}{|c|}{ Afecto } & \multicolumn{2}{|c|}{ Adelfo } & \multirow[t]{2}{*}{ Af. } & \multirow[t]{2}{*}{ Ad. } \\
\hline & a| (1) & No (0) & a| (1) & No (10) & & \\
\hline DMAE & a| (1) & No $(0)$ & a| (1) & No (0) & & \\
\hline Glaucoma & a| (1) & No (0) & a| (1) & No (10) & & \\
\hline Catarata & al (1) & No $(0)$ & an (1) & No (10) & & \\
\hline Ret.t. Diabética & a! (1) & No $(0)$ & a! (1) & No $(0)$ & & \\
\hline Otros & & & & & & \\
\hline
\end{tabular}

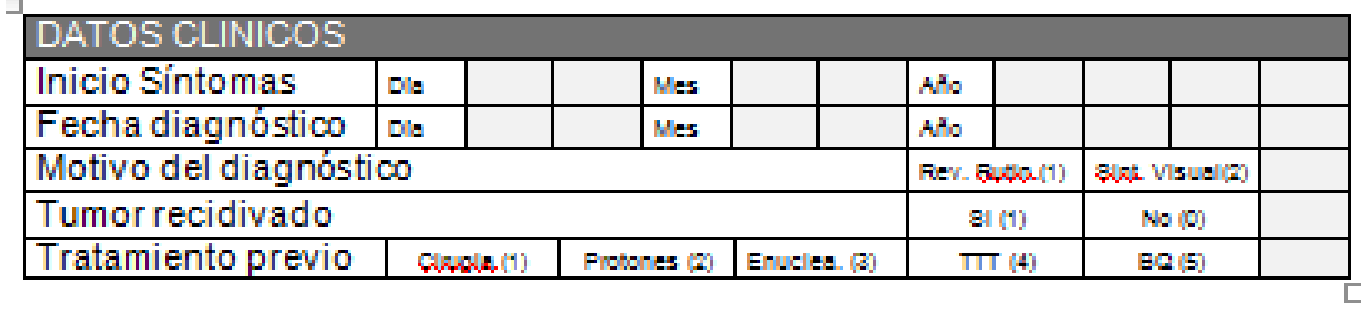

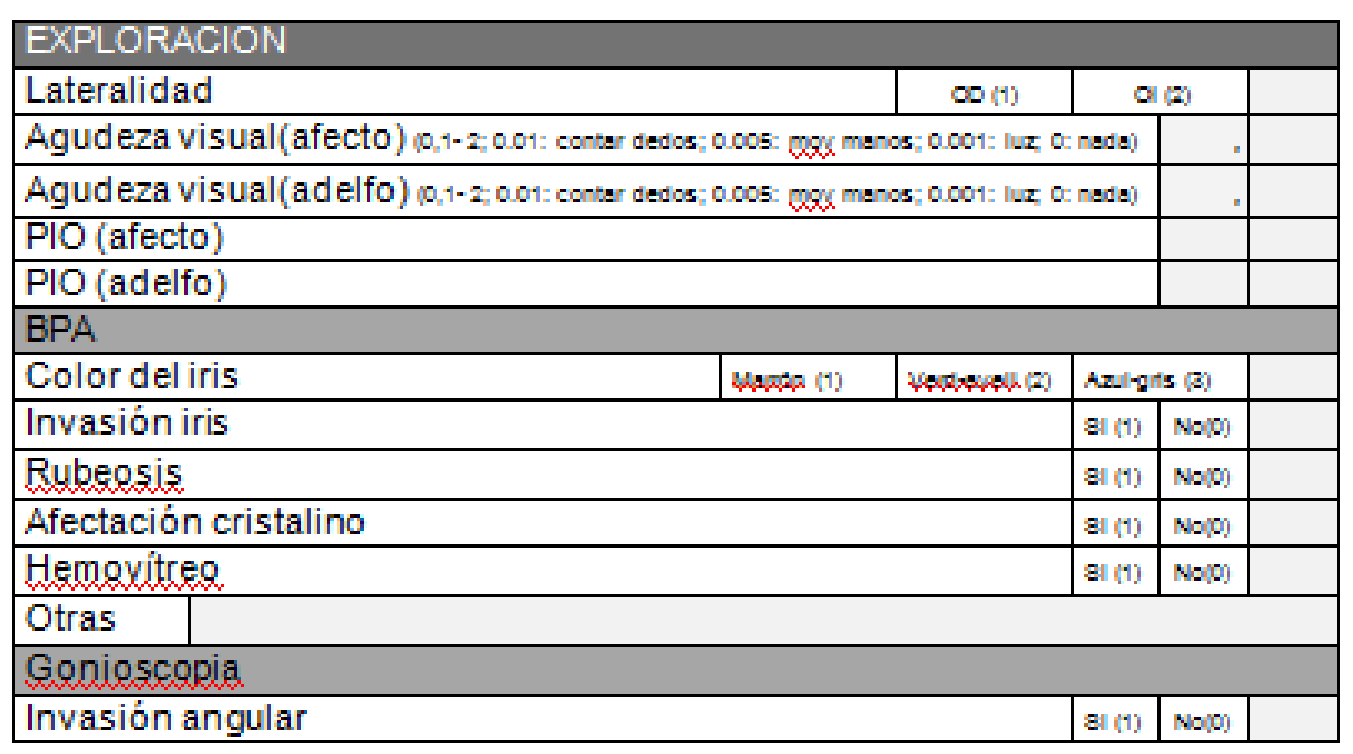




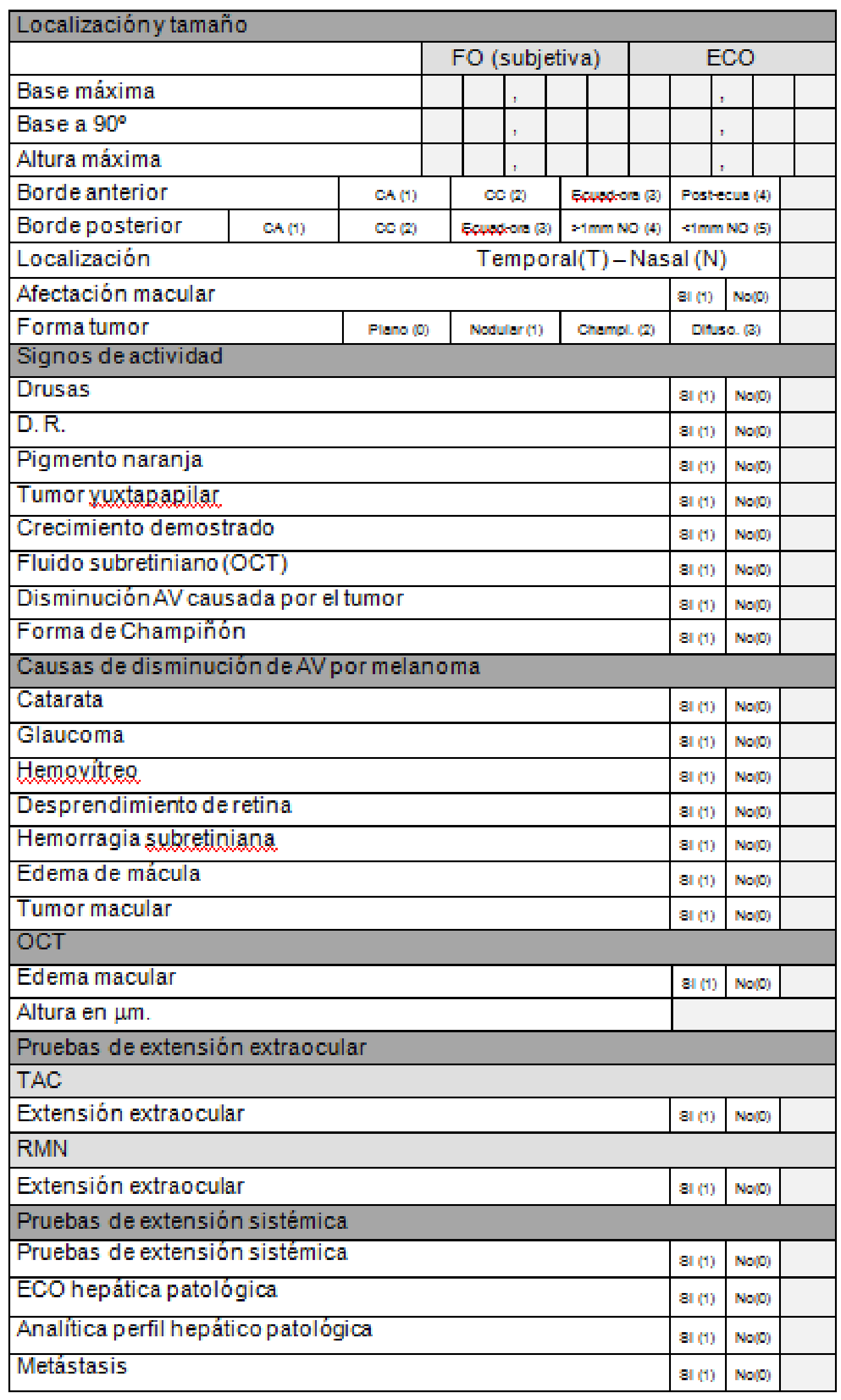




\begin{tabular}{|c|c|c|c|c|}
\hline Tamaño & Fequeto (0) & Medleno (1) & Gend & $e(2)$ \\
\hline Localización & Coroldes (0) & $\infty(1)$ & ins & (2) \\
\hline Actividad & & & al (1) & No(0) \\
\hline Extensión extraocular & & & a! (1) & $\mathrm{No}(\mathrm{O})$ \\
\hline Extensión sistémica & & & a! (1) & No(O) \\
\hline Melanótico & & & al (1) & $\mathrm{No}(\mathrm{O})$ \\
\hline Clasificación TNM & $\mathrm{T}$ & $N$ & & M \\
\hline
\end{tabular}

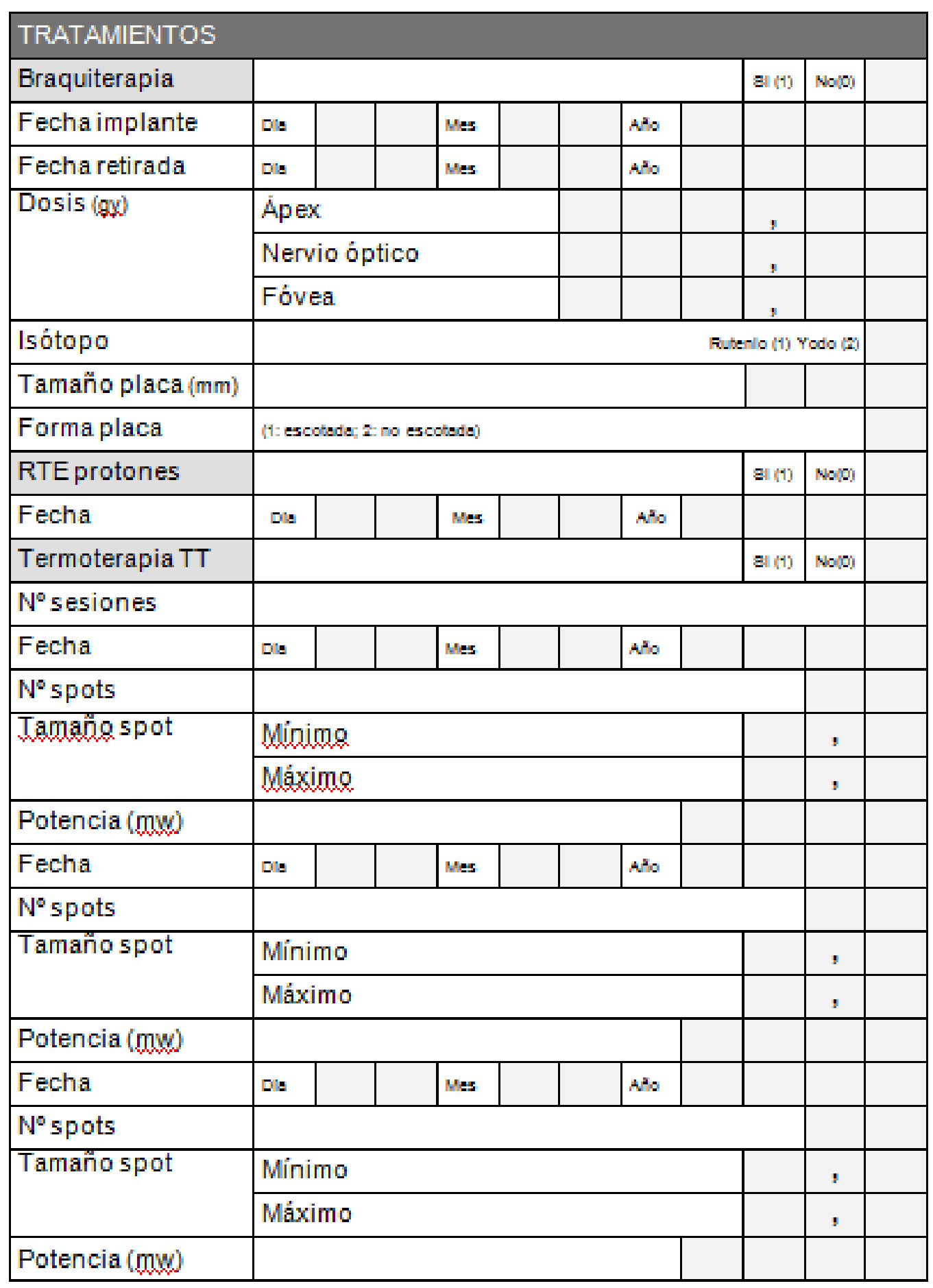




\begin{tabular}{|c|c|c|c|c|c|c|}
\hline Resección Qca. & & & & & a! (1) & $\mathrm{No}(0)$ \\
\hline Fecha & Dis & Mes & & $A^{2}$ & & \\
\hline Enucleación & & No(O) & $\operatorname{ain}$ RT (1) & $\operatorname{Con} \mathrm{RT}(2)$ & & onde \\
\hline Fecha & Dis & Mes & & ANo & & \\
\hline Observación & & & & & at (1) & No(b) \\
\hline Fecha & Dis & Mes & & $A^{2} \%$ & & \\
\hline Causa & FeQ: & (1) Rechess : & (2) Eded a & ide (3) 90 & $=0(4) \mathrm{M}$ & $E Q(5)$ \\
\hline
\end{tabular}

\section{RECIDIVA}

\begin{tabular}{|l|l|l|l|l|l|l|l|l|l|l|l|}
\hline Fecha & Dis & & & Mes & & & A*s & & & & \\
\hline
\end{tabular}

\section{ENUCLEACION SECUNDARIA}

\begin{tabular}{|l|l|l|l|l|l|l|l|l|l|l|l|}
\hline Fecha & Dis & & & Mes & & & Ano & & & & \\
\hline Motivo & \multicolumn{7}{|c|}{ Recidiva (1) Esectos secundertos (2) } & \\
\hline
\end{tabular}

\section{METASTASIS}

\begin{tabular}{|l|l|l|l|l|l|l|l|l|l|l|l|}
\hline Fecha & Dis & & & Mes & & & A* & & & & \\
\hline
\end{tabular}

\begin{tabular}{|l|c|l|l|l|l|l|l|l|l|l|l|}
\hline DEFUNCION \\
\hline Fecha & Dis & & & Mes & & & Aso & & & & \\
\hline Causa
\end{tabular}




\begin{tabular}{|c|c|c|c|c|c|}
\hline \multicolumn{6}{|c|}{ ANATOMIA PATOLOGICA } \\
\hline \multicolumn{6}{|l|}{$\mathrm{N}^{\circ}$ de biopsia } \\
\hline \multicolumn{6}{|l|}{ Tamaño } \\
\hline \multicolumn{6}{|c|}{ Descripción macroscópica } \\
\hline \multicolumn{5}{|c|}{ Diámetro basal } & , \\
\hline \multicolumn{5}{|l|}{ Altura } & , \\
\hline \multicolumn{6}{|l|}{ Preparación } \\
\hline \multicolumn{4}{|l|}{ Base } & & , \\
\hline \multicolumn{4}{|l|}{ Altura } & & , \\
\hline \multicolumn{6}{|l|}{ Localización } \\
\hline \multicolumn{6}{|l|}{ Del tumor } \\
\hline \multicolumn{3}{|l|}{ Iris } & \multicolumn{2}{|c|}{$\mathrm{Si}(1)$} & $\mathrm{No}(0)$ \\
\hline \multicolumn{3}{|c|}{ Malla trabecular } & \multicolumn{2}{|c|}{$\mathrm{Si}(1)$} & $\mathrm{No}(0)$ \\
\hline \multicolumn{3}{|l|}{ Cuerpo ciliar } & \multicolumn{2}{|c|}{$\mathrm{Si}(1)$} & $\mathrm{No}(0)$ \\
\hline Entre ora y ecu & & & & & $\mathrm{No}(0)$ \\
\hline Ecuador & & & & & $\mathrm{No}(0)$ \\
\hline Entre ecuador & pila & & & & $\mathrm{No}(0)$ \\
\hline Del margen an & & & & & \\
\hline & & & & (1) & $\operatorname{Resto}(2)$ \\
\hline Tipo celular (\%) & & & & & \\
\hline Névicas & & & & & \\
\hline Fusiforme A & & & & & \\
\hline Fusiforme B & & & & & \\
\hline Epitelioides & & & & & \\
\hline Clasificación & Fusifor. (1) & Mixto (2) & & 1. (3) & N.C. (4) \\
\hline Mitosis & & & & & \\
\hline $\mathrm{N}^{\circ}$ en $10 \mathrm{HPF}$ & & & & & \\
\hline Indice Prolifer & o (Mib-1) & & & & , \\
\hline Otras caracterí & & & & & \\
\hline Tipo infiltrativ & fuso & Si (1) & & $(0)$ & ND (9) \\
\hline Membrana de & ch rota & Si (1) & & (0) & ND (9) \\
\hline Invasión de ret & & Si (1) & & (0) & ND (9) \\
\hline Desprendimien & le retina & Si (1) & & (0) & ND (9) \\
\hline Células tumora & en vítreo & Si (1) & & $(0)$ & ND (9) \\
\hline Invasión de ve & vorticosas & Si (1) & & (0) & ND (9) \\
\hline Invasión en ca & emisario & Si (1) & & (0) & ND (9) \\
\hline Localización y & apapilar & Si (1) & & (0) & ND (9) \\
\hline Invasión del ne & óptico & & & & \\
\hline (0) No & & & & & \\
\hline (1) Anterior & mina cribosa & & & & \\
\hline (2) Lámina c & & & & & \\
\hline (3) Detrás de & nina cribosa & & & & \\
\hline (9) No deterı & able & & & & \\
\hline Extensión extr & leral & & & & \\
\hline (0) No & & & & & \\
\hline (1) Esclera $\mathrm{s}$ & egar a superficie & & & & \\
\hline (2) Superfici & cleral & & & & \\
\hline (3) Extensió & traescleral sin tran & ción & & & \\
\hline (4) Extensiól & traescleral con resi & o orbitario $\mathrm{p}$ & & & \\
\hline Inflamación & No o mínima (0) & Moderad & & & cada (2) \\
\hline Pigmentación & No o mínima (0) & Moderad & & & cada (2) \\
\hline Necrosis & No $(0)$ & $<10 \%(1)$ & & $\%(2)$ & $>50 \%(3)$ \\
\hline
\end{tabular}



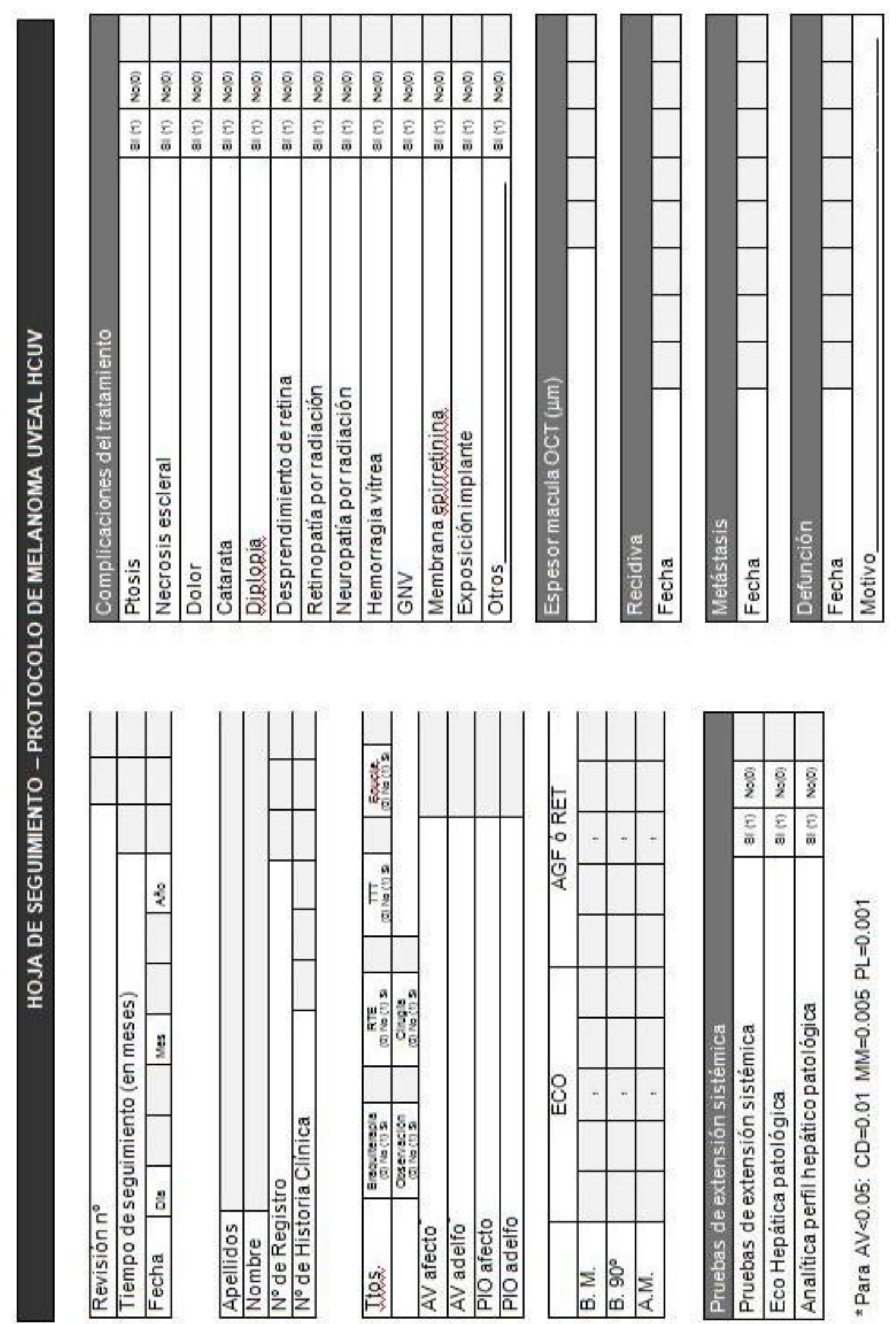
